\title{
Antibiotics in the clinical pipeline in October 2019
}

\author{
Mark S. Butler $\mathbb{D}^{1} \cdot$ David L. Paterson $\mathbb{1}^{1}$
}

Received: 17 December 2019 / Revised: 30 January 2020 / Accepted: 30 January 2020 / Published online: 10 March 2020

(c) The Author(s), under exclusive licence to the Japan Antibiotics Research Association 2020

\begin{abstract}
The development of new and effective antibacterial drugs to treat multi-drug resistant (MDR) bacteria, especially Gramnegative $(\mathrm{G}-\mathrm{ve})$ pathogens, is acknowledged as one of the world's most pressing health issues; however, the discovery and development of new, nontoxic antibacterials is not a straightforward scientific task, which is compounded by a challenging economic model. This review lists the antibacterials, $\beta$-lactamase/ $\beta$-lactam inhibitor (BLI) combinations, and monoclonal antibodies (mAbs) first launched around the world since 2009 and details the seven new antibiotics and two new $\beta$-lactam/ BLI combinations launched since 2016. The development status, mode of action, spectra of activity, lead source, and administration route for the 44 small molecule antibacterials, eight $\beta$-lactamase/BLI combinations, and one antibody drug conjugate (ADC) being evaluated in worldwide clinical trials at the end of October 2019 are described. Compounds discontinued from clinical development since 2016 and new antibacterial pharmacophores are also reviewed. There has been an increase in the number of early stage clinical candidates, which has been fueled by antibiotic-focused funding agencies; however, there is still a significant gap in the pipeline for the development of new antibacterials with activity against $\beta$-metallolactamases, orally administered with broad spectrum $\mathrm{G}-\mathrm{ve}$ activity, and new treatments for MDR Acinetobacter and gonorrhea.
\end{abstract}

\section{Introduction}

Since their development in the 1940s, antibacterial drugs have become lifesaving medicines that are integral to human health. Unfortunately, antibacterial drug resistance is widespread amongst pathogenic bacteria, which significantly reduces the medical effectiveness of currently marketed drugs. These drug-resistant and multi-drug resistant (MDR) bacteria have been acknowledged by Governments and scientists as one of the world's most pressing health issues; however, the discovery and development of new antibiotics and antibiotic-alternatives to treat these infections is not straightforward. As a consequence, it is important to analyze the antibacterial development pipeline

Supplementary information The online version of this article (https:// doi.org/10.1038/s41429-020-0291-8) contains supplementary material, which is available to authorized users.

Mark S. Butler

mark@msbchem.com

1 Centre for Clinical Research, Faculty of Medicine, The University of Queensland, Royal Brisbane and Women's Hospital Complex, Herston, Brisbane, QLD 4072, Australia to capture a snapshot of what is happening today and compare it to previous years. This review provides an update to previous reviews in this series in 2015 [1], 2013 [2] and 2011 [3], which are complementary to recent reviews that describe the pre-clinical [4] and clinical pipeline [5-11]. There have also been several important reviews that analyze the lead discovery and development of antibiotics [12-22], antibiotic alternatives [23-25], $\beta$-lactam/ $\beta$-lactamase inhibitors [26, 27], and antibiotic conjugate and prodrug strategies [28]. There has also been reviews that discuss issues with antibiotic stewardship, resistance and, the commercialization challenge [29-41].

This review details antibacterials launched since 2009 (Table 1; Table S1 from 2000 to 2009) and analyzes new antibacterials approved (Figs. 1-3) since the previous 2015 review [1]. Small molecule antibacterials, BLI combinations, and antibody drug conjugates (ADC) that are being evaluated in phase-I, -II, or -III clinical trials and under pre-approval regulatory evaluation as of 31 October 2019 (Tables 2-5, Figs. 4-12) are reviewed highlighting their development status, mode of action, spectra of activity, historical discovery, and origin of the lead compound's pharmacophore. The clinical trial codes, which are predominantly from ClinicalTrials.gov (NCT), are listed in parentheses for each antibacterial, 
Table 1 Antibiotics, $\beta$-lactamase inhibitor (BLI) combinations, and monoclonal antibodies (mAb) launched from January 2009 to October 2019 , their antibiotic class, activity spectra, country of first approval, and lead source

\begin{tabular}{|c|c|c|c|c|}
\hline $\begin{array}{l}\text { Year } \\
\text { approved }\end{array}$ & Drug name $e^{a, b}$ & Class & $\begin{array}{l}\text { Country of first } \\
\text { approval }\end{array}$ & Lead source \\
\hline \multicolumn{5}{|c|}{ Small molecule antibacterials } \\
\hline 2009 & Tebipenem pivoxil & Carbapenem & Japan & $\mathrm{NP}$ \\
\hline 2009 & Telavancin & Glycopeptide & USA & $\mathrm{NP}$ \\
\hline 2009 & Antofloxacin & Fluoroquinolone & China & $\mathrm{S}$ \\
\hline 2009 & Besifloxacin $^{c}$ & Fluoroquinolone & USA & $\mathrm{S}$ \\
\hline 2010 & Ceftaroline fosamil & Cephalosporin & USA & $\mathrm{NP}$ \\
\hline 2011 & Fidaxomicin $^{\mathrm{b}}$ & Tiacumicin & USA & NP \\
\hline 2012 & Bedaquiline $^{\mathrm{b}}$ & Diarylquinoline & USA & $\mathrm{S}$ \\
\hline 2012 & Perchlozone & Thiosemicarbazone & Russia & $\mathrm{S}$ \\
\hline 2014 & Delamanid & Nitroimidazole & Europe & $\mathrm{S}$ \\
\hline 2014 & Dalbavancin & Glycopeptide & USA & $\mathrm{NP}$ \\
\hline 2014 & Oritavancin & Glycopeptide & USA & NP \\
\hline 2014 & Tedizolid phosphate & Oxazolidinone & USA & $\mathrm{S}$ \\
\hline 2014 & Nemonoxacin & Quinolone & Taiwan & $\mathrm{S}$ \\
\hline 2014 & Morinidazole $(\mathbf{1})^{\mathrm{e}}$ & Nitroimidazole & $\begin{array}{l}\text { People's Republic } \\
\text { of China }\end{array}$ & $\mathrm{S}$ \\
\hline 2014 & Finafloxacin ${ }^{c}$ & Fluoroquinolone & USA & $\mathrm{S}$ \\
\hline 2015 & Zabofloxacin (2) & Fluoroquinolone & Republic of Korea & $\mathrm{S}$ \\
\hline 2017 & Delafloxacin $(\mathbf{3})$ & Fluoroquinolone & USA & $\mathrm{S}$ \\
\hline 2018 & Plazomicin (4) & Aminoglycoside & USA & $\mathrm{NP}$ \\
\hline 2018 & Eravacycline (5) & Tetracycline & Europe & NP \\
\hline 2018 & Omadacycline (6) & Tetracycline & USA & NP \\
\hline 2018 & Sarecycline $(7)^{c}$ & Tetracycline & USA & NP \\
\hline 2019 & Pretomanid $(\mathbf{8})$ & Nitroimidazole & USA & $\mathrm{S}$ \\
\hline 2019 & Lefamulin (9) & Pleuromutilin & USA & $\mathrm{NP}$ \\
\hline 2019 & Lascufloxacin (10) & Fluoroquinolone & Japan & $\mathrm{S}$ \\
\hline 2019 & Cefiderocol (11) & Cephalosporin siderophore & USA & NP \\
\hline \multicolumn{5}{|c|}{ BLI combinations } \\
\hline 2014 & $\begin{array}{l}\text { Zerbaxa: ceftolozane }+ \\
\text { tazobactam }^{\mathrm{d}}\end{array}$ & $\beta$-Lactam + BLI & USA & $\mathrm{NP}+\mathrm{NP}$ \\
\hline 2015 & $\begin{array}{l}\text { Avycaz: } \text { avibactam }^{\mathrm{b}}+ \\
\text { ceftazidime }^{\mathrm{d}}\end{array}$ & $\mathrm{DBO} \mathrm{BLI}+\beta$-lactam & USA & $\mathrm{S}+\mathrm{NP}$ \\
\hline 2017 & $\begin{array}{l}\text { Vabomere: vaborbactam } \\
(\mathbf{1 2})+\text { meropenem }^{\mathrm{d}}(\mathbf{1 3})\end{array}$ & Boronate BLI + $\beta$-lactam & USA & $\mathrm{S}+\mathrm{NP}$ \\
\hline 2019 & $\begin{array}{l}\text { Recarbrio: relebactam }(\mathbf{1 4}) \\
+ \text { imipenem }(\mathbf{1 5})^{\mathrm{d}}+ \\
{\text { cilastatin }(\mathbf{1 6})^{\mathrm{d}}}\end{array}$ & $\begin{array}{l}\text { DBO BLI }+\beta \text {-lactam }+ \text { renal } \\
\text { dehydropeptidase inhibitor }\end{array}$ & USA & $\mathrm{S}+\mathrm{NP}+\mathrm{S}$ \\
\hline \multicolumn{5}{|l|}{$m A b s$} \\
\hline 2012 & Raxibacumab & $\mathrm{mAb}$ & USA & $\mathrm{mAb}$ \\
\hline 2016 & Obiltoxaximab & $\mathrm{mAb}$ & USA & $\mathrm{mAb}$ \\
\hline 2016 & Bezlotoxumab & $\mathrm{mAb}$ & USA & $\mathrm{mAb}$ \\
\hline
\end{tabular}

$B L I \beta$-lactamase inhibitor, $D B O$ diazabicyclooctane, $m A b$ monoclonal antibody, $N P$ natural product-derived, $S$ synthetic, $U S A$ United States of America

${ }^{a}$ The structures of the antibiotics approved from 2000 to 2014 can be found in our previous reviews [1-3]

${ }^{b}$ First member of a new antibiotic or $\beta$-lactamase inhibitor class approved for human therapeutic use

${ }^{\mathrm{c}}$ Approved for topical use

${ }^{\mathrm{d}}$ First launches: tazobactam in 1992, ceftazidime in 1983, meropenem (13) in 1998, and imipenem (15) + cilastatin (16) in 1985

${ }^{\mathrm{e}}$ Also approved for the treatment of amebiasis and trichomoniasis 


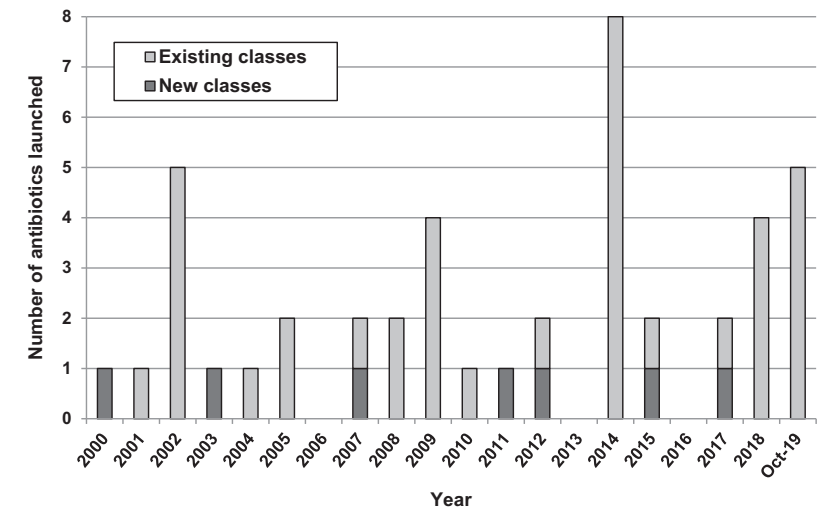

Fig. 1 New antibacterial and BLI classes January 2000 to October 2019 with new classes highlighted

Fig. 2 Structures of the recently launched antibacterial drugs while non-registered trials are referenced at least by a Press Release or peer-reviewed publication. A list of online clinical trial databases can be found in the Supplementary information. Repurposed drugs that have not previously been approved as antibacterials have been included in this analysis. Pro-drugs are grouped together with their active metabolites, while ongoing trials of antibacterial drugs that already approved anywhere in the world are not discussed but are listed in Table S2. Compounds for which no development activity has been reported since 2017 are listed in Table 6. The antibacterials in clinical development have been further analyzed by phase and source derivation (Fig. 13) and to the previous 2011 [3], 2013 [2], and 2015 [1] reviews

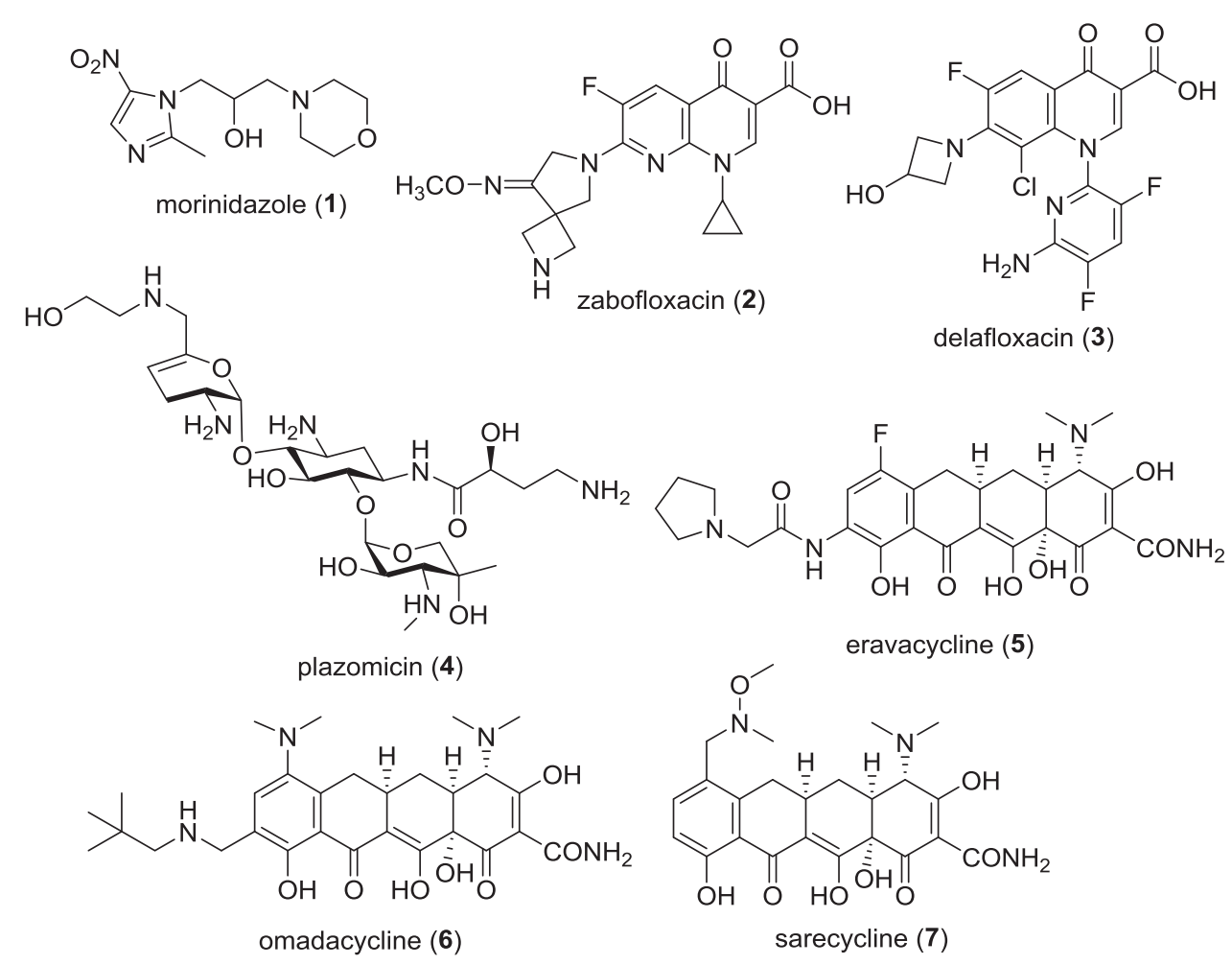

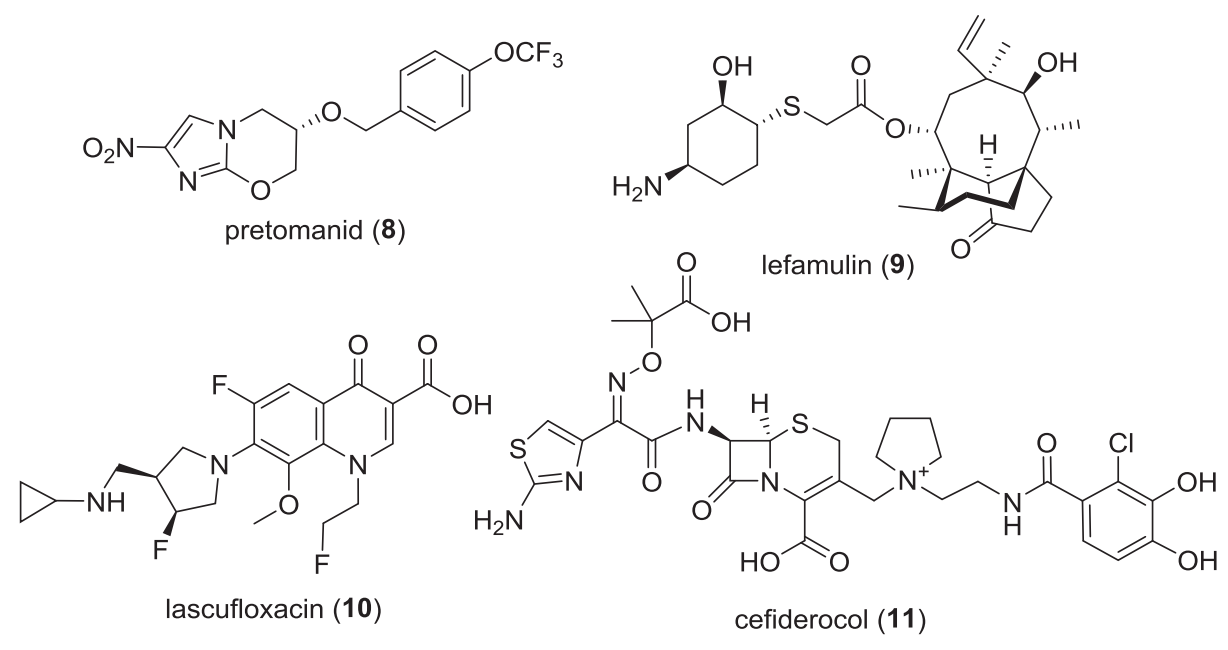


Fig. 3 Structures of the recently $\beta$-lactam $/ \beta$-lactamase inhibitor (BLI) combinations
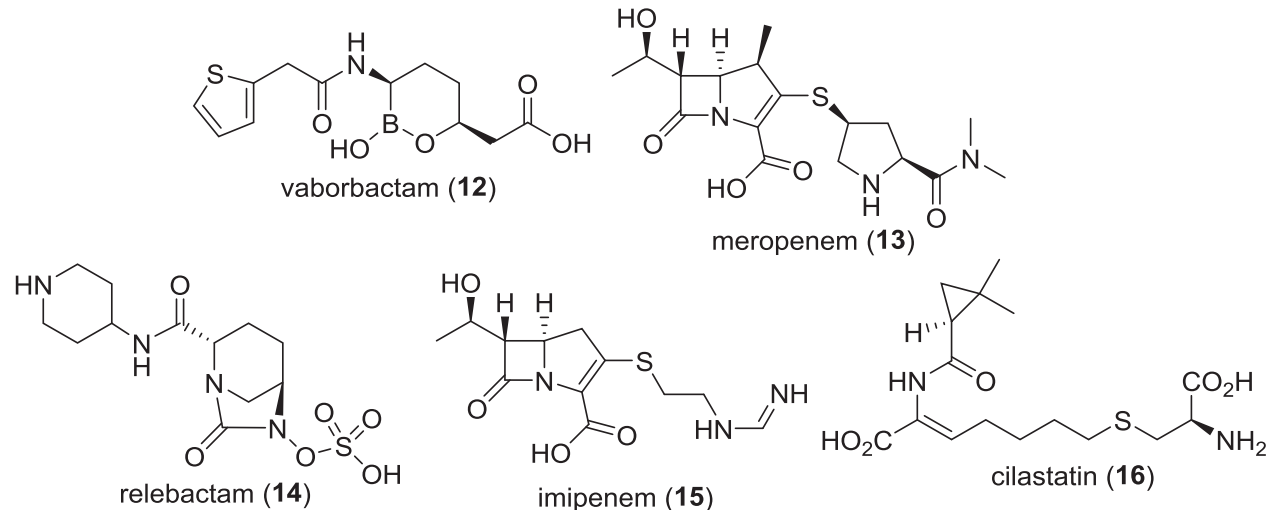

(Fig. 14). An analysis of new antibacterial pharmacophores (Table 7, Figs. 15 and 16) and administration routes (Figs. S1 and S2) has also been undertaken.

Data in this review were obtained by analyzing the scientific literature and internet resources such as company web pages, clinical trial registers, The Pew Charitable Trusts (Philadelphia, PA, USA) [42, 43] and World Health Organization (WHO) (Geneva, Switzerland) pipeline analyses [5] and biotechnology newsletters. Every effort has been undertaken to ensure that these data are accurate; however, it is possible compounds in the earlier stages of clinical development have been overlooked as there is limited information available in the public domain. An overview of the drug development and approval process, antibiotic clinical trial categories and abbreviations can be found in the Supplementary information.

\section{Antibacterial drugs launched since $\mathbf{2 0 0 0}$}

Since 2000, 38 new antibacterials (two NP, 16 NP-derived and 20 synthetic-derived), four new $\beta$-lactam/BLI combinations and three monoclonal antibodies (mAbs) have been launched worldwide (Tables 1 and S1, Figs. 1 and 2). Of the 38 new antibacterials, five were first-in-class: linezolid (oxazolidinone, S, 2000), daptomycin (lipopeptide, NP, 2003), retapamulin (pleuromutilin, NP-derived, 2007), fidaxomicin (tiacumicin, NP, 2011) and bedaquiline (diarylquinoline, S, 2012). These five antibacterials have Gram-positive $(\mathrm{G}+\mathrm{ve})$ activity only; however, bedaquiline is noteworthy as it was the first new drug class approved for tuberculosis (TB) since 1963 [44]. Although the approval of a new class of G-ve antibacterial is still elusive, there has been two new BLI classes launched (diazabicyclooctane (DBO)-BLI (avibactam, S, 2015) and boron-type BLI (vaborbactam (12), S, 2017)) that have activity in combination with $\beta$-lactams against $\mathrm{G}$-ve bacteria. Two of the approved mAbs, raxibacumab [45] and obiltoxaximab [46], help reduce the effects of anthrax toxins but further work is required to fully establish their efficacy in preclinical and clinical studies [47]. Bezlotoxumab is a mAb that binds and neutralizes Clostridioides difficile (formally Clostridium difficile [48]) toxin B, which is approved to help reduce the occurrence of $C$. difficile infections (CDI) in patients undergoing antibacterial drug treatments [49, 50].

\section{Description of antibacterial drugs launched since 2016}

Since the 2016, seven new antibacterials (Fig. 2) and two new $\beta$-lactam/BLI combinations (Fig. 3) have been approved around the world. These new approvals are discussed, along with morinidazole (1) and zabofloxacin (2), which were not detailed in the previous review [1].

\section{Small molecules antibacterials}

Morinidazole (1) was developed by Jiangsu Hansoh Pharmaceutical (Lianyungang, People's Republic of China) and approved in China for the treatment of anaerobic bacterial infections including appendicitis and pelvic inflammatory disease in February 2014 [51]. Morinidazole (1), which is also used to treat amebiasis and trichomoniasis [52], belongs to the nitroimidazole class [53] (Table 1, Fig. 2).

Zabofloxacin (2) (Zabolante, PB-101, DW-224a) is an orally administered fluoronaphthyridone (fluoroquinolone class) developed by Dong Wha Pharmaceutical (Seoul, Republic of Korea) that was approved in March 2015 in South Korea for the treatment of patients with acute bacterial exacerbation of chronic obstructive pulmonary disease [54, 55]. Zabofloxacin (2) has activity against G-ve and $\mathrm{G}+\mathrm{ve}$ respiratory pathogens, notably Streptococcus pneumoniae [56, 57], and drug-resistant Neisseria gonorrhoeae [58]. There is ongoing development for the treatment of 
Table 2 Antibiotics with NDA/MAA submitted or in phase-III clinical trials

\begin{tabular}{|c|c|c|c|}
\hline Name $\left(\right.$ synonym) ${ }^{\mathrm{a}}$ & Compound class (lead source) & Mode of action & Administration; indication (developer) \\
\hline \multicolumn{4}{|l|}{$N D A / M A A$} \\
\hline Solithromycin (17) (T-4288) & Erythromycin (NP) & Protein synthesis inhibition & $\begin{array}{l}\text { iv/po; respiratory tract infection (FUJIFILM } \\
\text { Toyama) }\end{array}$ \\
\hline Iclaprim (18) & Trimethoprim (S) & DHFR & iv/po; ABSSSI (Motif Bio) \\
\hline \multicolumn{4}{|l|}{ Phase-III } \\
\hline $\begin{array}{l}\text { Sulopenem (19) (IV); oral prodrug: sulopenem } \\
\text { etzadroxil (20) + probenecid (21) }\end{array}$ & Penem (NP) & PBP (cell wall) & po; uUTI, cUTI, and cIAI (Iterum) \\
\hline Murepavadin (22) (POL7080) & Protegrin I (P) & $\begin{array}{l}\beta \text {-barrel protein LptD (Imp/OstA) } \\
\text { inhibition (cell wall) }\end{array}$ & $\begin{array}{l}\text { Inhalation, iv; bronchiectasis and VABP } \\
\text { (Polyphor) }\end{array}$ \\
\hline SQ109 (23) & "Ethambutol analog" (S) & Cell wall synthesis & po; TB (Infectex/Sequella) \\
\hline Ridinilazole (24) (SMT 19969) & bis-benzimidazole (S) & Cell division inhibitor & po topical; CDI (Summit) \\
\hline Gepotidacin & Triazaacenaphthylene (S) & $\begin{array}{l}\text { DNA gyrase (GyrA)—different to } \\
\text { quinolones }\end{array}$ & po; UTI and gonorrhea (GSK) \\
\hline Zoliflodacin (26) (ETX0914) & Spiropyrimidinetrione $(\mathrm{S})$ & DNA gyrase (GyrB) & $\begin{array}{l}\text { po; gonorrhea (Entasis Therapeutics/ } \\
\text { GARDP) }\end{array}$ \\
\hline $\begin{array}{l}\text { Contezolid (27) (MRX-I); prodrug: Contezolid } \\
\text { acefosamil (28) }\end{array}$ & Oxazolidinone (S) & Protein synthesis inhibition & $\begin{array}{l}\text { iv/po; SSSI (phase-III) [ABSSSI phase-II] } \\
\text { (MicuRx) }\end{array}$ \\
\hline $\begin{array}{l}\text { Levonadifloxacin (WCK-771) (29); prodrug: } \\
\text { alalevonadifloxacin (WCK-2349) (30) }\end{array}$ & Fluoroquinolone (S) & $\begin{array}{l}\text { DNA gyrase (GyrA) and Topo } \\
\text { IV (ParC) }\end{array}$ & iv/po; MRSA and G-ve (Wockhardt) \\
\hline
\end{tabular}

ABSSSI acute bacterial skin and skin structure infections, CABP community-acquired bacterial pneumonia, CDI C. difficile infection, cIAI complicated intra-abdominal infections, cUTI complicated urinary tract infections, DHFR dihydrofolate reductase, iv intravenous, MRSA methicillin-resistant $S$. aureus, NP natural product, $P B P$ penicillin binding protein, po per orem (oral), $S$ synthetic, SSSI skin and skin structure infections, $T B$ tuberculosis, $V A B P$ ventilator-associated bacterial pneumonia

${ }^{a}$ Underlined compounds are new antibacterial pharmacophores

respiratory infections and drug-resistant bacteria [59]. Dong Wha has licensing and supply agreements with China and 12 Middle Eastern and North African countries [60].

Delafloxacin (3) (Baxdela, RX-3341, WQ-3034, ABT492) [61, 62], which is a fluoroquinolone that was being developed by Melinta Therapeutics (New Haven, CT, USA), was approved by the U.S. Food and Drug Administration (FDA) in June 2017 for the treatment of acute bacterial skin and skin structure infections (ABSSSI) using both intravenous (IV) and oral formulations [63]. In addition to activity against $\mathrm{G}+$ ve bacteria, delafloxacin (3) is also approved for the treatment of the following $\mathrm{G}-\mathrm{ve}$ bacteria: Escherichia coli, Enterobacter cloacae, Klebsiella pneumoniae, and Pseudomonas aeruginosa [64]; however, 3 is rarely used to treat these $\mathrm{G}-\mathrm{ve}$ pathogens due to resistance. In October 2019, Melinta announced that the FDA had approved an SNDA for $\mathbf{3}$ for the treatment of community-acquired bacterial pneumonia (CABP) [65].

Plazomicin (4) (Zemdri, ACHN-490), which is a semi-synthetic derivative [66-68] of the aminoglycoside sisomicin $[69,70]$ developed by Achaogen, Inc. (South San Francisco, CA, USA). An IV formulation of $\mathbf{4}$ was approved by the FDA in June 2018 for the treatment of cUTI, including pyelonephritis, due to certain Enterobacteriaceae where treatment options are limited [71]. At the same time, Achaogen also sort the approval of plazomicin (4) to treat bloodstream infection (BSI), but the FDA indicated further trials would be required to demonstrate its effectiveness. Achaogen had submitted an marketing authorization application (MAA) in October
2018 with The European Medicines Agency (EMA) for complicated urinary tract infections (cUTI), including pyelonephritis, BSI due to certain Enterobacteriaceae, and Enterobacteriaceae in patients with limited treatment options [72]. However, in April 2019, Achaogen filed for bankruptcy [73] and it was announced in June 2019 that Cipla USA Inc. (Sunrise, FL, USA) had purchased the worldwide rights to plazomicin (4) except for China where the rights were held by QiLu Antibiotics Pharmaceutical Co. (Jinan, People's Republic of China) [74].

Eravacycline (5) (Xerava, TP-434), which is an IV administered, synthetic fluorocycline-type tetracycline derivative [75-77] developed by Tetraphase Pharmaceuticals (Watertown, MA, USA), was approved for treatment of complicated intra-abdominal infections (cIAI) by the EMA in July 2018 [78] and by the FDA in August 2018 $[79,80]$. Eravacycline (5) had also been evaluated in a cUTI phase-III trial (NCT01978938) but did not achieve statistical non-inferiority to ertapenem and no further development is likely [81].

Omadacycline (6) (Nuzyra, amadacycline, PTK-0796) [82], which a semi-synthetic minocycline derivative developed by Paratek Pharmaceuticals (Boston, MA, USA) with both oral and IV administration, was approved by the FDA in October 2018 for the treatment CABP and ABSSSI [83-85]. As a ten-year European market exclusivity starts after a product's first approval, Paratek has decided to resubmit their MAA for CABP and ABSSSI after the completion of their post-marketing CABP study for the FDA; this is because the EMA required an addition CABP study 


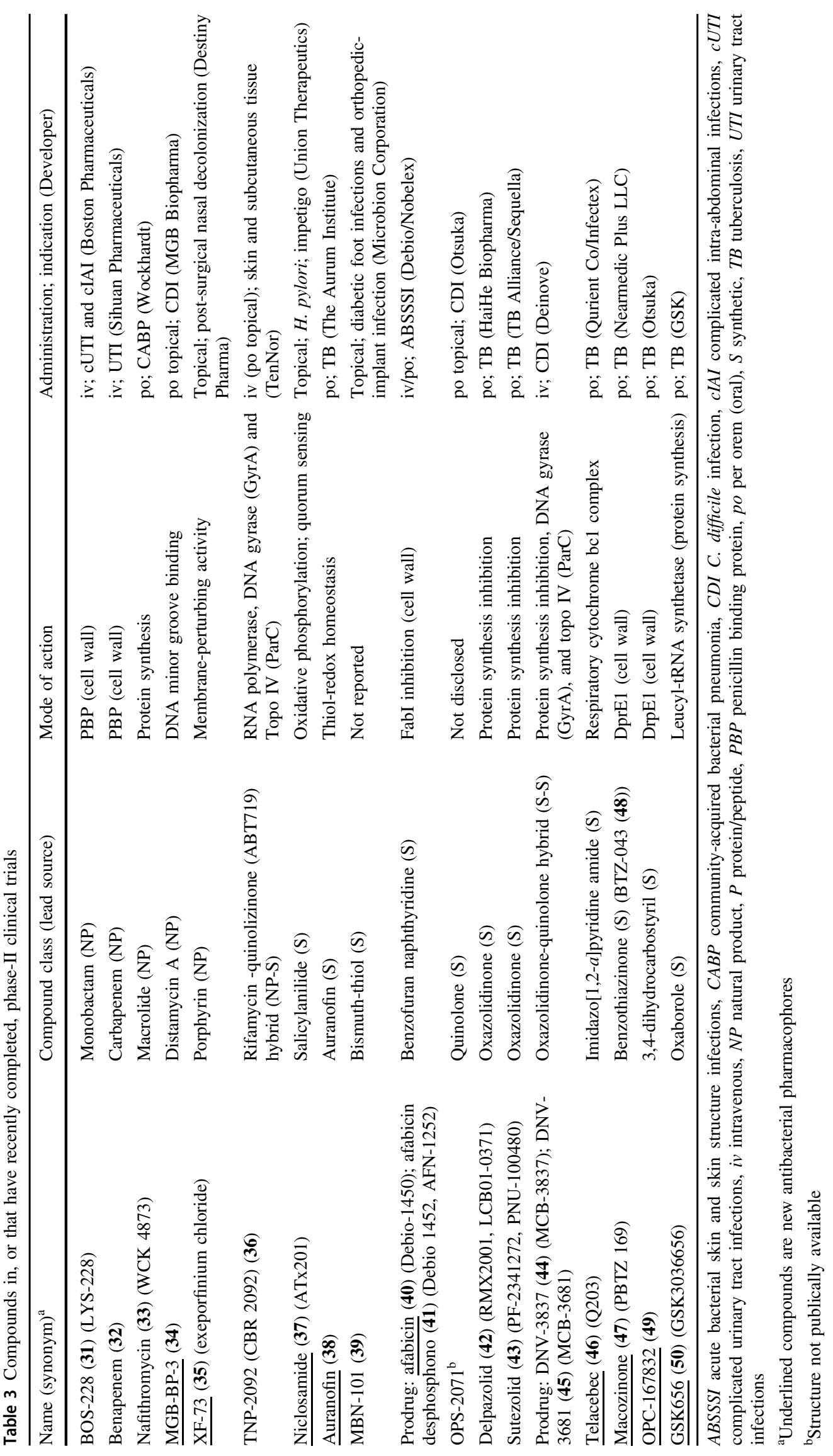




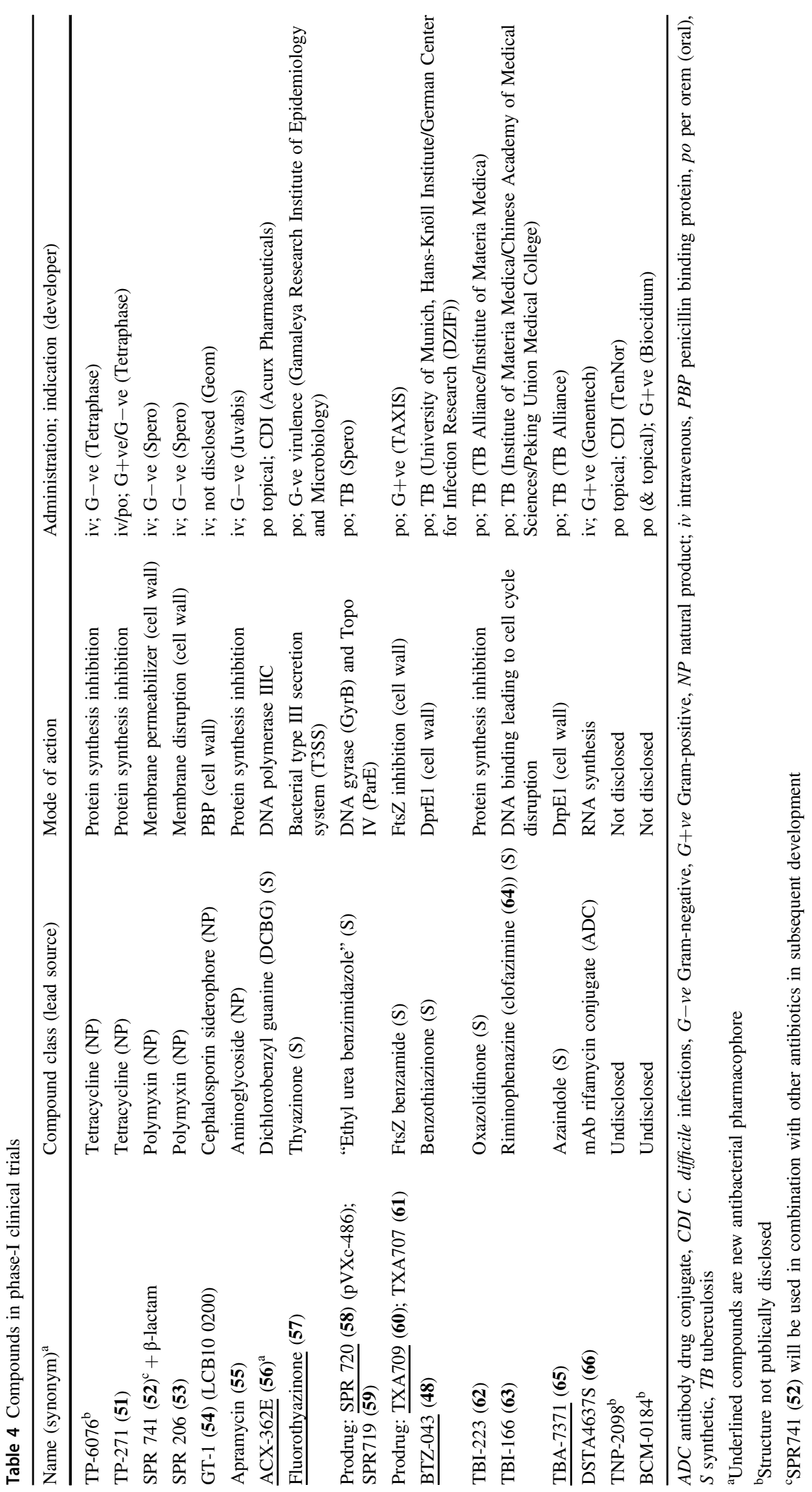


Table $5 \beta$-lactamase inhibitor/ $\beta$-lactam combinations in clinical trials

\begin{tabular}{|c|c|c|}
\hline Name (synonym) & Compound (lead source) & $\begin{array}{l}\text { Administration; indication } \\
\text { (developer) }\end{array}$ \\
\hline \multicolumn{3}{|l|}{ Phase-III } \\
\hline Enmetazobactam (68) (AAI 101) + cefepime (69) & $\begin{array}{l}\text { Clavulanic acid }(67)(\mathrm{NP})+ \\
\text { cephalosporin (NP) }\end{array}$ & iv; UTI (Allecra Therapeutics) \\
\hline $\begin{array}{l}\text { ETX2514SUL [durlobactam (70) }(\text { ETX2514) + sulbactam } \\
\text { (71)] }\end{array}$ & DBO $(\mathrm{S})^{\mathrm{a}}+$ clavulanic acid $(67)(\mathrm{NP})$ & $\begin{array}{l}\text { iv; MDR Acinetobacter infections } \\
\text { (Entasis) }\end{array}$ \\
\hline Taniborbactam (72) (VNRX-5133) + cefepime (69) & Boronate $(\mathrm{S})+$ cephalosporin $(\mathrm{NP})$ & iv; cUTI (VenatoRx) \\
\hline \multicolumn{3}{|l|}{ Phase-I } \\
\hline Nacubactam (73) (OP0595) + meropenem (13) & $\mathrm{DBO}(\mathrm{S})^{\mathrm{a}}+$ carbapenem $(\mathrm{NP})$ & iv; G-ve (NacuGen Therapeutics) \\
\hline Zidebactam (74) + cefepime (69) & $\mathrm{DBO}(\mathrm{S})^{\mathrm{a}} \& \mathrm{PBP} 2+$ cephalosporin $(\mathrm{NP})$ & iv; G-ve (Wockhardt) \\
\hline $\begin{array}{l}\text { Prodrug: ETX0282 (75) + prodrug: cefpodoxime proxetil }(\mathbf{7 7}) ; \\
\text { ETX1317 (76) + cefpodoxime } \mathbf{( 7 8 )}\end{array}$ & $\mathrm{DBO}(\mathrm{S})^{\mathrm{a}}+$ cephalosporin $(\mathrm{NP})$ & po; UTI (Entasis Therapeutics) \\
\hline Prodrug: VNRX-7145 (79) + ceftibuten $(\mathbf{8 0})$ & Boronate $(\mathrm{S})+$ cephalosporin $(\mathrm{NP})$ & po; $\mathrm{G}-\mathrm{ve}(\mathrm{VenatoRx})$ \\
\hline Prodrug: ARX-1796 (81) (ARX-006) & DBO prodrug of avibactam $(\mathbf{8 2})$ prodrug & po; G-ve (Arixa) \\
\hline
\end{tabular}

$c I A I$ complicated intra-abdominal infections, $c U T I$ complicated urinary tract infections, $G-v e$ Gram-negative, $i v$ intravenous, $N P$ natural product, $M D R$ multi-drug resistant, po per orem (oral), $S$ synthetic, UTI urinary tract infections

${ }^{a}$ These DBO BLIs also have activity against selected Enterobacteriaceae

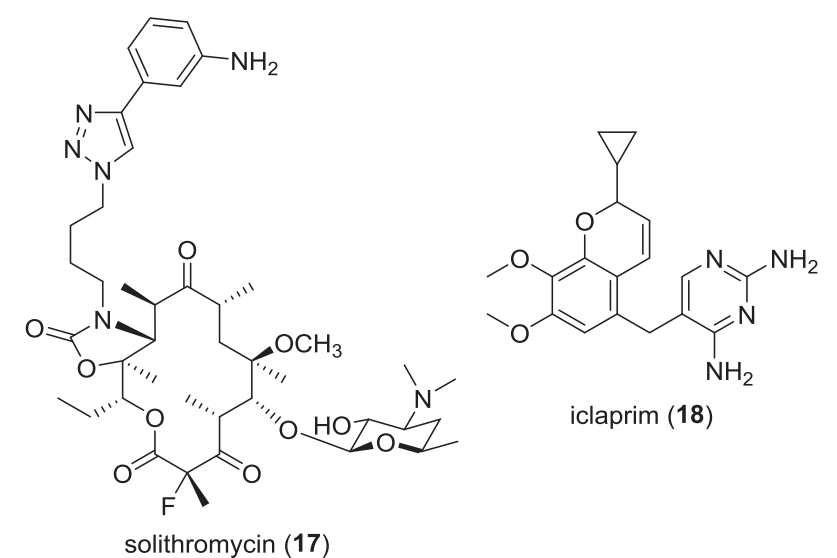

Fig. 4 Structures of antibacterials in the NDA and MAA development stage

but voted to approve 6 for ABSSSI [86]. Omadacycline (6) is also being evaluated in phase-II trials as a treatment of acute pyelonephritis (NCT03757234) and cystitis (UTI, NCT03425396).

Sarecycline (7) (Seysara, WC-3035, P005672, PTKAR01) was approved by the FDA in October 2018 as a topical treatment of moderate to severe acne [87-90]. Sarecycline (7) is a semi-synthetic tetracycline derivative discovered by Paratek Pharmaceuticals (Boston, MA, USA) and developed by Allergan, plc (Dublin, Ireland), which had its US dermatology assets acquired by Almirall S.A. (Barcelona, Spain) in August 2018.

Pretomanid (8) (PA-824) is a nitroimidazole [53] derived from CGI-17341 [91] that was approved by the FDA in
August 2019 as an orally-administered treatment for extensively drug resistant (XDR)-TB in combination with bedaquiline and linezolid under the Limited Population Pathway for Antibacterial and Antifungal Drugs (LPAD) [92]. The Global Alliance for TB Drug Development (TB Alliance) (New York, NY, USA) has been evaluating pretomanid (8) in three phase-III trials: in combination with linezolid and bedaquiline (NCT03086486), linezolid (NCT02333799), and linezolid, bedaquiline, moxifloxacin and clofazimine (NCT02589782). A phase-III in combination with moxifloxacin and pyrazinamide was completed in May 2018 (NCT02342886). Pretomanid (8) acts as prodrug that is reductively activated by the deazaflavin (cofactor $\mathrm{F}_{420}$ )-dependent nitroreductase Rv3547 [93-95]. Pretomanid (8) inhibits cell wall growth in aerobic conditions by hindering mycolic acid formation, while its activity involves the induction of respiratory poisoning under anaerobic conditions [93-95]. A recent report has also implicated the production of methylglyoxal using an untargeted metabolomics approach [96].

Lefamulin (9) (Xenleta, BC-3781) is a semi-synthetic pleuromutilin [97-99] derivative developed by Nabriva Therapeutics AG (Vienna, Austria) that was approved by the FDA in August 2019 as a treatment for patients with CABP [100]. Nabriva has also submitted an MAA for lefamulin (9) to the EMA in June 2019 [101]. Lefamulin (9) has had both oral and IV formulations approved, which should lead to shorter hospital stays, and is the second pleuromutilin derivative approved for human use but the first that can be systemically administered. The first approved pleuromutilin in 2007 was retapamulin, which is a topical treatment for impetigo [97, 98]. 
Fig. 5 Structures of compounds in phase-III clinical trials

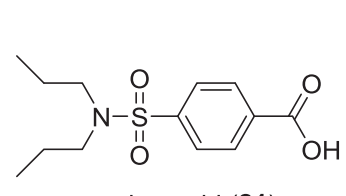

probenecid (21)<smiles>[R]OC(=O)C1=C(SC2CC[S+]([O-])C2)SC2C([C@H](C)O)C(=O)N12</smiles>

19) $\mathrm{R}=\mathrm{H}$

sulopenem (19) $\mathrm{R}=$

sulopenem etzadroxil (20) $\mathrm{R}=$<smiles>CCOC(=O)C(CC)CC</smiles><smiles></smiles><smiles>CNC(=O)C(CCN)NC(=O)C(Cc1c[nH]c2ccccc12)NC</smiles><smiles>CC(C)C(C)C(C)C=O</smiles>

SQ109 (23)<smiles>c1cc(-c2nc3cc(-c4ccc5[nH]c(-c6ccncc6)nc5c4)ccc3[nH]2)ccn1</smiles>

ridinilazole (24)<smiles>C[C@@H]1O[C@H](C)CN2c3c(cc4c(N5C(=O)OC[C@@H]5C)noc4c3F)CC3(C(=O)NC(=O)NC3=O)C12</smiles>

zoliflodacin (26)<smiles>[R]N(C[C@H]1CN(c2cc(F)c(N3C=CC(=O)CC3)c(F)c2F)C(=O)O1)c1ccon1</smiles><smiles>[R]OC1CCN(c2c(F)cc3c4c2-n2cc(C(=O)O)c(=O)c(c2-4)CC[C@@H]3C)CC1</smiles>

contezolid (27) $\mathrm{R}=\mathrm{H}$

contezolid acefosamil<smiles>[R6][R6]=[PH](=O)(O)OC(C)=O</smiles>

Like other pleuromutilins, lefamulin (9) inhibits bacterial protein synthesis and has activity against a range of skin [102], respiratory [103, 104] and sexually transmitted pathogens [105].

Lascufloxacin (10) (Lasvic, KRP-AM1977) is a fluoroquinolone with broad-spectrum activity [106, 107] that was developed by Kyorin Pharmaceutical Co., Ltd (Tokyo, Japan). In September 2019, Kyorin announced that an oral formulation of $\mathbf{1 0}$ (called KRPAM1977X) has been approved for the treatment of CAP, otorhinolaryngological and respiratory tract infections [108], while an NDA for the IV formulation (KRPAM1977Y) is under preparation.
Cefiderocol (11) (Fetroja, S-649266) is an IV administered, semi-synthetic cephalosporin-type $\beta$-lactam developed by Shionogi \& Co., Ltd. (Osaka, Japan), which incorporates a catechol siderophore that facilitates active transport into the bacteria via iron transporters, that has activity against MDR G-ve pathogens including carbapenemase producers [109-112]. Cefiderocol (11) is first approved antibacterial that exploits the iron transport uptake mechanism. Shionogi filed an NDA with the FDA in December 2018 for cUTI including pyelonephritis and an MAA with EMA in March 2019 multi-drug G-ve infections [113]. In November 2019, the FDA approved cefiderocol (11) for the treatment of cUTI [114]. 
Fig. 6 Structures of NP-derived compounds in phase-II clinical trials<smiles>Nc1nc(/C(=N/OC2(C(=O)O)CC2)C(=O)N[C@H]2C(=O)N(S(=O)(=O)O)[C@H]2CN2CCOC2=O)cs1</smiles><smiles>C[C@H](O)[C@H]1C(=O)N2C(C(=O)O)=C(S[C@@H]3CN[C@H](C(=O)NCc4ccc(S(N)(=O)=O)cc4)C3)[C@H](C)[C@H]12</smiles>

benapenem (32)

BOS-228 (31)

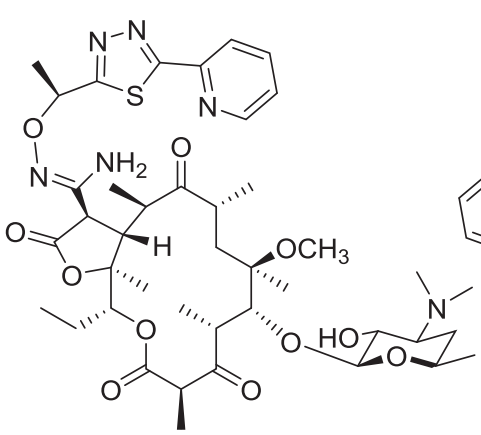

nafithromycin (33)<smiles>CO[C@H](/C=C/[C@@H](C)[C@@H](OC(C)=O)[C@@H](C)[C@H](C)O)[C@@H](C)O</smiles><smiles>CC(=O)c1ccc(/C=C/c2cnc3ccccc3c2)cc1</smiles><smiles>CNc1cc(C(=O)Nc2cc(C(=O)NCCN3CCOCC3)n(C)c2)n(C)c1</smiles>

MGB-BP-3 (34)<smiles></smiles>

exeporfinium chloride (35)

TNP-2092 (36)

Cefiderocol (11) has been evaluated in phase-III trials as a treatment for carbapenem-resistant G-ve pathogens at various sites (NCT02714595) and hospital-acquired pneumonia (HAP)/ventilator-associated pneumonia (VAP)/healthcare-associated pneumonia (HCAP) (NCT03032380). Positive results for a phase-II trial against cUTI (NCT02321800) has recently been published [115].

\section{$\beta$-lactam/BLI combinations}

Vabomere is an IV administered combination of the first-inclass boronate-type BLI, vaborbactam (12) (RPX7009), and meropenem (13) that was discovered by Rempex Pharmaceuticals. Rempex were acquired by The Medicines Company (Parsippany, NJ, USA) in December 2013, who were granted FDA approval in the August 2017 for the treatment of G-ve cUTIs (E. coli, K. pneumoniae and E. cloacae species complex), including pyelonephritis [116, 117]. Soon after this approval, The Medicines Company sold its anti-infective business units to Melinta Therapeutics (New Haven, CT, USA) [118]. In November 2017, the EMA approved Vabomere for the treatment of patients with cIAI, HAP/VAP, bacteremia, and other aerobic G-ve organisms with limited treatment options [119]. Vaborbactam (12) is noteworthy for its rapid movement from Rempex's 8 August 2011 patent filing [120] to its first approval in just over six years on 29 August 2017 (Table 1, Fig. 3).

Recarbrio, which is a combination of the relebactam (14), imipenem (15) and cilastatin (16) developed by Merck \& Co (Rahway, NJ, USA; known as Merck Sharp \& Dohme (MSD) outside of the USA), was approved by the FDA in 
Fig. 7 Structures of synthetic compounds in phase-II clinical trials<smiles>O=C(Nc1ccc([N+](=O)[O-])cc1Cl)c1cc(Cl)ccc1O</smiles>

niclosamide (37)

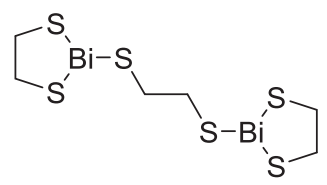

bismuth ethanedithiol (39)<smiles>CN1CCN(c2ccc(N3C[C@H](CO)OC3=O)cc2F)C=N1</smiles>

delpazolid (42)<smiles>CC[PH](CC)(CC)C[Al]SC1OC(OC(C)=O)C(OC(C)=O)C(OC(C)=O)C1OC(C)=O</smiles>

auranofin (38)<smiles>[R]N1C(=O)CCc2cc(/C=C/C(=O)N(C)Cc3oc4ccccc4c3C)cnc21</smiles><smiles>O=P(O)(O)OCC([GeH2])[R]#[W][Ba]</smiles>
afabicin desphosphono (41) $\mathrm{R}=\mathrm{H}$<smiles>CC(=O)NC[C@H]1CN(c2ccc(N3CCSCC3)c(F)c2)C(=O)O1</smiles>
sutezolid (43)<smiles>[R]OC1(COc2ccc(N3C[C@H](CNC(C)=O)OC3=O)cc2F)CCN(c2cc3c(cc2F)c(=O)c(C(=O)O)cn3C2CC2)CC1</smiles><smiles>CCc1nc2ccc(Cl)cn2c1C(=O)NCc1ccc(N2CCC(c3ccc(OC(F)(F)F)cc3)CC2)cc1</smiles>

OPC-167832 (49)<smiles>NC[C@@H]1OB(O)c2c(OCCO)ccc(Cl)c21</smiles>

GSK3036656 (50)

July 2019 as an IV administered treatment of cUTI and cIAI [117, 121-123]. Relebactam (14) is a DBO-type BLI [124] that is administered with the imipenem (15), which is a carbapenem first launched in 1987, and cilastatin (16), which is a dehydropeptidase inhibitor that improves the in vivo stability of imipenem (15) [125].

\section{Compounds undergoing clinical evaluation}

The compounds currently undergoing clinical trials or under regulatory evaluation for the treatment of bacterial infections as of the end of October 2019 are detailed in the following tables and figures: NDA and phase-III in Tables 2 
Fig. 8 Structures of NP-derived compounds in phase-I clinical trials

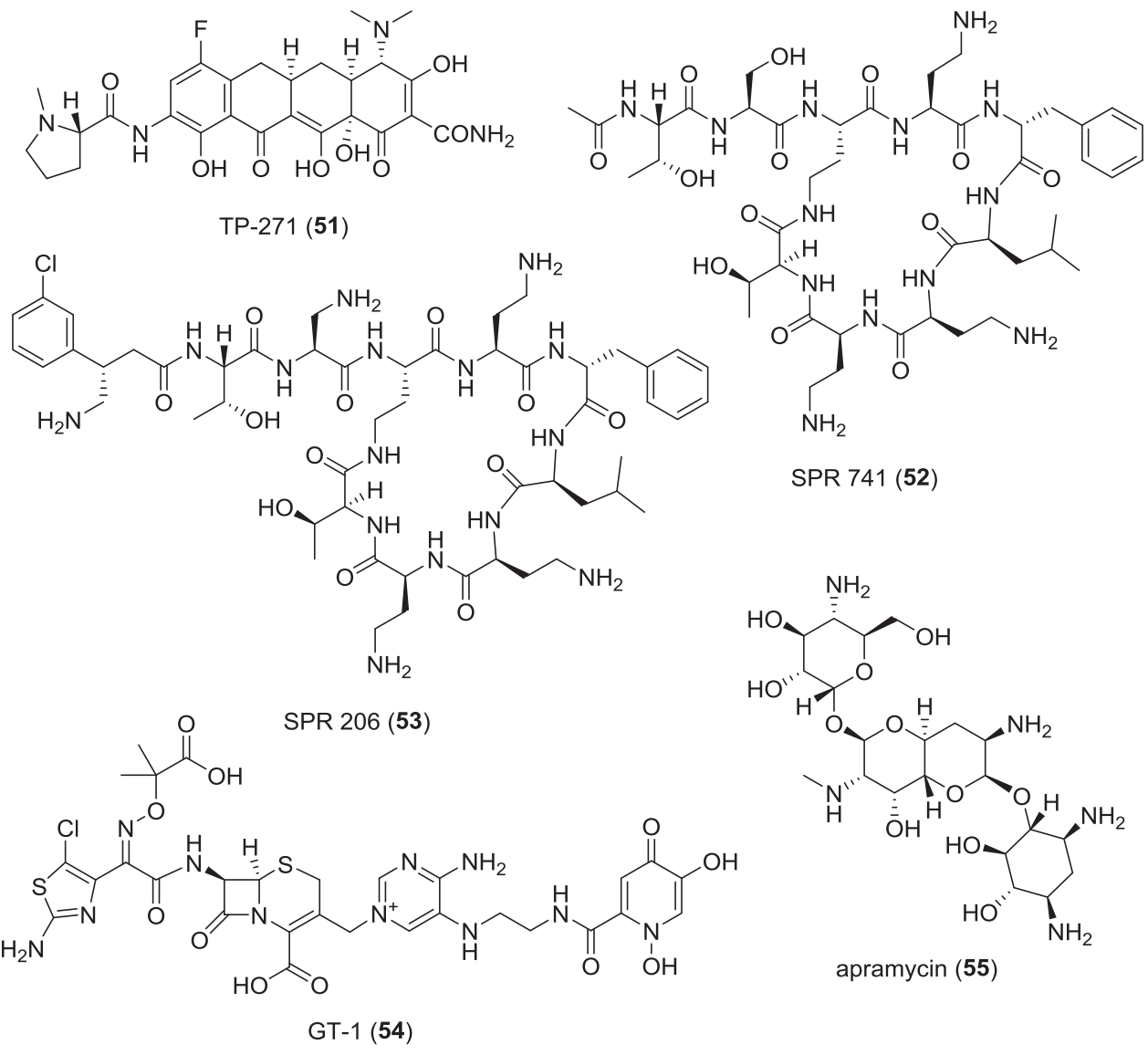

and 5 with structures in Figs. 4, 5, and 11, phase-II in Table 3 with structures in Figs. 6 and 7, and phase-I in Tables 4 and 5 with structures in Figs. 8-10 and 12.

\section{Compounds in NDA/MAA filing}

Solithromycin (17) (T-4288, CEM-101) is a semi-synthetic 2-fluoroketolide [126] that is being evaluated by FUJIFILM Toyama Chemical Co., Ltd. (Tokyo, Japan) in several phaseIII trials in Japan as an oral treatment for sinusitis (JPRNJapicCTI-173733), otorhinolaryngological (head and neck) infections (JPRN-JapicCTI-163467), respiratory tract infections (JPRN-JapicCTI-163438) and CAP (JPRN-JapicCTI163439). The National Institute of Allergy and Infectious Diseases (NIAID) (Bethesda, MD, USA) has also been evaluated $\mathbf{1}$ in a phase-I trial for gonorrhea (NCT02348424). In April 2019, FUJIFILM Toyama applied for a NDA in Japan with the Japanese Pharmaceuticals and Medical Devices Agency (PMDA) as a treatment bacterial infections in otorhinolaryngology (ear, nose and throat) [127]. Solithromycin (17) was discovered by Optimer Pharmaceuticals (San Diego, CA, USA) and was being developed in the USA by Cempra Pharmaceuticals (Chapel Hill, NC, USA). Cempra submitted an NDA for CABP to the FDA in May 2016 but the FDA sent a Complete Letter Response in December
2016 that requested additional clinical safety information and the satisfactory resolution of manufacturing facility inspection deficiencies [128]. Cempra withdrew the CABP MAA for the EMA in March 2017 [129]. Cempra merged in August 2017 with Melinta Therapeutics (New Haven, CT, USA), who are not currently developing solithromycin (17) (Table 2, Fig. 4).

Iclaprim (18) is an IV and orally dosed trimethoprim analog that was being developed by Motif Bio plc (London, UK) [130, 131]. Iclaprim (18) was discovered by Roche (Basel, Switzerland; coded RO-48-2622) and licensed in 2001 to their anti-infectives spin-out Arpida AG (Reinach, Switzerland; coded AR-100). Arpida completed two phaseIII trials evaluating 18 for SSSI but the FDA rejected their NDA in 2009, while their MAA was later withdrawn due to concerns about not reaching non-inferiority to its comparator antibiotic and potential QT interval prolongation issues [132]. Motif Bio started to develop iclaprim (18) in 2015 and submitted an NDA with the FDA in June 2018 for ABSSSI from data derived from two phase-III trials (NCT02600611 and NCT02607618) [133] with altered dosing regimens compared with Arpida's trials [131]; however, the FDA required an additional clinical trial before granting approval [134] and Motif Bio have subsequentially halted development. 
Fig. 9 Structures of syntheticderived compounds in phase-I clinical trials<smiles>O=c1[nH]c(NCc2ccc(Cl)c(Cl)c2)nc2ncn(CCN3CCOCC3)c12</smiles>

ACX-362E (56)<smiles>[R]OC(C)(C)c1ncc(-c2cc3nc(NC(=O)NCC)[nH]c3c(C3CCCO3)c2F)cn1</smiles>

SPR-719 (59) R = H<smiles>COC(=O)NC[C@H]1CN(c2ccc(N3CC4(COC4)C3)c(F)c2)C(=O)O1</smiles>

TBI-223 (62)<smiles>CCOc1cc(CN2N=C(C(=O)Nc3ccc(F)cc3F)SCC2=O)ccc1O</smiles>

fluorothyazinone (57)<smiles>[R]NC(=O)c1c(F)ccc(OCc2nc3cc(C(F)(F)F)cnc3s2)c1F</smiles>

TXA707 (61) $\mathrm{R}=\mathrm{H}$<smiles>CC1COC2(CCN(c3nc(=O)c4cc(C(F)(F)F)cc([N+](=O)[O-])c4s3)CC2)O1</smiles>

BTZ043 (48)<smiles>COc1ncccc1Nc1cc2nc3ccccc3n(-c3ccc(OC(F)(F)F)cc3)c-2cc1=NC1CCC(OC)CC1</smiles>

TBI-166 (63)<smiles>CC(C)/N=c1\cc2n(-c3ccc(Cl)cc3)c3ccccc3nc-2cc1Nc1ccc(Cl)cc1</smiles>

clofazimine (64)<smiles>COc1ncnc(Cn2cc(C(=O)NCCO)c3ncc(C)cc32)c1C</smiles>

TBA-7341 (65)

\section{Compounds in phase-III trials}

Sulopenem (19) (CP-70,429) is a synthetic thiopenem $\beta$-lactam discovered in Pfizer's Japanese laboratories that underwent clinical evaluation in the mid-1990s but development was discontinued due to high development costs and market return concerns [135]. Interestingly, the $R$ enantiomer of sulopenem caused unpleasant sulfurous odors when dosed in human volunteers and the racemate CP65,207 could not be used [136]. Pfizer re-started clinical development in 2003 using a more efficient production-scale synthesis procedure to help alleviate the cost issue [137, 138]. In late 2015, Iterum Therapeutics plc (Dublin, Ireland) licensed sulopenem (19) and its prodrug sulopenem etzadroxil (20) (PF-03709270) from Pfizer [139]. Iterum are now evaluating 19 using IV administration followed by oral dosing of $\mathbf{2 0}$ in phase-III studies for the treatment of cIAI (NCT03358576) and cUTI

Fig. 10 Structure of the mAb-rifamycin antibiotic conjugate in phaseI trials 
Fig. 11 Structures of BLIs and associated $\beta$-lactam antibiotics in phase-III clinical trials and clavulanic acid (67)

Fig. 12 Structures of BLIs and associated $\beta$-lactam antibiotics in phase-I clinical trials<smiles>O=C(O)[C@H]1/C(=C/CO)O[C@@H]2CC(=O)N21</smiles>

clavulanic acid (67)<smiles>CC1=CC2CN(C(=O)N2OS(=O)(=O)O)[C@@H]1C(N)=O</smiles>
durlobactam (70)<smiles>C[n+]1ccn(C[C@]2(C)[C@H](C(=O)O)N3C(=O)C[C@H]3S2(=O)=O)n1</smiles>

enmetazobactam (68)<smiles>C[N+]1(CC2=C(C(=O)O)N3C(=O)[C@@H](NC(=O)/C(=N\O)c4csc(N)n4)[C@H]3SC2)CCCC1</smiles>

cefepime (69)<smiles>CC1(C)[C@H](C(=O)O)N2C(=O)C[C@H]2S1(=O)=O</smiles>
sulbactam (71)<smiles>NCCN[C@H]1CC[C@H](CC(=O)N[C@H]2Cc3cccc(C(=O)O)c3OB2O)CC1</smiles><smiles>NCCONC(=O)[C@@H]1CCC2CN1C(=O)N2OS(=O)(=O)O</smiles>

nacubactam (73)<smiles>[R]OC(=O)C(F)ON1C(=O)N2C[C@@H]1C(C)=C[C@H]2C(N)=O</smiles>

ETX0282 (75) R =

$\operatorname{ETX1317~(76)~} \mathrm{R}=\mathrm{H}$<smiles></smiles>

VNRX $7145(79)$<smiles>O=C(NNC(=O)[C@@H]1CCC2CN1C(=O)N2OS(=O)(=O)O)C1CCCNC1</smiles>

zidebactam (74)<smiles>[R]OC(=O)C1=C(COC)CS[C@H]2[C@H](NC(=O)/C(=N\OC)c3csc(N)n3)C(=O)N12</smiles>

cefpodoxime proxetil (77) $R=$ cefpodoxime $(78) \mathrm{R}=\mathrm{H}$<smiles>Nc1nc(/C(=C/CC(=O)O)C(=O)N[C@H]2C(=O)N3C(C(=O)O)=CCS[C@H]23)cs1</smiles>

ceftibuten (80)<smiles>[R]OS(=O)(=O)ON1C(=O)N2C[C@H]1CC[C@@H]2C(N)=O</smiles><smiles>[Y10][R5][Ba]</smiles>
avibactam (82) $\mathrm{R}=\mathrm{H}$ 


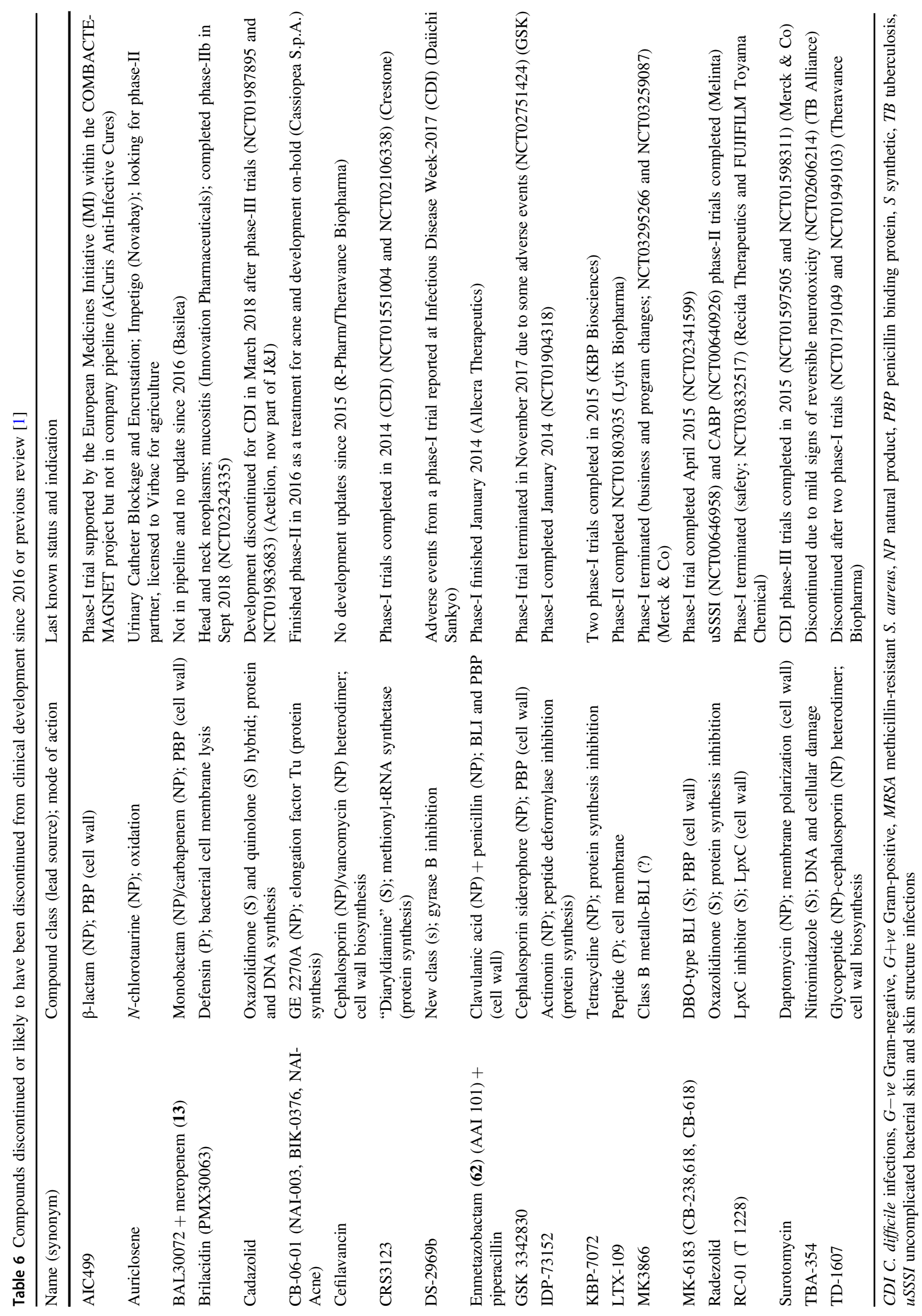




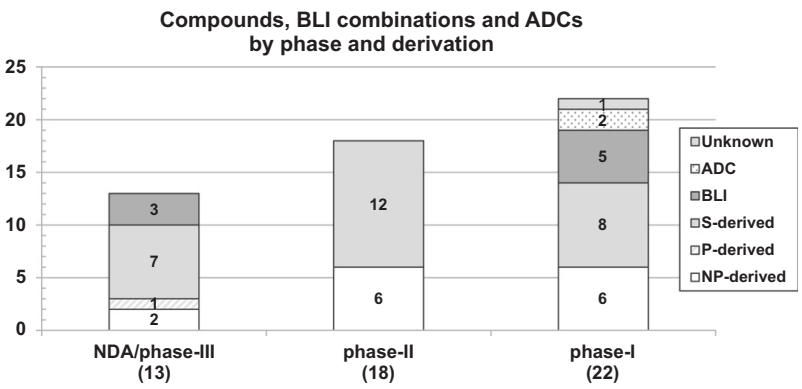

Fig. 13 Compounds under clinical evaluation divided into development phases and their lead derivation source: natural product (NP), synthetic (S), protein/mammalian peptide $(\mathrm{P}), \beta$-lactam/ $\beta$-lactamase inhibitor (BLI) combinations, and antibody drug conjugate (ADC)

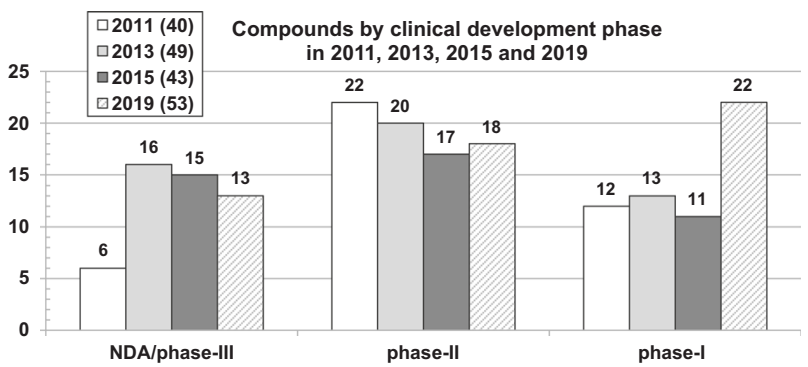

Fig. 14 Comparison of the numbers of compounds undergoing clinical development as of 2011 [3], 2013 [2], 2015 [1], and 2019 by development phase

(NCT03357614) and oral 20 alone for uUTI (NCT03354598). In these trials, sulopenem etzadroxil (19) is administered along with probenecid (21) [140], which is a marketed drug for gout and hyperuricemia that increases uric acid production, that inhibits the tubular secretion of some $\beta$-lactams and leads to a longer drug half-life and higher serum concentrations [141] (Table 3, Figs. 6 and 7).

Murepavadin (22) (POL7080, RG7929) is a synthetic cyclic peptide 14-mer based on protegrin I that is being developed by Polyphor, Ltd. (Basel, Switzerland) [142-144]. Murepavadin (22) has a new mode of action through binding to the $N$-terminal of the $\beta$-barrel protein LptD (Imp/OstA) from $P$. aeruginosa [142, 145], which affects lipopolysaccharide transport to the cell surface and leads to bacterial death [146]. As this binding pocket is only present in $P$. aeruginosa $\mathrm{LptD}$, murepavadin (22) displays selective anti$P$. aeruginosa activity, which should help to reduce resistance and microbiome disturbance. Polyphor have been evaluating murepavadin (22) in two phase-III trials for the treatment of Pseudomonas nosocomial pneumonia (NCT03582007) and VAP infections (NCT03409679); however, it was announced in May 2019 that there was an increase in serum creatinine and acute kidney injury using IV administration in the nosocomial pneumonia trial [147]. In July 2019, Polyphor announced that this trial had been closed but stressed that the inhaled administration route was not impacted [148].
SQ 109 (23) is an ethambutol analog discovered at the NIAID (Bethesda, MD, USA) [149, 150] that was first developed by Sequella, Inc (Rockville, MD, USA), who later licensed the development for the Russian Federation and Commonwealth of Independent States to Infectex (Moscow, Russia). In March 2017, Infectex announced positive results from a phase-II/III trial for the treatment of MDR pulmonary TB $[151,152]$, but since then there has been no update. Results from a Sequella-sponsored phase-II trial evaluating high range oral doses of rifampicin, moxifloxacin and SQ109 (23) for treating TB (NCT01785186) has been published [153]. Although SQ109 (23) is structurally derived from ethambutol, SQ109 (23) has different modes of action and activity against other bacteria and parasites. Ethambutol targets arabinofuranosyl transferases EmbA and EmbB $[154,155]$, which are involved in cell wall synthesis, and was recently reported to show synergy with isoniazid targeting a transcriptional repressor of the inhA gene [156] and glutamate racemase (MurI) [157]. Conversely, SQ109 (23) has been reported to inhibit $\mathrm{mMpl3}$, which is a trehalose monomycolate transporter important in cell wall synthesis [158], as well as inhibit the quinone biosynthesis enzymes MenA and MenG and affect bacterial respiration and electron transfer $[159,160]$.

Ridinilazole (24) (SMT19969) is a synthetic bis-benzimidazole [161] that is being developed by Summit Therapeutics plc (Oxford, UK). Ridinilazole (24) will be evaluated in two phase-III trials as for the treatment of CDI compared with vancomycin (NCT03595553 and NCT03595566) with assistance from the Biomedical Advanced Research and Development Authority (BARDA) (Washington DC, USA), which is an office of the U.S. Department of Health and Human Services [162]. The mode of action of $\mathbf{2 4}$ has not been fully elucidated but has been shown to affect cell division [163]. Importantly, ridinilazole (24) has been shown to reduce toxin production [163] and be less harsh on the gut microbiome compared with vancomycin [164].

Gepotidacin (25) (GSK-2140944) is an orally bioavailable, first-in-class antibacterial (triazaacenaphthylene class), which is new type of bacterial Type II topoisomerase inhibitor [165], being developed by GlaxoSmithKline (GSK) (London, UK) that has just started phase-III trials as a treatment for uncomplicated UTI (NCT04020341) and uncomplicated urogenital gonorrhea (NCT04010539). Gepotidacin (25) has previously completed three phase-II clinical trials: G+ve ABSSSI (NCT02045797), uncomplicated urogenital gonorrhea caused by $N$. gonorrhoeae (NCT02294682) [166, 167] and uncomplicated UTI (NCT03568942). Gepotidacin (25) has activity against range of both $\mathrm{G}+\mathrm{ve}$ and $\mathrm{G}-\mathrm{ve}$ pathogens [168-170], including several species associated with sexually transmitted infections (STIs) such as N. gonorrhoeae [166, 171], Mycoplasma, and Ureaplasma [172]. 
Table 7 New antibacterial pharmacophores by compound name, phase, class, lead source, activity, mode of action, and administration

\begin{tabular}{|c|c|c|}
\hline Name-phase & Class (lead source) & Mode of action-administration \\
\hline Murepavadin (22)—III & "Protegrin" $(\mathrm{P})$ & Cell wall (LptD)_-inhalation (previously iv) \\
\hline Afabicin (40)-II & Benzofuran naphthyridine (S) & Cell wall (FabI)—iv/po \\
\hline Macozinone (47)-II & Benzothiazinone (BTZ) (S) & Cell wall (DprE1)—po \\
\hline BTZ-043 (48)-I & Benzothiazinone (BTZ) (S) & Cell wall (DprE1)—po \\
\hline OPC-167832 (49)-II & 3,4-dihydrocarbostyril (S) & Cell wall (DprE1)—po \\
\hline TBA-7371 (65)I & Azaindole (S) & Cell wall (DprE1)-po \\
\hline TXA709 (60)-I & FtsZ benzamide (S) & Cell wall (FtsZ)—po \\
\hline Ridinilazole (24)—III & bis-Benzimidazole (S) & Cell wall (division)—-po topical \\
\hline XF-73 (35)—II & Porphyrin (NP) & Cell wall/membrane perturbation-topical \\
\hline Gepotidacin (25)—III & Triazaacenaphthylene $(\mathrm{S})$ & DNA (GyrA)—iv/po \\
\hline Zoliflodacin (26)—III & Spiropyrimidinetrione $(\mathrm{S})$ & DNA (GyrB)—po \\
\hline MGB-BP-3 (34)-II & Distamycin (NP) & DNA (groove binding)—po topical \\
\hline ACX-362E (56)-I & Dichlorobenzyl guanine (S) & DNA (DNA polymerase IIIC)—po topical \\
\hline SPR $720(\mathbf{5 8})-\mathrm{I}$ & "Ethyl urea benzimidazole" (S) & DNA (GyrB and ParE) - po \\
\hline GSK656 (50)—II & Oxaborole (S) & $\begin{array}{l}\text { Protein synthesis (leucyl-tRNA synthetase) } \\
\text { - po }\end{array}$ \\
\hline Telacebec (46)_II & Imidazo[1,2- $a]$ pyridine amide $(\mathrm{S})$ & $\begin{array}{l}\text { Oxidative phosphorylation (respiratory } \\
\text { complex } \mathrm{bc}_{1} \text { )—po }\end{array}$ \\
\hline Niclosamide (39) ${ }^{\mathrm{a}}$ - II & Salicylanilide (S) & $\begin{array}{l}\text { Oxidative phosphorylation (quorum } \\
\text { sensing?)— topical }\end{array}$ \\
\hline Auranofin $(\mathbf{3 8})^{\mathrm{a}-\mathrm{II}}$ & "Gold complex" $(\mathrm{S})$ & Thioredoxin reductase-po \\
\hline Fluorothyazinone (57)-I & Thyazinone (S) & Virulence (type III secretion system)—po \\
\hline
\end{tabular}

${ }^{\mathrm{a}}$ Repurposed drugs

Compounds with new pharmacophores

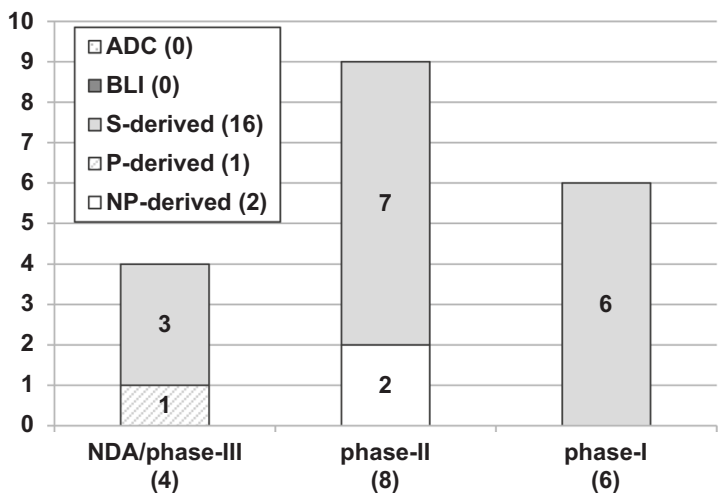

Fig. 15 Antibacterials [natural product (NP), synthetic (S), protein/ mammalian peptide $(\mathrm{P})$ ], $\beta$-lactamase inhibitors (BLI), and antibody drug conjugates (ADCs)] with new antibacterial pharmacophores divided into development phases and their lead derivation source

Zoliflodacin (26) (ETX0914, AZD0914) is the first member of a new class of topoisomerase inhibitor class [173] called the spiropyrimidinetriones being developed by Entasis Therapeutics (Waltham, MA, USA) that has started a phase-III trial (NCT03959527) as an orally administered treatment of uncomplicated gonorrhea [174] in collaboration with the Global Antibiotics Research and Development Partnership (GARDP) (Geneva, Switzerland). Zoliflodacin
New antibiotic pharmacophores in clinical trials in 2011, 2013, 2015 and 2019

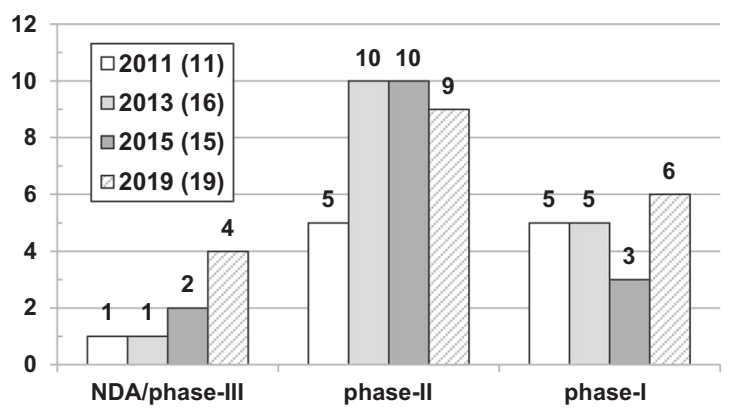

Fig. 16 Comparison of the numbers of novel antibacterial pharmacophores undergoing clinical development in 2011 [3], 2013 [2], 2015 [1], and 2019 by development phase

(26) also has activity against Mycoplasma genitalium, which could enhance its usefulness in treating STIs [175]. Entasis completed a phase-II trial (NCT02257918) that showed that zoliflodacin (26) was able to successfully treat uncomplicated urogenital and rectal gonococcal infections but was less efficacious against pharyngeal infections [176].

Contezolid (27) (MRX-I) is an oxazolidinone being evaluated by MicuRx Pharmaceuticals (Hayward, CA, USA and Shanghai, People's Republic of China) [177]. MicuRx announced positive results for a China-based phase-III trial for cSSTI and they plan to file an NDA with the Chinese 
National Medical Products Administration (NMPA) before the end of 2019 [178]. Contezolid (27) has completed a phase-II trial against ABSSSI (NCT02269319) using oral dosing. Contezolid (27) was selected for development due to a proposed superior safety profile compared with linezolid [177] and promising activity against $\mathrm{G}+$ ve bacteria $[179,180]$ and TB [181]. The prodrug of contezolid (27), contezolid acefosamil (28) (MRX-4) [182], is being evaluated in a phase-II trial for the treatment of ABSSSI in both China and the USA (NCT03747497) using an IV to oral switch route.

Levonadifloxacin (29) (WCK-771) and its alanine prodrug alalevonadifloxacin (30) (WCK-2349) [183] are currently being evaluated in a phase-III trial for CSSSI in India $[184,185]$ using IV and oral administration. Levonadifloxacin (29) is the arginine salt of the fluoroquinolone $S$-(-)nadifloxacin [186-188]; racemic nadifloxacin has been topically used to treat acne and MRSA [186].

\section{Compounds in phase-II trials}

BOS228 (31) (LYS228) is an IV-administered monobactam with potent activity against both serine and metallo$\beta$-lactamase expressing [189] discovered by Novartis (Basel, Switzerland) [190-192]. Novartis started phase-II trials of BOS228 (31) for G-ve cUTI (NCT03377426) and cIAI (NCT03354754); however, after Novartis exited antibiotic development in July 2018, these trials were halted and $\mathbf{3 1}$ was licensed to Boston Pharmaceuticals (Cambridge, MA, USA) for further development [193] (Table 3, Figs. 6 and 7).

Benapenem (32) is a carbapenem, which is structurally similar to ertapenem and shares its longer half-life compared with other carbapenems, that is currently being evaluated phase-II trial as a treatment for a cUTI including pyelonephritis by Sihuan Pharmaceutical (Beijing, People's Republic of China) using IV administration (CT20181302) [194]. Benapenem (32) has completed three phase-I trials (NCT03570970, NCT03578588, and NCT03588156) and results from these trials indicated that 32 was well tolerated and the PK data supported oncedaily IV dosing [195].

Nafithromycin (33) (WCK 4873) is an orally bioavailable ketolide being developed by Wockhardt Limited (Mumbai, India) that completed a CABP phase-II trial (NCT02903836) in July 2017. Nafithromycin (33) recently started a new multiple dosing phase-I trial (NCT03981887) and has activity against both $\mathrm{G}+\mathrm{ve}$ (e.g., S. pneumoniae and Staphylococcus aureus) and $\mathrm{G}-\mathrm{ve}$ (e.g., Haemophilus influenzae, Moraxella catarrhalis, Legionella pneumophila, Mycoplasma pneumoniae, and Chlamydophila pneumoniae) bacteria [196, 197].

MGB-BP-3 (34) is a DNA binding antibacterial being developed by MGB Biopharma (Glasgow, UK) that recently started a phase-II trial for the treatment of patients with C. difficile-associated diarrhea (CDAD) (NCT03824795). MGB-BP-3 (34) was first synthesized at the University of Strathclyde (Glasgow, UK) and its structure is based on the actinomycetes-derived minor groove binders the distamycin, netropsin and thiazotropsin ("lexitropsins") [198].

XF-73 (35) (exeporfinium chloride) is a topically administered, photosensitizing porphyrin with derivative broad spectrum G+ve activity [199-202] that is being developed by Destiny Pharma (Brighton, UK). XF-73 (35) has recently started a phase-II trial to study its effect on nasal $S$. aureus in patients at risk of post-operative staphylococcal infections (NCT03915470). XF-73 (35) has been evaluated in phase-I/II trials for the prevention of postsurgical staphylococcal nasal infections (NCT02282605) and positive data from a phase-I trial have been reported (NCT01592214) [203].

TNP-2092 (36) (CBR 2092) is currently being developed by TenNor Therapeutics (Suzhou, People's Republic of China) in a phase-II trial for the treatment of G+ve ABSSSI infections using IV dosing (NCT03964493). TenNor are also evaluating TNP-2092 (36) against catheter-related bloodstream infections and prosthetic joint infections [204]. TNP-2092 (36) is a rifamycin-quinolizinone hybrid antibacterial discovered by Cumbre Pharmaceuticals [205] that had excellent activity against $\mathrm{G}+\mathrm{ve}$ pathogens [206]. The rifamycin lead was rifampicin, while the quinolizinone component lead was ABT-719, which had a similar activity profile to quinolones [205]. It was shown that the $G+v e$ antibacterial activity of $\mathbf{3 6}$ was via the modes of action of the hybrid components: RNA polymerase (rifamycin) and balanced DNA gyrase and DNA topoisomerase IV (quinolone) inhibition [207].

ATx201 is a topical formulation of niclosamide (37), which is a halogenated salicylanilide derivative being developed by UNION Therapeutics A/S (Hellerup, Denmark; previously called AntibioTx) [208, 209]. Niclosamide (37) was discovered in the late 1950s by Bayer (Leverkusen, Germany) and is currently used an anthelmintic, predominantly to treat tapeworm infections [210]. ATx201 completed phase-II trials in 2018 for the treatment for impetigo (NCT03429595) and atopic dermatitis (NCT03304470) with its future development being focused on atopic dermatitis (EudraCT2019-002771-33) [211]. In addition to bacterial infections [212-215], there have also been efforts to "re-purpose" 37 as a treatment for Parkinson's disease, Type 2 diabetes, viral infections and oncology [216, 217]. Niclosamide (37) has multiple mechanisms in these therapeutic areas [216]. In bacteria, there is evidence that $\mathbf{3 7}$ interferes with oxidative phosphorylation in TB, which could affect membrane potential and $\mathrm{pH}$ homeostasis [218], and inhibit P. aeruginosa quorum sensing [219]. 
Auranofin (38), which is a 2,3,4,6-tetra- $O$-acetyl-1-thio$\beta$-D-glucopyranosato-[triethylphosphine] gold complex first approved as a rheumatoid arthritis drug in 1985 [220-222], is currently being evaluated in a phase-II trial by The Aurum Institute (Johannesburg, Republic of South Africa) as an adjunctive host directed therapies to assess its potential to shorten TB treatment and/or prevent permanent lung damage (NCT02968927). Auranofin (38) primarily exerts its biological activity through inhibition of thioredoxin reductase [223-225] but its mode of action in bacteria is more complex [226-228]. There has also been interest in re-purposing auranofin (38) for C. difficile [229], Helicobacter pylori [230], and MRSA, S. pneumoniae and Enterococcus faecalis [223, 226, 231, 232].

MBN-101 (39) (bismuth ethanedithiol, BisEDT) has broad spectrum, topical antibacterial and antibiofilm activity, and is being developed by Microbion Corporation (Bozeman, MT, USA) [233, 234]. MBN-101 is currently being evaluated in a phase-II trial patients diagnosed with an orthopedic infection (NCT02436876), and a phase-Ib/IIa trial as a topical treatment for diabetic foot infection (NCT02723539). Microbion licensed MBN-101 to Haisco Pharmaceutical Group (Chengdu, People's Republic of China) for development in China in February 2016 [235]. Bismuth has some intrinsic antibacterial activity as demonstrated by bismuth subsalicylate (later called Pepto Bismol $^{\circ}$ ), which has been used since 1900 to help treat stomachaches and traveler's diarrhea [236], and Xeroform ${ }^{\circ}$, which is a petrolatum-based fine mesh gauze containing $3 \%$ bismuth tribromophenate [237]. Bismuth is also used in combinations with other antibiotics and a proton pump inhibitor to treat $H$. pylori infections [238].

Afabicin (40) (Debio 1450, AFN 1720), which is a prodrug of afabicin desphosphono (41) (Debio 1452, AFN1252), is being evaluated by Debiopharm Group (Lausanne, Switzerland) in a phase-II trial (NCT03723551) using an IV/oral switch strategy for the treatment of $S$. aureus bone or joint infection [239]. Afabicin (40) had previously completed another phase-II ABSSSI trial (NCT02426918). Afabicin (40) specifically inhibits staphylococcal FabI $[240,241]$, which is an essential enzyme in the final step of the fatty acid elongation cycle [242, 243], and the initial lead was discovered [244, 245] by GSK (London, UK) and further developed [246] by Affinium Pharmaceuticals (Austin, TX, USA) before licensing to Debiopharm.

OPS-2071 (structure not disclosed) is a quinolone-based antibacterial being developed by Otsuka Pharmaceutical (Tokyo, Japan) that has completed a phase-II trial against $C$. difficile and enteric infections (NCT02473393) [247]. In February 2019, Otsuka announced an additional phase-II trial evaluating OPS-2071 as an add-on therapy for Crohn's disease where patients show symptoms of active inflammation during ongoing treatment (NCT03850509).
Delpazolid (42) (RMX2001, LCB01-0371) is an oxazolidinone discovered by LegoChem Biosciences, Inc. (Daejeon, Republic of Korea), which has activity against $\mathrm{G}+\mathrm{ve}$ bacteria [248], TB [249] and Mycobacterium abscessus [250], that is being evaluated in a phase-II trial for the treatment of TB using oral administration (NCT02836483). Delpazolid (42) is being co-developed in China with HaiHe Biopharma (Shanghai, People's Republic of China) and China Shijiazhuang Holding Group Co (Hong Kong, People's Republic of China) [251].

Sutezolid (43) (PF-2341272, PNU-100480) [252] is an oxazolidinone-type antibacterial that was originally developed alongside linezolid by Upjohn \& Co (later Pharmacia \& Upjohn), which was later absorbed into Pfizer (New York, NY, USA) in 1995. Sutezolid (43) has potent activity against TB [253-255] and Sequella (Rockville, MD, USA) licensed $\mathbf{4 3}$ from Pfizer in 2013 and a phase-II trial was completed as a treatment for naive patients with drug-sensitive pulmonary tuberculosis using oral administration (NCT01225640) [256]. Sequella and the TB Alliance (New York, NY, USA) have recently started a phase-II trial evaluating sutezolid $(\mathbf{4 3})$ in combination with bedaquiline, delamanid, and moxifloxacin against a combination of bedaquiline, delamanid, and moxifloxacin (NCT03959566).

DNV-3837 (44) (MCB-3837) is an oxazolidinonequinolone hybrid prodrug of DNV-3681 (45) (MCB-3681) developed by Morphochem AG/Biovertis AG, which was acquired in 2018 by Deinove (Montpellier, France). that recently started a phase-II trial as a potential treatment of CDI (NCT03988855) [257]. DNV-3837 (44) is administered intravenously, which differentiates it from other antibacterials being developed for CDI that are delivered orally with little or no systemic distribution (po topical). DNV3837 (44) shows activity against $\mathrm{G}+\mathrm{ve}$ bacteria including MRSA, C. difficile, Francisella tularensis, and Bacillus anthracis [258-261].

Telacebec (46) (Q203) is an orally bioavailable imidazo $[1,2-a]$ pyridine amide $[262,263]$ that is currently being developed by Qurient Co., Ltd. (Seongnam-si, Republic of Korea) in a phase-II trial for treatment of TB (NCT03563599). The imidazo[1,2-a]pyridine amide pharmacophore was identified during phenotypic high-content assay in infected macrophages and inhibits TB growth via targeting QcrB, which is a subunit of the menaquinol cytochrome c oxidoreductase ( $b c_{1}$ complex) [262, 264, 265]. Infectex (Moscow, Russia), who has licensed 46 from Qurient, announced the successful completion of a Russian phase-I trial in June 2017 [266].

Macozinone (47) (PBTZ169) is a benzothiazinone (BTZ) derivative being evaluated by Nearmedic Plus LLC (Moscow, Russia) in a phase-II trial for the treatment of TB in Russia and Belarus but the trial was discontinued due to slow enrollment in February 2018 (NCT03334734). 
The Innovative Medicines for Tuberculosis (iM4TB) Foundation (Lausanne, Switzerland) is leading the development in the rest of the world and are currently evaluating oral dosing of macozinone (47) in a phase-I trial (NCT03776500). Macozinone (47) is a second generation BTZ043 (48; Fig. 8) analog, which had potent in vitro activity against TB but suboptimal in vivo efficacy, that has enhanced physico-chemical properties [267]; however, macozinone (47) still has relatively poor solubility, which could affect oral bioavailability [268]. The nitro group present BTZs is reduced in vivo and the reactive nitroso intermediate forms a covalent semi-mercaptal adduct with cysteine-387 of Mycobacterium tuberculosis decaprenylphosphoryl- $\beta$-D-ribose (DPR) 2'-oxidase (DprE1), which is an essential enzyme used to cell wall synthesis [269-271]. Macozinone (47) has activity against a range of Mycobacterium species but resistance can arise through amino acid polymorphism of cysteine-387 [271, 272]. It has been recently shown that macozinone (47) and BTZ043 (48) can be de-aromatized in vivo through formation of a Meisenheimer complex, which could also reduce their in vivo half-lives [273].

OPC-167832 (49) is an orally bioavailable 3,4-dihyrdocarbostyril derivative being developed by Otsuka Pharmaceutical (Tokyo, Japan) as a potential treatment for uncompleted pulmonary TB in a phase-I/II trial (NCT03678688) [274, 275]. OPC-167832 (49) exerts its antimycobacterial activity through inhibition of cell wall synthesis target DprE1 [274], which is the same target as the BTZ-043 (48) and macozinone (47) $[269,273,276]$.

GSK656 (50) (GSK3036656) is a boron containing leucyl t-RNA synthetase inhibitor [277, 278] being developed by GSK (London, UK) that is currently being evaluated in a phase-II trial as a treatment for patients with drugsensitive pulmonary TB using oral dosing (NCT03557281). GSK3036656 (50) was discovered in collaboration with Anacor Pharmaceuticals (Palo Alto, CA, USA), who had identified that 3-aminomethylbenzoxaboroles inhibit leucyl-tRNA synthetase [277, 279]. The closely related epetraborole (AN3365, GSK 2251052), which is the dechloro-derivative GSK656 (50), entered phase-II clinical trials in 2012 but was discontinued to the rapid emergence of resistance [280, 281].

\section{Compounds in phase-I trials}

TP-6076 (structure not disclosed) is an IV administered, fully synthetic fluorocycline (tetracycline class) being developed by Tetraphase Pharmaceuticals (Watertown, MA, USA) that is being evaluated in a phase-I trial (NCT03691584). TP-6076 has shown promising activity against carbapenem-resistant Acinetobacter baumannii clinical isolates [282] and Tetraphase has received support from CARB-X (Boston, MA, USA) to help with development [283] (Table 4, Figs. 8-10).

TP-271 (51) is another fully synthetic fluorocycline being developed by Tetraphase Pharmaceuticals (Watertown, MA, USA) that completed two phase-I trials investigating oral administration (NCT03450187 and NCT03024034) and two phase-I trials evaluating IV administration (NCT02724085 and NCT03234738). TP-271 (51) has activity against $\mathrm{G}+\mathrm{ve}$ and $G$-ve pathogens associated with respiratory tract infections [284] and the biothreat pathogens $F$. tularensis [285] and B. anthracis [286].

SPR 741 (52) (NAB 741), which is a polymyxin derivative with antibiotic potentiating activity being developed by Spero Therapeutics (Cambridge, MA, USA), has completed two phase-I trials (NCT03022175 and NCT03376529). SPR 741 (52) will need to be partnered with another antibacterial and be administered using an IV route to show clinical effect. The mode of action of polymyxins involves membrane disruption but is complex [287]. SPR 741 (52) was initially developed by Northern Antibiotics (Helsinki, Finland) and designed to have less nephrotoxicity by reducing the number of positive charges [288-290]. The replacement of the 3-hydroxyoctanoate group with an acetate leads to a significant reduction in antibacterial activity, while maintaining Lipid A binding in a similar way to polymyxin nonapeptide; the combination of these effects leads to strong synergisms and enhanced G-ve activity of several antibacterials [290-293].

SPR 206 (53) is an IV administered polymyxin derivative [294] with activity against MDR G-ve bacteria being developed by Spero Therapeutics (Cambridge, MA, USA) that has recently started a phase-I trial (NCT03792308). In January 2019, Spero announced that Everest Medicines (Shanghai, People's Republic of China) had licensed SPR 206 (53), along with an exclusive option to rights to SPR741 (52), in China, South Korea and several Southeast Asian countries [295].

GT-1 (54) (LCB10 0200) is an IV administered cephalosporin siderophore $\beta$-lactam being developed by Geom Therapeutics (San Francisco, CA, USA), which is a joint venture with LegoChem Biosciences (Seoul, Republic of Korea). GT-1 (54) started a phase-I trial (ACTRN12618001980224) in Australia in March 2019 but the trial has been stopped due to safety concerns. There has been no subsequent update about whether development will continue.

Apramycin (55) is an aminoglycoside-type protein synthesis inhibitor being developed by Juvabis Therapeutics (Zurich, Switzerland) that recently started a phase-I trial evaluating IV dosing (NCT04105205). Apramycin (55) was discovered at Eli Lilly \& Co (Indianapolis, IN, USA) in the 1960s [296] and its structure was published in 1976 [297]. Apramycin (55) is currently being used as veterinary antibiotic to treat $E$. coli infections [298] and it will be interesting 
to follow the impact of the possible re-purposing a veterinary drug into a human medicine and how this could impact its future animal use. Apramycin (55) has activity against carbapenem- and aminoglycoside-resistant Enterobacteriaceae, A. baumannii and $P$. aeruginosa [299-301].

ACX-362E (56) is a bis-substituted guanine derivative $[302,303]$ that is being evaluated in a phase-I trial by Acurx Pharmaceuticals (White Plains, NY, USA) [304, 305]. ACX-362E (56) inhibits bacterial DNA polymerase IIIC and will be evaluated as potential treatment for CDI [306]. DNA polymerase IIIC, which is a new target for clinical development, is an essential enzyme in low guanine and cytosine classes of bacteria such as Bacillus, Clostridioides, Enterococcus, Mycoplasma, Lactobacillus, Listeria, Pneumococcus, Staphylococcus and Streptococcus. The discovery of ACX-362E (56) and a historical overview of the development of DNA polymerase IIIC inhibitors has recently been reviewed [305].

Fluorothyazinone (57) (C-55, fluorothyazinon) recently completed a phase-I trial (NCT03205462), which was sponsored by Gamaleya Research Institute of Epidemiology and Microbiology, Health Ministry of the Russian Federation (Moscow, Russia). Fluorothyazinone (57) is an orally administered inhibitor the bacterial type III secretion system (T3SS) [307-309], which is highly conserved in many $\mathrm{G}-\mathrm{ve}$ pathogens that is considered to be a promising antivirulence target [310]. It will be interesting to follow the clinical development and later stage clinical trial design of this antivirulence agent.

SPR720 (58) (pVXc-486) is a prodrug of the DNA gyrase inhibitor SPR719 (59) (VXc-486) that is being evaluated in a phase-I trial by Spero Therapeutics (Cambridge, MA, USA) as a potential oral treatment for TB and nontuberculous Mycobacterium (NTM) infections such as Mycobacterium avium complex and M. abscessus (NCT03796910) [311-314]. SPR720 (58) inhibits DNA synthesis via DNA gyrase GyrB and Topoisomerase IV parC, which is similar to novobiocin [315]. The development of SPR720 (58) is being supported by the Novo REPAIR Fund (Copenhagen, Denmark) and the Bill \& Melinda Gates Medical Research Institute (Cambridge, MA, USA), who fund the TB development [316]. SPR720 (58) and SPR719 (59) were discovered by Vertex Pharmaceuticals (Boston, MA, USA) [311, 312].

TXA709 $(\mathbf{6 0})$ is an orally bioavailable prodrug of TXA707 (61) that belongs to the new FtsZ benzamide class, which inhibits an essential enzyme FtsZ (bacterial homolog of tubulin) in bacterial cell wall division in both $\mathrm{G}+\mathrm{ve}$ and $\mathrm{G}-\mathrm{ve}$ bacteria $[317,318]$. TXA709 (60) is currently being evaluated in a phase-I trial by TAXIS Pharmaceuticals (Monmouth Junction, NJ, USA) [319]. The benzamide class, as exemplified by PC190723 [320-322] that has a $\mathrm{Cl}$ in place of the $\mathrm{CF}_{3}$ in TXA707 (61), was discovered by
Prolysis Ltd (Oxford, UK). Prolysis were bought in November 2009 by Biota Holdings (Melbourne, Australia) and Biota's FtsZ IP portfolio was licensed to TAXIS in August 2014 [323]. The development of PC190723 and its prodrug TXY541 [324] was hindered by poor physicochemical and PK properties; however, TXA709 (60) has enhanced metabolic stability, PK properties and superior in vivo efficacy against $S$. aureus compared with TXY541 $[325,326]$.

BTZ-043 (48), which is a member of the anti-TB BTZ class, has recently completed a phase-I trial (NCT03590600). This trial was sponsored by the University of Munich (Munich, Germany), Hans-Knöll Institute (Jena, Germany) and the German Center for Infection Research (DZIF) (Heidelberg, Germany). As with macozinone (47), BTZ-043 (48) inhibits the essential mycobacterial cell wall biosynthesis enzyme DprE1 [269, 273, 276].

TBI-223 (62) is an oxazolidinone being developed by the TB Alliance (New York, NY, USA) and the Institute of Materia Medica (Shanghai, People's Republic of China) that is currently being evaluated in a phase-I trial using oral dosing (NCT03758612). TBI-223 (62) has similar in vitro $\mathrm{TB}$ activity and in vivo properties in mouse models but has a higher safety margin in pre-clinical studies and enhanced metabolic properties compared to linezolid [327, 328].

TBI-166 (63) (pyrifazimine) is an orally bioavailable clofazimine (64) analog [329] (riminophenazine class) that is being evaluated in a phase-I trial (ChiCTR1800018780) as a treatment for TB by the Global Alliance for TB Drug Development (New York, NY, USA) in partnership with the Institute of Materia Medica (Shanghai, People's Republic of China), Chinese Academy of Medical Sciences (Beijing, People's Republic of China) and Peking Union Medical College (Beijing, People's Republic of China). Clofazimine (64) has been used to treat leprosy since 1962 and has more recently been incorporated into short-course MDR-TB regimens [330, 331]; however, clofazimine (64) has suboptimal PK/PD that leads to tissue accumulation, which due to its red color causes skin discoloration that can take months to clear. TBI-166 (63) was designed to have improved PK/PD properties, while maintaining potent anti-TB activity with less skin discoloration [332, 333].

TBA-7371 (65) is a 1,4-azaindole that is being developed by the Global Alliance for TB Drug Development (New York, NY, USA), which has completed a phase-I trial (NCT03199339) that evaluated safety, tolerability, PK, and PK interactions using oral dosing. TBA-7371 (65) is a noncovalent DprE1 inhibitor that was discovered by researchers at AstraZeneca's Bangalore site in India by scaffold hopping from telacebec (46), which has a different mechanism [334-336]. 
TNP-2198 (structure not disclosed but likely to be hybrid like TNP-2092 (36)) is being developed by TenNor Therapeutics (Suzhou, People's Republic of China) for diseases of anaerobic infections, which includes gastrointestinal diseases associated with $H$. pylori, bacterial vaginosis and CDAD [337]. TNP-2198 is being evaluated in a phase-I trial examining an ascending dose regimen and the effect of eating (CTR20190734).

BCM-0184 (structure not disclosed) is currently being evaluated by Biocidium Biopharmaceuticals (North Vancouver, BC, Canada) in a phase-I trial [338]. BCM-0184 has activity against MRSA and has oral and topical formulations, but no further information is available.

DSTA4637S (66) (RG7861, Sym009) is an IV administered thiomab-type $S$. aureus mAb-rifamycin ADC [339, 340] being developed by Genentech (South San Francisco, CA, USA) that has successfully completed a phase-1 trial in healthy volunteers (NCT02596399) [341] and is currently being evaluated in a phase-I trial in patients with $S$. aureus bacteremia that are receiving antibacterials (NCT03162250). DSTA4637S (66) is designed to cleave in phagocytic cells, which can be a reservoir for $S$. aureus infections, and being developed for the treatment of serious $S$. aureus infections including MRSA. DSTA4637S (66) has an engineered human immunoglobulin G1 (IgG1) anti-S. aureus mAb (MSTA3852A) that was discovered in collaboration with Symphogen (Ballerup, Denmark), which binds to teichoic acid $\beta$ - $O$-linked $N$-acetylglucosamine sugars in the cell wall, attached via a protease-cleavable valine-citrulline linker to a rifamycin derivative (dmDNA31) with an average stoichiometry of two antibiotic units to one $\mathrm{mAb}[339,340,342,343]$. The rifamycin derivative dmDNA31 exerts is activity through inhibition of RNA synthesis.

\section{$\beta$-lactam and $\beta$-lactamase inhibitor (BLI) combinations undergoing clinical evaluation}

The discovery of the first $\beta$-lactamase inhibitor clavulanic acid (67) [344-346], which was isolated from Streptomyces clavuligerus, was an important breakthrough that rescued $\beta$-lactams antibacterial activity. Augmentin, which is combination of clavulanic acid (67) and amoxicillin, is still heavily used today after 38 years of being sold. There have been four new BLI combinations approved in the last five years (Table 1, Fig. 3): Zerbaxa in 2014 (new cephalosporin ceftolozane), Avycaz in 2015 (new DBO-type BLI avibactam), Vabomere in 2017 (new boronate-type BLI vaborbactam (12)), and Recarbrio in 2019 (new DBO-type BLI relebactam (14)). In this section, new BLI combinations undergoing clinical evaluation are discussed (Table 5, Figs. 11 and 12).
$\beta$-lactam/BLI combinations in phase-III trials

Enmetazobactam (AAI 101) (68) is a clavulanic acid (67)type BLI [347-349] with activity against extended spectrum $\beta$-lactamases (ESBLs) and some class A and D carbapenemases that is currently being evaluated by Allecra Therapeutics Gmbh (Weil am Rhein, Germany)/Allecra SAS (Saint Louis, France) in combination with cefepime (69) in a phase-III trial for cUTI using IV administration (NCT03687255) (Table 5, Fig. 11).

ETX2514SUL is an IV administered combination of the DBO-type BLI durlobactam (70) (ETX2514) [350-352], which also has antibacterial activity, and clavulanic acid-type BLA inhibitor sulbactam (71), which was first launched in 1986. ETX2514SUL is active against MDR Acinetobacter spp. [353, 354] and is being evaluated by Entasis Therapeutics (Waltham, MA, USA) is a phase-III trial as a treatment for infections caused by $A$. baumannii-calcoaceticus complex (NCT03894046). ETX2514SUL has also been evaluated in a phase-II trial for acute pyelonephritis and cUTI (NCT03445195).

The boronate-type BLI taniborbactam (72) (VNRX5133) [355] and cefepime (69), which is a fourth-generation cephalosporin first approved in 1994, are being evaluated by VenatoRx Pharmaceuticals (Malvern, PA, USA) in a phase-III trial (NCT03840148) as an IV treatment for cUTI and acute pyelonephritis. Taniborbactam (72) has activity against both serine- and metallo- $\beta$-lactamases, including ESBL, OXA, KPC, NDM and VIM enzymes, and it was recently shown by $\mathrm{X}$-ray crystallography that $\mathbf{7 2}$ bound to NDM-1 though cyclization of its acylamino oxygen onto the boron of the bicyclic core [356].

\section{$\beta$-Lactam/BLI combinations in phase-I trials}

Nacubactam (73) (OP0595, FPI-1459, RG6080, RO7079901), which is a DBO-type BLI [357-359], and meropenem (13), which is a carbapenem first approved in 1998, was developed by Meiji Seika Pharma, Co. Ltd. (Tokyo, Japan) and Fedora Pharmaceuticals (Edmonton, AB, Canada). Meji and Fedora formed the joint venture NacuGen Therapeutics (Edmonton, AB, Canada) in January 2019 for further development of nacubactam (73) [360]. Meiji Seika and Fedora had previously partnered with Roche (Basel, Switzerland) [361, 362] and several phase-I trials using IV dosing have been completed (Meiji Seika: NCT02134834; Roche: NCT02972255, NCT02975388 and NCT03174795) (Table 5, Fig. 12).

A DBO-type BLI, zidebactam (74) (WCK 5107), is being developed in combination with the fourth generation cephalosporin cefepime (69) (combination WCK 5222, FEP-ZID) by Wockhardt Limited (Mumbai, India) and has completed five phase-I trials using IV dosing (NCT02532140 [363], NCT02674347, NCT02707107, 
NCT02942810, NCT03630094). Zidebactam (74) inhibits PBPs and several $\beta$-lactamases while enhancing $\beta$-lactam activity [364] and the combination shows in vitro and in vivo activity against $\mathrm{G}-\mathrm{ve}$ bacteria such as $A$. baumannii, $P$. aeruginosa and CRE [364-368].

ETX0282CPDP, which is a combination of the DBOtype BLI ETX0282 (75) and cefpodoxime proxetil (77), is currently being evaluated in a phase-I trial using oral dosing (NCT03491748) by Entasis Therapeutics (Waltham, MA, USA) with partial CARB-X (Boston, MA, USA) funding [369]. Both ETX0282 (75) and cefpodoxime proxetil (77) are prodrugs that are hydrolyzed in vivo releasing their active metabolites, ETX1317 (76) and cefpodoxime (78) [370, 371]. ETX0282 (75) is noteworthy as the $N$-oxysulfonic acid group previously found in DBO BLIs has been replaced with $(R)$-2-( $N$-oxy)-2-fluoroacetic acid; ETX0282 (75) also displays antibacterial activity against $E$. coli in addition to BLI activity.

A combination of the boronate-type BLI VNRX-7145 (79) $[372,373]$ and ceftibuten (80), which is a third generation cephalosporin first approved in 1995, is currently being developed by VenatoRx Pharmaceuticals (Malvern, PA, USA) [374]. VNRX-7145 (79) has activity against CRE (KPC and OXA carbapenemases) and ESBLs. Both VNRX-7145 (79) and ceftibuten (80) are orally bioavailable, which is a differentiator to VenatoRx's more advanced IV administered, phase-III taniborbactam (72) and cefepime (69) program.

ARX-1796 (81) (ARX-006) is an orally bioavailable prodrug derivative of the approved DBO-type BLI avibactam (82) [375, 376] being developed by Arixa Pharmaceuticals (Palo Alto, CA, USA) that recently started a phase-I trial (NCT03931876).

\section{Compounds discontinued from clinical development}

Compounds and $\beta$-lactam/BLI combinations that have been discontinued from clinical development or have had their development halted since the 2015 review [2] are listed in Table 6 with comments about their the development halt or cessation noted if known.

\section{Analysis of compounds undergoing clinical trials}

\section{Numbers of compounds undergoing clinical evaluation and their source derivation}

There are currently 44 compounds, eight $\beta$-lactam/BLI inhibitor combinations currently and one ADC undergoing clinical trials (Figs. 13 and 14). Of the 44 compounds, two are in NDA/MAA (Table 2, Fig. 4), eight are in phase-III (Table 2; Fig. 5), 18 in phase-II (Table 3; Figs. 6 and 7) and 16 in phase-I (Table 4; Figs. 8 and 9), three $\beta$-lactam/BLI combinations in phase-III (Table 5; Fig. 11) and five in phase-I (Table 5; Fig. 12) and one ADC in Phase-I (Table 4, Fig. 10). Of the 44 compounds, 27 antibacterials were synthetically-derived (S), 14 were NP-derived (NP), one protein/mammalian peptide-derived $(\mathrm{P})$, one $\mathrm{ADC}$ and the derivation of two are not known (Fig. 13).

There has been a similar number of compounds in the different development phases between 2011, 2013 and 2015, except for in phase-III trials in 2011 (6) compared with 2013 (16) and 2015 (15). In 2019, the number in phase-III/NDA (13) and phase-II (18) is similar to previous years, but the number in phase-I trials (22) in 2019 has increased from an average 12 compounds in the previous reviews [1-3]. Thirteen of the phase-I compounds target $\mathrm{G}$-ve bacteria (seven compounds including one antivirulence and five BLI combinations), while there are nine with $\mathrm{G}+$ ve activity (including five against TB and one for CDI). It will be interesting to monitor how many of the current phase-I antibacterials move to phase-II studies and beyond in the next few years and whether this higher number of antibacterials in phase-I level will be maintained or even increased.

\section{New antibacterial pharmacophore analysis}

The modes of action of nearly all antibacterial drugs can be categorized into four major "macro" level classes: cell wall, protein synthesis, DNA synthesis and RNA synthesis inhibitors [377]. In the TB field, there is also an emerging mode of action around the mycobacterial respiratory system, which is inhibited by bedaquiline (launched 2012) and the clinical candidate telacebec (46) [378]. Recent work has also shown that inhibition of the respiratory system in other bacteria is an important factor in bacteria cell death [379]. The "macro" mode of action classes (e.g., cell wall inhibitors) are further divided into structure classes (e.g., $\beta$-lactam), which and sometimes further into structure subclasses (e.g., penicillins, cephalosporins, carbapenems, and monobactams). A pharmacophore is the common sub-unit of active molecules that interacts with the biological target (e.g., the $\beta$-lactam subunit of the $\beta$-lactam antibacterials).

In this review, new pharmacophores not previously used in a human antibacterial drug have been analyzed as a measure of antibacterial structure innovation (Table 7). There are 19 different compounds with six in phase-I, 9 in phase-II and 4 in phase-III (Fig. 15) and this is slightly higher than previous reviews: 11 in 2011, 17 in 2013 and 15 in 2015 (Fig. 16). Fifteen of these compounds have new structure classes and/or new mode of action of the well- 
established "macro" targets: cell wall (9), DNA (5) and protein synthesis inhibition (1). There are no new RNA synthesis inhibitors in clinical development. There are no new BLI classes in development after the recent approvals of the DBO (avibactam, 2015) and boronate classes (vaborbactam, (12), 2017). The ADC DSTA4637S (66) was not classified as a new pharmacophore as the payload is a rifamycin derivative; however, if approved, it would be a first antibacterial ADC alongside and would add to the three approved mAbs, raxibacumab, obiltoxaximab, and bezlotoxumab (Table 1).

Existing antibacterial classes that inhibit the bacterial cell wall include the $\beta$-lactams, glycopeptides, fosfomycin, cylcloserine; daptomycin (lipopeptide) and polymyxin. The new cell wall antibacterials inhibit several different targets (LptD: murepavadin (22), FabI: afabicin (40), $3 \times$ DprE: macozinone (47)/BTZ-043 (48), OPC-167832 (49), and TBA-7371 (65), and FtsZ: TXA709 (60)) and two that have less defined mechanisms (ridinilazole (24) and XF-73 (35)) (Table 7).

There is currently one class of DNA synthesis inhibitors (DNA gyrase GyrA and Topoisomerase IV parC), the quinolones, in clinical use. Novobiocin has not been clinically used for many years but it inhibits DNA gyrase GyrB and Topoisomerase IV parE [313, 315]. SPR720 (58) is an "ethyl urea benzimidazole" that also inhibits GyrB and parE, while geptotidacin (25) inhibits GyrB at a different site to the quinolones and zoliflodacin (26) inhibits GyrB [315]. The dichlorobenyl guanine ACX-362E (56) inhibits a new target DNA polymerase IIIC. MGB-BP-03 (34) belongs to the distamycin class that is a DNA groove binder, which is the mechanism also found in several anticancer drugs, such as daunorubicin, dactinomycin, and bleomycins.

The protein synthesis inhibitor class has many representatives that include the macrolides, aminoglycosides, tetracyclines, lincosamides, chloramphenicol, oxazolidinones, pleuromutilins, and streptogramins. Other protein synthesis inhibitors include fusidic acid, which inhibits elongation factor $\mathrm{G}$, and mupirocin that inhibits isoleucine t-RNA synthetase (IleRS). The oxaborole GSK656 (50) is a new pharmacophore that inhibits leucine t-RNA synthetase (LeuRS), which would be a new antibacterial mechanism.

Telacebec (46) and bedaquiline both have inhibitory effects on the bacterial electron-transport chain (respiration). Auranofin (38) targets thiol-redox homeostasis through thioredoxin reductase inhibition, while niclosamide (39) inhibits oxidative phosphorylation (amongst other mechanisms) but also has been reported to inhibit quorum sensing in $P$. aeruginosa. Fluorothyazinone (57) inhibits the $\mathrm{G}-\mathrm{ve}$ type III secretion system, which is an antivirulence target that has not been previously explored in the clinic.

\section{Administration analysis}

The antibacterial clinical pipeline's administration routes (po, oral; iv/po intravenous oral switch; iv, intravenous; po topical, CDI oral; topical, topical or drops) was analyzed by development phase (Fig. S1) and lead source (Fig. S2). Oral administration is the most predominate route (27) with just under 50\% (13) being 13 TB clinical candidates, for which oral administration route is almost mandatory. The second highest category is iv administration with 17 , while there are six candidates that use iv/po; the iv/po switch strategy is used when patients move from iv administration in intensive care to oral afterwards. Eight of the 15 iv administered drugs are derived from NP lead, which is not unexpected due their physico-chemical properties $[21,380]$. The po topical (5) administration route is used to treat for gastrointestinal infections, such as $C$. difficile and $H$. pylori. For po topical, the clinical candidates are taken orally as tablets, but are not significantly systemically absorbed; this contrasts with po administered compounds that are taken orally but pass through the gut and into blood for delivery throughout the body. Interestingly, one of the CDI clinical candidates, DNV3837 (44) is being developed using iv administration, which differentiates it to the other five CDI clinical candidates in development and marketed drugs that use the po topical route. Finally, there are three topical delivered candidates that can be delivered as creams and eye drops.

\section{Conclusion and outlook}

The antibacterial pipeline composition (number, phase breakdown, and pharmacophores) is similar previous numbers in 2011 [3], 2013 [2], and 2015 [1] except for a spike in the number of phase-I candidates from 11 in 2015 to 21 in 2019 (Fig. 14). It is likely that this increase in phase-I candidates has been helped by increased funding and the development expertise offered by organizations like the Wellcome Trust (London, UK), BARDA (Washington DC, USA), GARDP (Geneva, Switzerland), CARB-X (Boston, MA, USA) and the Novo Holdings's REPAIR Impact Fund (Copenhagen, Denmark), as well as funding provided for the development of new anti-Mycobacterium drugs by organizations such as the TB Alliance (New York, NY, USA) and Bill \& Melinda Gates Foundation (Seattle, WA, USA). However, despite this increase, there are also some unmet medical needs that need to be addressed in the clinical pipeline: new antibacterials with activity against $\beta$-metallolactamases, orally administered that have broad spectrum $\mathrm{G}$-ve activity, and new treatments for MDR Acinetobacter and gonorrhea. It is imperative that we discover and develop new antibacterials, especially against these unmet medical needs, to keep replenishing the pipeline and help limit the health impacts of MDR bacteria. 
Acknowledgements DLP is the recipient of an NHMRC Investigator Grant (APP1177777). The authors would like to thank the manuscript reviewers for their incisive comments, which helped to considerably improve this review.

\section{Compliance with ethical standards}

Conflict of interest DLP has received grants and/or personal fees from Achaogen, AstraZeneca, Bayer, Cubist, Entasis Therapeutics, GlaxoSmithKline, Leo Pharmaceuticals, Merck Sharp \& Dohme (Merck \& Co), Pfizer, and Shionogi \& Co. MSB declares no conflicts of interest.

Publisher's note Springer Nature remains neutral with regard to jurisdictional claims in published maps and institutional affiliations.

\section{References}

1. Butler MS, Blaskovich MAT, Cooper MA. Antibiotics in the clinical pipeline at the end of 2015. J Antibiot. 2017;70:3-24.

2. Butler MS, Blaskovich MA, Cooper MA. Antibiotics in the clinical pipeline in 2013. J Antibiot. 2013;66:571-91.

3. Butler MS, Cooper MA. Antibiotics in the clinical pipeline in 2011. J Antibiot. 2011;64:413-25.

4. Theuretzbacher U, Outterson K, Engel A, Karlén A The global preclinical antibacterial pipeline. Nat Rev Microbiol. 2019. https://doi.org/10.1038/s41579-019-0288-0.

5. Theuretzbacher U, Gottwalt S, Beyer P, Butler M, Czaplewski L, Lienhardt C, et al. Analysis of the clinical antibacterial and antituberculosis pipeline. Lancet Infect Dis. 2019;19:e40-50. https://doi.org/10.1016/S1473-3099(18)30513-9.

6. Deak D, Outterson K, Powers JH, Kesselheim AS. Progress in the fight against multidrug-resistant bacteria? A review of U.S. Food and Drug Administration-approved antibiotics, 20102015. Ann Intern Med. 2016;165:363-72.

7. Fernandes P, Martens E. Antibiotics in late clinical development. Biochem Pharm. 2017;133:152-63.

8. Koulenti D, Song A, Ellingboe A, Abdul-Aziz MH, Harris P, Gavey E, et al. Infections by multidrug-resistant Gram-negative bacteria: What's new in our arsenal and what's in the pipeline? Int J Antimicrob Agents. 2019;53:211-24.

9. Gould IM, Gunasekera C, Khan A. Antibacterials in the pipeline and perspectives for the near future. Curr Opin Pharm. 2019;48:69-75.

10. Ribeiro da Cunha B, Fonseca LP, Calado CRC. Antibiotic discovery: where have we come from, where do we go? Antibiotics (Basel). 2019;8:45. https://doi.org/10.3390/antibiotics8020045.

11. Lepore C, Silver L, Theuretzbacher U, Thomas J, Visi D. The small-molecule antibiotics pipeline: 2014-2018. Nat Rev Drug Discov. 2019;18:739.

12. Rossiter SE, Fletcher MH, Wuest WM. Natural products as platforms to overcome antibiotic resistance. Chem Rev. 2017; 117:12415-74.

13. Lakemeyer M, Zhao W, Mandl FA, Hammann P, Sieber SA. Thinking outside the box-novel antibacterials to tackle the resistance crisis. Angew Chem Int Ed. 2018;57:14440-75.

14. Farrell LJ, Lo R, Wanford JJ, Jenkins A, Maxwell A, Piddock LJV. Revitalizing the drug pipeline: antibiotic DB, an open access database to aid antibacterial research and development. J Antimicrob Chemother. 2018;73:2284-97.

15. Tommasi R, Iyer R, Miller AA. Antibacterial drug discovery: some assembly required. ACS Infect Dis. 2018;4:686-95.

16. Jackson N, Czaplewski L, Piddock LJV. Discovery and development of new antibacterial drugs: learning from experience? J Antimicrob Chemother. 2018;73:1452-9.
17. Cattoir V, Felden B. Future antibacterial strategies: from basic concepts to clinical challenges. J Infect Dis. 2019;220:350-60.

18. Dougan G, Dowson C, Overington J. Meeting the discovery challenge of drug-resistant infections: progress and focusing resources. Drug Discov Today. 2019;24:452-61.

19. Baker SJ, Payne DJ, Rappuoli R, De Gregorio E. Technologies to address antimicrobial resistance. Proc Natl Acad Sci USA. 2018;115:12887-95.

20. McDowell LL, Quinn CL, Leeds JA, Silverman JA, Silver LL. Perspective on antibacterial lead identification challenges and the role of hypothesis-driven strategies. SLAS Discov. 2019;24:440-56.

21. Ruggiu F, Yang S, Simmons RL, Casarez A, Jones AK, Li C, et al. Size matters and how you measure it: a gram-negative antibacterial example exceeding typical molecular weight limits. ACS Infect Dis. 2019;5:1688-92.

22. Singer AC, Kirchhelle C, Roberts AP. (Inter)nationalising the antibiotic research and development pipeline. Lancet Infect Dis. 2020;20:e54-62. https://doi.org/10.1016/S1473-3099(19)30552-3.

23. Czaplewski L, Bax R, Clokie M, Dawson M, Fairhead H, Fischetti VA, et al. Alternatives to antibiotics - a pipeline portfolio review. Lancet Infect Dis. 2016;16:239-51.

24. Theuretzbacher U, Piddock LJV. Non-traditional antibacterial therapeutic options and challenges. Cell Host Microbe. 2019;26:61-72.

25. Górski A, Międzybrodzki R, Węgrzyn G, Jończyk-Matysiak E, Borysowski J, Weber-Dąbrowska B Phage therapy: current status and perspectives. Med Res Rev. 2019. https://doi.org/10. 1002/med.21593.

26. Tehrani KHME, Martin NI. $\beta$-Lactam/ $\beta$-lactamase inhibitor combinations: an update. MedChemComm. 2018;9:1439-56.

27. Tooke CL, Hinchliffe P, Bragginton EC, Colenso CK, Hirvonen VHA, Takebayashi $\mathrm{Y}$, et al. $\beta$-Lactamases and $\beta$-lactamase inhibitors in the 21st century. J Mol Biol. 2019;431:3472-500.

28. Cheng AV, Wuest WM. Signed, sealed, delivered: conjugate and prodrug strategies as targeted delivery vectors for antibiotics. ACS Infect Dis. 2019;5:816-28.

29. Wernli D, Jørgensen PS, Harbarth S, Carroll SP, Laxminarayan R, Levrat N, et al. Antimicrobial resistance: the complex challenge of measurement to inform policy and the public. PLOS Med. 2017;14:e1002378. https://doi.org/10.1371/journal.pmed.1002378.

30. Livermore DM. The 2018 Garrod Lecture: preparing for the Black Swans of resistance. J Antimicrob Chemother. 2018;73:2907-15.

31. Engel A The broken antibiotics business model Part I. 2018: https://www.linkedin.com/pulse/broken-antibiotics-businessmodel-part-i-aleks-engel/. Accessed 12 Nov 2019.

32. Engel A The broken antibiotics business model Part II. 2018: https://www.linkedin.com/pulse/broken-antibiotics-businessmodel-part-ii-aleks-engel/. Accessed 12 Nov 2019.

33. Engel A The broken antibiotics business model Part III. 2018: https://www.linkedin.com/pulse/broken-antibiotics-businessmodel-part-iii-aleks-engel/. Accessed 12 Nov 2019.

34. Engel A The broken antibiotics business model Part IV. 2018: https://www.linkedin.com/pulse/broken-antibiotics-businessmodel-part-iv-aleks-engel/. Accessed 12 Nov 2019.

35. Jean S-S, Gould IM, Lee W-S, Hsueh P-R. International Society of Antimicrobial Chemotherapy new drugs for multidrug-resistant Gram-negative organisms: Time for stewardship. Drugs. 2019;79:705-14.

36. Graham DW, Bergeron G, Bourassa MW, Dickson J, Gomes F, Howe A, et al. Complexities in understanding antimicrobial resistance across domesticated animal, human, and environmental systems. Ann NY Acad Sci. 2019;1441:17-30.

37. Kållberg C, Salvesen Blix H, Laxminarayan R. Challenges in antibiotic R\&D calling for a global strategy considering both short- and long-term solutions. ACS Infect Dis. 2019;5:1265-8.

38. Megiddo I, Drabik D, Bedford T, Morton A, Wesseler J, Laxminarayan $\mathrm{R}$. Investing in antibiotics to alleviate future catastrophic 
outcomes: What is the value of having an effective antibiotic to mitigate pandemic influenza? Health Econ. 2019;28:556-71.

39. Wernli D, Jørgensen PS, Morel CM, Carroll S, Harbarth S, Levrat N, et al. Mapping global policy discourse on antimicrobial resistance. BMJ Glob Health. 2017;2:e000378. https://doi.org/ 10.1136/bmjgh-2017-000378.

40. Nielsen TB, Brass EP, Gilbert DN, Bartlett JG, Spellberg B. Sustainable discovery and development of antibiotics-is a nonprofit approach the future? N Engl J Med. 2019;381:503-5.

41. Sharland M, Gandra S, Huttner B, Moja L, Pulcini C, Zeng M, et al. Encouraging AWaRe-ness and discouraging inappropriate antibiotic use-the new 2019 Essential Medicines List becomes a global antibiotic stewardship tool. Lancet Infect Dis. 2019;19:1278-80.

42. Antibiotics Currently in Global Clinical Development (The Pew Trusts). 2019. https://www.pewtrusts.org/en/research-and-ana lysis/data-visualizations/2014/antibiotics-currently-in-clinicaldevelopment. Accessed 19 Nov 2019.

43. Nontraditional products for bacterial infections in clinical development (The Pew Trusts). 2019. https://www.pewtrusts. org/en/research-and-analysis/data-visualizations/2017/nontra ditional-products-for-bacterial-infections-in-clinicaldevelopment. Accessed 19 Nov 2019.

44. Bedaquiline: First new tuberculosis drug in 50 years. Médecins Sans Frontières (MSF), Press Release 31 December 2012. https://www.msf.org/bedaquiline-first-new-tuberculosis-drug-50years. Accessed 29 Nov 2019.

45. Tsai C-W, Morris S Approval of raxibacumab for the treatment of inhalation anthrax under the US Food and Drug Administration "Animal Rule". Front Microbiol. 2015; 6. https://doi.org/10. 3389/fmicb.2015.01320.

46. Greig SL. Obiltoxaximab: first global approval. Drugs. 2016;76: 823-30.

47. Xu W, Ohanjandian L, Sun J, Cui X, Suffredini D, Li Y, et al. A systematic review and meta-analysis of preclinical trials testing anti-toxin therapies for $B$. anthracis infection: a need for more robust study designs and results. PLoS ONE. 2017;12:e0182879. https://doi.org/10.1371/journal.pone.0182879.

48. Editorial. $C$ difficile-a rose by any other name. Lancet Infect Dis. 2019;19:449.

49. Kufel WD, Devanathan AS, Marx AH, Weber DJ, Daniels LM. Bezlotoxumab: a novel agent for the prevention of recurrent Clostridium difficile infection. Pharmacotherapy. 2017;37: 1298-308.

50. Kelly CP, Poxton IR, Shen J, Wilcox MH, Gerding DN, Zhao X, et al. Effect of endogenous Clostridioides difficile toxin antibodies on recurrence of $C$. difficile infection. Clin Infect Dis. 2019. https://doi.org/10.1093/cid/ciz809.

51. Cao C, Luo A, Wu P, Weng D, Zheng H, Wang S. Efficacy and safety of morinidazole in pelvic inflammatory disease: results of a multicenter, double-blind, randomized trial. Eur J Clin Microbiol Infect Dis. 2017;36:1225-30.

52. Pang X, Zhang Y, Gao R, Zhong K, Zhong D, Chen X. Effects of rifampin and ketoconazole on pharmacokinetics of morinidazole in healthy Chinese subjects. Antimicrob Agents Chemother. 2014;58: 5987-93.

53. Ang CW, Jarrad AM, Cooper MA, Blaskovich MAT. Nitroimidazoles: molecular fireworks that combat a broad spectrum of infectious diseases. J Med Chem. 2017;60:7636-57.

54. Dong Wha obtains approval for Zabolante from MFDS (Press release 20 March 2015). https://www.dong-wha.co.kr/english/ customer/dnews/content.asp?t_idx =856. Accessed 4 Jan 2019.

55. Kocsis B, Szabo D. Zabofloxacin for chronic bronchitis. Drugs Today. 2016;52:495-500.

56. Park H-S, Oh S-H, Kim H-S, Choi D-R, Kwak J-H. Antimicrobial activity of zabofloxacin against clinically isolated
Streptococcus pneumoniae. Molecules. 2016;21:1562. https:// doi.org/10.3390/molecules21111562.

57. Park H-S, Kim H-J, Seol M-J, Choi D-R, Choi E-C, Kwak J-H. In vitro and in vivo antibacterial activities of DW-224a, a new fluoronaphthyridone. Antimicrob Agents Chemother. 2006;50: 2261-4.

58. Jones RN, Biedenbach DJ, Ambrose PG, Wikler MA. Zabofloxacin (DW-224a) activity against Neisseria gonorrhoeae including quinolone-resistant strains. Diagn Microbiol Infect Dis. 2008;62:110-2.

59. Dong Wha Pharmaceutical R\&D Pipeline. 2019. https://www. dong-wha.co.kr/english/rnd/rnd06.asp. Accessed 3 Sept 2019.

60. Dong Wha Pharm's quinolone antibacterial agent, "Zabolante," wins at the 19th KNDA (Press Release 28 Feb 2018). https://www.dong-wha.co.kr/english/customer/dnews/content. asp?t $\mathrm{idx}=1139$. Accessed 4 Jan 2019.

61. Saravolatz LD, Stein GE. Delafloxacin: a new anti-methicillinresistant Staphylococcus aureus fluoroquinolone. Clin Infect Dis. 2019;68:1058-62.

62. Lan S, Lai C, Lu L, Chang S, Huang H. Efficacy and safety of delafloxacin in the treatment of acute bacterial skin and skin structure infections: a systematic review and metaanalysis of randomized controlled trials. Infect Drug Resist. 2019;12:1415-23.

63. Melinta Therapeutics Launches Antibiotic Baxdela ${ }^{\mathrm{TM}}$ (delafloxacin) in the United States (Press Release 29 January 2018). http://ir.melinta.com/news-releases/news-release-details/melintatherapeutics-launches-antibiotic-baxdelatm-delafloxacin. Accessed 16 Jan 2019.

64. Ocheretyaner ER, Park TE. Delafloxacin: a novel fluoroquinolone with activity against methicillin-resistant Staphylococcus aureus (MRSA) and Pseudomonas aeruginosa. Exp Rev Anti Infect Ther. 2018;16:523-30.

65. Melinta Therapeutics announces U.S. FDA approval of supplemental new drug application for BAXDELA ${ }^{\circledR}$ (delafloxacin) for the treatment of community-acquired bacterial pneumonia (CABP) (Press Release 24 October 2019). http://ir.melinta. com/news-releases/news-release-details/melinta-therapeutics-a nnounces-us-fda-approval-supplemental-new. Accessed 19 Nov 2019.

66. Aggen JB, Armstrong ES, Goldblum AA, Dozzo P, Linsell MS, Gliedt MJ, et al. Synthesis and spectrum of the neoglycoside ACHN-490. Antimicrob Agents Chemother. 2010;54:4636-42.

67. Abdul-Mutakabbir JC, Kebriaei R, Jorgensen SCJ, Rybak MJ. Teaching an old class new tricks: a novel semi-synthetic aminoglycoside, plazomicin. Infect Dis Ther. 2019;8:155-70.

68. Eljaaly K, Alharbi A, Alshehri S, Ortwine JK, Pogue JM. Plazomicin: a novel aminoglycoside for the treatment of resistant Gram-negative bacterial infections. Drugs. 2019;79:243-69.

69. Weinstein MJ, Marquez JA, Testa RT, Wagman GH, Oden EM, Waitz JA. Antibiotic 6640, a new Micromonospora-produced aminoglycoside antibiotic. J Antibiot. 1970;23:551-4.

70. Reimann H, Cooper DJ, Mallams AK, Jaret RS, Yehaskel A, Kugelman M, et al. Structure of sisomicin, a novel unsaturated aminocyclitol antibiotic from Micromonospora inyoensis. J Org Chem. 1974;39:1451-7.

71. UPDATE - ZEMDRITM (plazomicin) approved by FDA for the treatment of adults with complicated urinary tract infections (cUTI) (Press Release 26 June 2018) http://investors.achaogen. com/news-releases/news-release-details/update-zemdritm-pla zomicin-approved-fda-treatment-adults. Accessed 17 Jan 2019.

72. Achaogen submits Marketing Authorization Application to the European Medicines Agency for plazomicin (Press Release 17 October 2018). http://investors.achaogen.com/news-releases/new s-release-details/achaogen-submits-marketing-authorization-a pplication-european. Accessed 17 Jan 2019. 
73. Achaogen plans for near-term sale using structured process through Chapter 11 of the U.S. Bankruptcy Code (Press Release 15 April 2019). http://investors.achaogen.com/news-releases/ news-release-details/achaogen-plans-near-term-sale-usingstructured-process-through. Accessed 3 Sept 2019.

74. Achaogen, Inc. announces results of auction for substantially all company assets (Press Release 6 June 2019). http://investors. achaogen.com/news-releases/news-release-details/achaogeninc-announces-results-auction-substantially-all-company. Accessed 2 Sept 2019.

75. Xiao X-Y, Hunt DK, Zhou J, Clark RB, Dunwoody N, Fyfe C, et al. Fluorocyclines. 1. 7-fluoro-9-pyrrolidinoacetamido-6demethyl-6-deoxytetracycline: a potent, broad spectrum antibacterial agent. J Med Chem. 2012;55:597-605.

76. Clark RB, Hunt DK, He M, Achorn C, Chen C-L, Deng Y, et al. Fluorocyclines. 2. Optimization of the C-9 side-chain for antibacterial activity and oral efficacy. J Med Chem. 2012; 55:606-22.

77. Lee YR, Burton CE. Eravacycline, a newly approved fluorocycline. Eur J Clin Microbiol Infect Dis. 2019;38:1787-94.

78. Tetraphase Pharmaceuticals receives positive CHMP opinion for Xerava $^{\mathrm{TM}}$ (eravacycline) as a treatment for complicated intraabdominal infections (Press Release 27 July 2018). https://ir.tpha se.com/news-releases/news-release-details/tetraphase-pharma ceuticals-receives-positive-chmp-opinion. Accessed 17 Jan 2019.

79. Tetraphase Pharmaceuticals announces commercial launch of Zerava $^{\mathrm{TM}}$ in the United States (Press Release 11 October 2018). https://ir.tphase.com/news-releases/news-release-details/tetrapha se-pharmaceuticals-announces-commercial-launch-xeravatm. Accessed 17 Jan 2019.

80. Solomkin JS, Gardovskis J, Lawrence K, Montravers P, Sway A, Evans D, et al. IGNITE4: Results of a phase 3, randomized, multicenter, prospective trial of eravacycline vs. meropenem in the treatment of complicated intra-abdominal infections. Clin Infect Dis. 2019;69:921-9.

81. Tetraphase announces top-line results from IGNITE3 phase 3 clinical trial of eravacycline in complicated urinary tract infections (cUTI) (Press Release 13 February 2018). https://ir.tphase. com/news-releases/news-release-details/tetraphase-announcestop-line-results-ignite3-phase-3-clinical. Accessed 17 Jan 2019.

82. Watkins RR, Deresinski S. Omadacycline: a novel tetracycline derivative with oral and intravenous formulations. Clin Infect Dis. 2019;69:890-6.

83. Paratek announces FDA approval of NUZYRA ${ }^{\mathrm{TM}}$ (Omadacycline) (Press Release 2 October 2019) http://phx.corporate-ir.net/ phoenix.zhtml?c $=253770 \& p=$ irol-newsArticle $\& I D=2369985$. Accessed 17 Jan 2019.

84. Markham A, Keam SJ. Omadacycline: first global approval. Drugs. 2018;78:1931-7.

85. O'Riordan W, Cardenas C, Shin E, Sirbu A, Garrity-Ryan L, Das $\mathrm{AF}$, et al. Once-daily oral omadacycline versus twice-daily oral linezolid for acute bacterial skin and skin structure infections (OASIS-2): a phase 3, double-blind, multicentre, randomised, controlled, non-inferiority trial. Lancet Infect Dis. 2019;19: 1080-90.

86. Paratek withdraws European Marketing Authorization application for oral and intravenous NUZYRA in skin infections and pneumonia (Press release 17 October 2019). https://investor.para tekpharma.com/news-releases/news-release-details/paratek-w ithdraws-european-marketing-authorization-application. Accessed 5 Dec 2019.

87. Deeks ED. Sarecycline: first global approval. Drugs. 2019;79: 325-9.

88. Moore AY, Charles JEM, Moore S. Sarecycline: a narrow spectrum tetracycline for the treatment of moderate-to-severe acne vulgaris. Future Microbiol. 2019;14:1235-42.
89. FDA approves Seysara ${ }^{\mathrm{TM}}$, a New Chemical Entity for moderate to severe acne (Press Release 2 October 2018). https://www. almirall.com/en $/ \mathrm{media} /$ press-releases/media-detail-new?title $=$ fda-approves-seysaratm-a-new-chemical-entity-for-moderate-tosevere-acne\&articleId=3540239. Accessed 17 Jan 2019.

90. Moore A, Green LJ, Bruce S, Sadick N, Tschen E, Werschler P, et al. Once-daily oral sarecycline $1.5 \mathrm{mg} / \mathrm{kg} /$ day is effective for moderate to severe acne vulgaris: results from two identically designed, phase 3 , randomized, double-blind clinical trials. J Drugs Dermatol. 2018;17:987-96.

91. Stover CK, Warrener P, VanDevanter DR, Sherman DR, Arain TM, Langhorne MH, et al. A small-molecule nitroimidazopyran drug candidate for the treatment of tuberculosis. Nature. 2000;405:962-6.

92. FDA approves new treatment for highly drug-resistant forms of tuberculosis (TB Alliance Press Release 14 August 2019). https://www.tballiance.org/news/fda-approves-new-treatmenthighly-drug-resistant-forms-tuberculosis. Accessed 3 Sept 2019.

93. Singh R, Manjunatha U, Boshoff HIM, Ha YH, Niyomrattanakit $\mathrm{P}$, Ledwidge $\mathrm{R}$, et al. PA-824 kills nonreplicating Mycobacterium tuberculosis by intracellular NO release. Science. 2008;322:1392-5.

94. Manjunatha U, Boshoff HI, Barry CE. The mechanism of action of PA-824: novel insights from transcriptional profiling. Commun Integr Biol. 2009;2:215-8.

95. Haver HL, Chua A, Ghode P, Lakshminarayana SB, Singhal A, Mathema B, et al. Mutations in genes for the F420 biosynthetic pathway and a nitroreductase enzyme are the primary resistance determinants in spontaneous in vitro-selected PA-824-resistant mutants of Mycobacterium tuberculosis. Antimicrob Agents Chemother. 2015;59:5316-23.

96. Baptista R, Fazakerley DM, Beckmann M, Baillie L, Mur LAJ. Untargeted metabolomics reveals a new mode of action of pretomanid (PA-824). Sci Rep. 2018;8:5084. https://doi.org/10. 1038/s41598-018-23110-1.

97. Novak R. Are pleuromutilin antibiotics finally fit for human use? Ann NY Acad Sci. 2011;1241:71-81.

98. Novak R, Shlaes DM. The pleuromutilin antibiotics: a new class for human use. Curr Opin Investig Drugs. 2010;11:182-91.

99. Veve MP, Wagner JL. Lefamulin: Review of a promising novel pleuromutilin antibiotic. Pharmacotherapy. 2018;38:935-46.

100. FDA approves new antibiotic to treat community-acquired bacterial pneumonia (Press Release 19 August 2019). https://www. fda.gov/news-events/press-announcements/fda-approves-new-a ntibiotic-treat-community-acquired-bacterial-pneumonia. Accessed 3 Sept 2019.

101. Nabriva Therapeutics announces European Medicines Agency (EMA) validation of marketing authorization application for lefamulin (Press Release 24 June 2019). http://investors.na briva.com/news-releases/news-release-details/nabriva-thera peutics-announces-european-medicines-agency-ema. Accessed 3 Sept 2019.

102. Sader HS, Biedenbach DJ, Paukner S, Ivezic-Schoenfeld Z, Jones RN. Antimicrobial activity of the investigational pleuromutilin compound BC-3781 tested against Gram-positive organisms commonly associated with acute bacterial skin and skin structure infections. Antimicrob Agents Chemother. 2012;56:1619-23.

103. Sader HS, Paukner S, Ivezic-Schoenfeld Z, Biedenbach DJ, Schmitz FJ, Jones RN. Antimicrobial activity of the novel pleuromutilin antibiotic BC-3781 against organisms responsible for community-acquired respiratory tract infections (CARTIs). J Antimicrob Chemother. 2012;67:1170-5.

104. Mendes RE, Farrell DJ, Flamm RK, Talbot GH, IvezicSchoenfeld Z, Paukner S, et al. In vitro activity of lefamulin tested against Streptococcus pneumoniae with defined serotypes, including multidrug-resistant isolates causing lower respiratory 
tract infections in the United States. Antimicrob Agents Chemother. 2016;60:4407-11.

105. Paukner S, Gruss A, Jensen JS. In vitro activity of lefamulin against sexually transmitted bacterial pathogens. Antimicrob Agents Chemother. 2018;62:e02380-17. https://doi.org/10. 1128/AAC.02380-17.

106. Kishii R, Yamaguchi Y, Takei M. In vitro activities and spectrum of the novel fluoroquinolone lascufloxacin (KRP-AM1977). Antimicrob Agents Chemother. 2017;61:e00120-17. https://doi. org/10.1128/AAC.00120-17.

107. Yamagishi Y, Matsukawa Y, Suematsu H, Mikamo H. In vitro activity of lascufloxacin, a novel fluoroquinolone antibacterial agent, against various clinical isolates of anaerobes and Streptococcus anginosus group. Anaerobe. 2018;54:61-4.

108. Kyorin Pharmaceutical receives marketing approval for oral quinolone antibacterial agent "Lasvic ${ }^{\circledR}$ Tablets 75mg" (Press Release 20 September 2019) [Internet]. Available from 2019: https://www.kyorin-pharm.co.jp/en/news/2019/001368.shtml. Accessed 18 Nov 2019.

109. Aoki T, Yoshizawa H, Yamawaki K, Yokoo K, Sato J, Hisakawa S, et al. Cefiderocol (S-649266), a new siderophore cephalosporin exhibiting potent activities against Pseudomonas aeruginosa and other Gram-negative pathogens including multi-drug resistant bacteria: structure activity relationship. Eur J Med Chem. 2018;155:847-68.

110. Choi JJ, McCarthy MW. Cefiderocol: a novel siderophore cephalosporin. Exp Opin Investig Drugs. 2018;27:193-7.

111. Kohira N, West J, Ito A, Ito-Horiyama T, Nakamura R, Sato T, et al. In vitro antimicrobial activity of siderophore cephalosporin S-649266 against Enterobacteriaceae clinical isolates including carbapenem-resistant strains. Antimicrob Agents Chemother. 2015;60:729-34.

112. Karlowsky JA, Hackel MA, Tsuji M, Yamano Y, Echols R, Sahm DF. In vitro activity of cefiderocol, a siderophore cephalosporin, against Gram-negative bacilli isolated by clinical laboratories in North America and Europe in 2015-2016: SIDERO-WT-2015. Int J Antimicrob Agents. 2019;53:456-66.

113. Shionogi \& Co., Ltd. pipeline (as of 29 July 2019). http://www. shionogi.co.jp/en/company/pmrltj0000000u4v-att/e_kaihatsu. pdf. Accessed 26 Sept 2019.

114. FETROJA $^{\circledast}$ (cefiderocol) approved by the FDA for treatment of complicated urinary tract infections (cUTI) in adult patients with limited or no alternative treatment options (Press Release 15 November 2019). http://www.shionogi.co.jp/en/company/ news/2019/pmrltj0000004e8d-att/e_191115.pdf. Accessed 18 Nov 2019

115. Portsmouth S, van Veenhuyzen D, Echols R, Machida M, Ferreira JCA, Ariyasu M, et al. Cefiderocol versus imipenemcilastatin for the treatment of complicated urinary tract infections caused by Gram-negative uropathogens: a phase 2, randomised, double-blind, non-inferiority trial. Lancet Infect Dis. 2018;18:1319-28.

116. The Medicines Company announces FDA approval of VABOMERE $^{\text {TM }}$ (meropenem and vaborbactam) (Press Release 30 August 2017). https://investor.themedicinescompany.com/w ebsites/themedco/English/1100/details.html?news_id=2667663.

117. Zhanel GG, Lawrence CK, Adam H, Schweizer F, Zelenitsky S, Zhanel M, et al. Imipenem-relebactam and meropenem-vaborbactam: two novel carbapenem- $\beta$-lactamase inhibitor combinations. Drugs. 2018;78:65-98.

118. The Medicines Company announces definitive agreement to sell its infectious disease business unit to Melinta Therapeutics (Press Release 29 November 2017). https://www.themedicinescompany. com/investors/news/medicines-company-announces-definitive-a greement-sell-its-infectious-disease-business. Accessed 16 January 2019.
119. Melinta Therapeutics granted European Commission Marketing Authorization for Vabomere (meropenem and vaborbactam) (Press Release 27 November 2018). http://ir.melinta.com/newsreleases/news-release-details/melinta-therapeutics-grantedeuropean-commission-marketing. Accessed 16 Jan 2019.

120. Hirst G, Reddy R, Hecker S, Totrov M, Griffith DC, Rodny O, et al., inventors; Rempex Pharmaceuticals, Inc., assignee. Cyclic boronic acid ester derivatives and therapeutic uses thereof. World patent WO 2012021455. 2012.

121. FDA approves new treatment for complicated urinary tract and complicated intra-abdominal infections (Press Release 17 July 2019). https://www.fda.gov/news-events/press-announcements/ fda-approves-new-treatment-complicated-urinary-tract-andcomplicated-intra-abdominal-infections. Accessed 3 Sept 2019.

122. Sims M, Mariyanovski V, McLeroth P, Akers W, Lee Y-C, Brown ML, et al. Prospective, randomized, double-blind, Phase 2 dose-ranging study comparing efficacy and safety of imipenem/cilastatin plus relebactam with imipenem/cilastatin alone in patients with complicated urinary tract infections. J Antimicrob Chemother. 2017;72:2616-26.

123. Lucasti C, Vasile L, Sandesc D, Venskutonis D, McLeroth P, Lala $\mathrm{M}$, et al. Phase 2, dose-ranging study of relebactam with imipenem-cilastatin in subjects with complicated intra-abdominal infection. Antimicrob Agents Chemother. 2016;60:6234-43.

124. Mangion IK, Ruck RT, Rivera N, Huffman MA, Shevlin M. A concise synthesis of a $\beta$-lactamase inhibitor. Org Lett. 2011;13: 5480-3.

125. Rodloff AC, Goldstein EJC, Torres A. Two decades of imipenem therapy. J Antimicrob Chemother. 2006;58:916-29.

126. Donald B, Surani S, Deol H, Mbadugha U, Udeani G. Spotlight on solithromycin in the treatment of community-acquired bacterial pneumonia: design, development, and potential place in therapy. Drug Des Dev Ther. 2017;11:3559-66.

127. Application for manufacturing and sales approval in Japan filed for T-4288, an antibacterial agent (FUJIFILM Toyama Chemical Co., Ltd. Press Release 25 April 2019). http://fftc.fujifilm.co.jp/ en/news/news190425e.html. Accessed 3 Sept 2019.

128. Cempra receives Complete Response Letter from FDA for Solithromycin NDAs (Press Release 29 December 2016). 2019. http://ir.melinta.com/news-releases/news-release-details/cemprareceives-complete-response-letter-fda-solithromycin-ndas. Accessed 23 Jan 2019

129. Cempra withdraws solithromycin Marketing Authorization Application in Europe (Press Release 28 March 2017). http://ir. melinta.com/news-releases/news-release-details/cempra-withdraw s-solithromycin-marketing-authorization. Accessed 23 Jan 2019.

130. Oefner C, Bandera M, Haldimann A, Laue H, Schulz H, Mukhija $\mathrm{S}$, et al. Increased hydrophobic interactions of iclaprim with Staphylococcus aureus dihydrofolate reductase are responsible for the increase in affinity and antibacterial activity. J Antimicrob Chemother. 2009;63:687-98.

131. Huang DB, Strader CD, MacDonald JS, VanArendonk M, Peck R, Holland T. An updated review of iclaprim: a potent and rapidly bactericidal antibiotic for the treatment of skin and skin structure infections and nosocomial pneumonia caused by Grampositive including multidrug-resistant bacteria. Open Forum Infect Dis. 2018;5:ofy003. https://doi.org/10.1093/ofid/ofy003.

132. EMEA. Questions and answers on the withdrawal of the marketing authorisation application for Mersarex (iclaprim) (19 November 2009). https://www.ema.europa.eu/documents/ medicine-qa/questions-answers-withdrawal-marketing-authorisa tion-application-mersarex-iclaprim_en.pdf. Accessed 23 Jan 2019.

133. Motif Bio submits NDA for iclaprim (Press Release 14 June 2018). http://ir.motifbio.com/phoenix.zhtml?c $=254416 \& p=$ irolnewsArticle \&ID=2354513. Accessed 23 January 2019. 
134. Motif Bio confirms meeting date with U.S. FDA regarding iclaprim (Press Release 26 July 2019). http://ir.motifbio.com/ news-releases/news-release-details/motif-bio-confirms-meetingdate-us-fda-regarding-iclaprim. Accessed 3 Sept 2019.

135. Minamimura M, Taniyama Y, Inoue E, Mitsuhashi S. In vitro antibacterial activity and $\beta$-lactamase stability of CP-70,429 a new penem antibiotic. Antimicrob Agents Chemother. 1993; 37:1547-51.

136. Foulds G, Knirsch AK, Lazar JD, Tensfelt TG, Gerber N. Pharmacokinetics of the penem CP-65,207 and its separate stereoisomers in humans. Antimicrob Agents Chemother. 1991;35:665-71.

137. Brenek SJ, Caron S, Chisowa E, Delude MP, Drexler MT, Ewing MD, et al. Development of a practical and convergent process for the preparation of sulopenem. Org Process Res Dev. 2012;16:1348-59.

138. Brenek SJ, Caron S, Chisowa E, Colon-Cruz R, Delude MP, Drexler MT, et al. Development of a second-generation process to antibacterial candidate sulopenem. Org Process Res Dev. 2012;16:1338-47.

139. Iterum announces sulopenem in development for treatment of Gram-negative, multi-drug resistant infections (Press Release 5 January 2017). https://ir.iterumtx.com/press-releases/detail/5/ iterum-announces-sulopenem-in-development-for-treatment-of. Accessed 24 Jan 2019.

140. Dunne M, Dunzo E, Puttagunta S. A phase 1 study to assess the pharmacokinetics of sulopenem etzadroxil (PF-03709270). Open Forum Infect Dis. 2017;4:S525-6. https://doi.org/10.1093/ofid/ ofx 163.1369.

141. Cox VC, Zed PJ. Once-daily cefazolin and probenecid for skin and soft tissue infections. Ann Pharmacother. 2004;38:45863.

142. Srinivas N, Jetter P, Ueberbacher BJ, Werneburg M, Zerbe K, Steinmann $\mathrm{J}$, et al. Peptidomimetic antibiotics target outermembrane biogenesis in Pseudomonas aeruginosa. Science. 2010;327:1010-3.

143. Zerbe K, Moehle K, Robinson JA. Protein epitope mimetics: from new antibiotics to supramolecular synthetic vaccines. Acc Chem Res. 2017;50:1323-31.

144. Martin-Loeches I, Dale GE, Torres A. Murepavadin: a new antibiotic class in the pipeline. Exp Rev Anti Infect Ther. 2018;16:259-68.

145. Andolina G, Bencze L-C, Zerbe K, Müller M, Steinmann J, Kocherla H, et al. A peptidomimetic antibiotic interacts with the periplasmic domain of LptD from Pseudomonas aeruginosa. ACS Chem Biol. 2018;13:666-75.

146. Botos I, Noinaj N, Buchanan Susan K. Insertion of proteins and lipopolysaccharide into the bacterial outer membrane. Philos Trans R Soc Lond B Biol Sci. 2017;372:20160224. https://doi. org/10.1098/rstb.2016.0224.

147. Polyphor temporarily halts enrollment in the phase III studies of murepavadin for the treatment of patients with nosocomial pneumonia (Press Release 9 May 2019) https://www.polyphor. com/news/corporate-news-details/?newsid=1775911. Accessed 3 Sept 2019

148. Polyphor closes the phase III PRISM studies of murepavadin intravenous formulation and evaluates further product improvement options (Press Release 17 July 2019). https://www. polyphor.com/news/corporate-news-details/?newsid $=1800485$. Accessed 3 Sept 2019.

149. Lee RE, Protopopova M, Crooks E, Slayden RA, Terrot M, Barry CE. Combinatorial lead optimization of $[1,2]$-diamines based on ethambutol as potential antituberculosis preclinical candidates. J Comb Chem. 2003;5:172-87.

150. Sacksteder KA, Protopopova M, Barry CE, Andries K, Nacy CA. Discovery and development of SQ109: a new antitubercular drug with a novel mechanism of action. Future Microbiol. 2012;7:823-37.

151. Infectex announces positive phase $2 b-3$ clinical trial results of SQ109 for the treatment of multidrug-resistant pulmonary tuberculosis (Press Release 21 March 2017). https://www.new tbdrugs.org/sites/default/files/downloads/Infectex\%20Press\% 20Release.2017.0321.pdf. Accessed 3 Sept 2019.

152. Borisov SE, Bogorodskaya EM, Volchenkov GV, Kulchavenya EV, Maryandyshev AO, Skornyakov SN, et al. Efficiency and safety of chemotherapy regimen with SQ109 in those suffering from multiple drug resistant tuberculosis. Tuberculosis Lung Dis. 2018;96:6-18.

153. Boeree MJ, Heinrich N, Aarnoutse R, Diacon AH, Dawson R, Rehal S, et al. High-dose rifampicin, moxifloxacin, and SQ109 for treating tuberculosis: a multi-arm, multi-stage randomised controlled trial. Lancet Infect Dis. 2017;17:39-49.

154. Belanger AE, Besra GS, Ford ME, Mikusová K, Belisle JT, Brennan PJ, et al. The embAB genes of Mycobacterium avium encode an arabinosyl transferase involved in cell wall arabinan biosynthesis that is the target for the antimycobacterial drug ethambutol. Proc Natl Acad Sci USA. 1996;93:11919-24.

155. Du Preez I, Loots DT. Novel insights into the pharmacometabonomics of first-line tuberculosis drugs relating to metabolism, mechanism of action and drug-resistance. Drug Metab Rev. 2018;50:466-81.

156. Zhu C, Liu Y, Hu L, Yang M, He Z-G. Molecular mechanism of the synergistic activity of ethambutol and isoniazid against Mycobacterium tuberculosis. J Biol Chem. 2018;293:16741-50.

157. Pawar A, Jha P, Konwar C, Chaudhry U, Chopra M, Saluja D. Ethambutol targets the glutamate racemase of Mycobacterium tuberculosis - an enzyme involved in peptidoglycan biosynthesis. Appl Microbiol Biotechnol. 2019;103:843-51.

158. Li W, Upadhyay A, Fontes FL, North EJ, Wang Y, Crans DC, et al. Novel insights into the mechanism of inhibition of MmpL3, a target of multiple pharmacophores in Mycobacterium tuberculosis. Antimicrob Agents Chemother. 2014;58:6413-23.

159. Li K, Schurig-Briccio LA, Feng X, Upadhyay A, Pujari V, Lechartier B, et al. Multitarget drug discovery for tuberculosis and other infectious diseases. J Med Chem. 2014;57:3126-39.

160. Veiga-Santos P, Li K, Lameira L, de Carvalho TMU, Huang G, Galizzi M, et al. SQ109, a new drug lead for Chagas disease. Antimicrob Agents Chemother. 2015;59:1950-61.

161. Vickers RJ, Tillotson G, Goldstein EJC, Citron DM, Garey KW, Wilcox MH. Ridinilazole: a novel therapy for Clostridium difficile infection. Int J Antimicrob Agents. 2016;48:137-43.

162. Summit announces BARDA increases award for ridinilazole clinical and regulatory development to up to $\$ 63.7$ million and exercises next contract option (Press Release 18 June 2019). https://www.summitplc.com/app/uploads/2019/06/2019_RNS_ 23-BARDA-option-exercise-FINAL.pdf. Accessed 3 Sept 2019.

163. Bassères E, Endres BT, Khaleduzzaman M, Miraftabi F, Alam MJ, Vickers RJ, et al. Impact on toxin production and cell morphology in Clostridium difficile by ridinilazole (SMT19969), a novel treatment for $C$. difficile infection. J Antimicrob Chemother. 2016;71:1245-51.

164. Thorpe CM, Kane AV, Chang J, Tai A, Vickers RJ, Snydman DR. Enhanced preservation of the human intestinal microbiota by ridinilazole, a novel Clostridium difficile-targeting antibacterial, compared to vancomycin. PLoS ONE. 2018;13:e0199810. https://doi.org/10.1371/journal.pone.0199810.

165. Gibson EG, Bax B, Chan PF, Osheroff N. Mechanistic and structural basis for the actions of the antibacterial gepotidacin against Staphylococcus aureus gyrase. ACS Infect Dis. 2019;5:570-81.

166. Scangarella-Oman NE, Hossain M, Dixon PB, Ingraham K, Min $\mathrm{S}$, Tiffany CA, et al. Microbiological analysis from a phase 2 randomized study in adults evaluating single oral doses of 
gepotidacin in the treatment of uncomplicated urogenital gonorrhea caused by Neisseria gonorrhoeae. Antimicrob Agents Chemother. 2018;62:e01221-01218. https://doi.org/10.1128/aac. 01221-18.

167. Taylor SN, Morris DH, Avery AK, Workowski KA, Batteiger BE, Tiffany CA, et al. Gepotidacin for the treatment of uncomplicated urogenital gonorrhea: a phase 2, randomized, dose-ranging, single-oral dose evaluation. Clin Infect Dis. 2018;67:504-12.

168. Flamm RK, Farrell DJ, Rhomberg PR, Scangarella-Oman NE, Sader HS. Gepotidacin (GSK2140944) in vitro activity against Gram-positive and Gram-negative bacteria. Antimicrob Agents Chemother. 2017;61:e00468-17. https://doi.org/10.1128/aac. 00468-17.

169. Koeth LM, DiFranco-Fisher JM, Scangarella-Oman NE, Miller LA. Analysis of MIC and disk diffusion testing variables for gepotidacin and comparator agents against select bacterial pathogens. J Clin Microbiol. 2017;55:1767-77.

170. Biedenbach DJ, Bouchillon SK, Hackel M, Miller LA, Scangarella-Oman NE, Jakielaszek $\mathrm{C}$, et al. In vitro activity of gepotidacin, a novel triazaacenaphthylene bacterial topoisomerase inhibitor, against a broad spectrum of bacterial pathogens. Antimicrob Agents Chemother. 2016;60:1918-23.

171. Jacobsson S, Golparian D, Scangarella-Oman N, Unemo M. In vitro activity of the novel triazaacenaphthylene gepotidacin (GSK2140944) against MDR Neisseria gonorrhoeae. J Antimicrob Chemother. 2018;73:2072-7.

172. Waites KB, Crabb DM, Xiao L, Duffy LB. In vitro activities of gepotidacin (GSK2140944) and other antimicrobial agents against Human mycoplasmas and ureaplasmas. Antimicrob Agents Chemother. 2017;61:e01064-17. https://doi.org/10. 1128/aac.01064-17.

173. Kern G, Palmer T, Ehmann DE, Shapiro AB, Andrews B, Basarab GS, et al. Inhibition of Neisseria gonorrhoeae type II topoisomerases by the novel spiropyrimidinetrione AZD0914. J Biol Chem. 2015;290:20984-94.

174. Jacobsson S, Golparian D, Alm RA, Huband M, Mueller J, Jensen JS, et al. High in vitro activity of the novel spiropyrimidinetrione AZD0914, a DNA gyrase inhibitor, against multidrug-resistant Neisseria gonorrhoeae isolates suggests a new effective option for oral treatment of gonorrhea. Antimicrob Agents Chemother. 2014;58:5585-8.

175. Damião Gouveia $\mathrm{AC}$, Unemo $\mathrm{M}$, Jensen JS. In vitro activity of zoliflodacin (ETX0914) against macrolide-resistant, fluoroquinolone-resistant and antimicrobial-susceptible Mycoplasma genitalium strains. J Antimicrob Chemother. 2018;73:1291-4.

176. Taylor SN, Marrazzo J, Batteiger BE, Hook EW, Seña AC, Long $J$, et al. Single-dose zoliflodacin (ETX0914) for treatment of urogenital gonorrhea. N Engl J Med. 2018;379:1835-45.

177. Gordeev MF, Yuan ZYY. New potent antibacterial oxazolidinone (MRX-I) with an improved class safety profile. J Med Chem. 2014;57:4487-97.

178. MicuRx reports positive top-line results of a China phase 3 clinical trial for novel antibiotic contezolid in complicated skin and soft tissue infections (Press Release 19 September 2019). http://micurxchina.com/1657.html. Accessed 18 Nov 2019.

179. Huang YQ, Xu YH, Liu SC, Wang HL, Xu XG, Guo QL, et al. Selection and characterisation of Staphylococcus aureus mutants with reduced susceptibility to the investigational oxazolidinone MRX-I. Int J Antimicrob Agents. 2014;43:418-22.

180. Li CR, Zhai QQ, Wang XK, Hu XX, Li GQ, Zhang WX, et al. In vivo antibacterial activity of MRX-I, a new oxazolidinone. Antimicrob Agents Chemother. 2014;58:2418-21.

181. Shoen C, DeStefano M, Hafkin B, Cynamon M. In vitro and in vivo activities of contezolid (MRX-I) against Mycobacterium tuberculosis. Antimicrob Agents Chemother. 2018;62:e049318. https://doi.org/10.1128/AAC.00493-18.

182. Gordeev MF, Liu J, Wang X, Yuan Z, inventors; MicuRx Pharmaceuticals, assignee. Water-soluble O-carbonyl phosphoramidate prodrugs for therapeutic administration. United States patent US 9,382,276. 2015.

183. Rodvold KA, Gotfried MH, Chugh R, Gupta M, Yeole R, Patel A, et al. Intrapulmonary pharmacokinetics of levonadifloxacin following oral administration of alalevonadifloxacin to healthy adult subjects. Antimicrob Agents Chemother. 2018;62:e0229717. https://doi.org/10.1128/aac.02297-17.

184. Wockhardt Annual Report 2017-18. http://www.wockhardt. com/pdf/Annual-Report-2017-2018-b7d2b.pdf. Accessed 29 May 2019.

185. Yeole RD, Rane VP, Ahirrao VK, Chavan RP, Patel AM, Deshpande PK, et al. Identification of metabolites of novel AntiMRSA fluoroquinolone WCK 771 in mouse, rat, rabbit, dog, monkey and human urine using liquid chromatography tandem mass spectrometry. Biomed Chromatogr. 2019;33:e4532. https:// doi.org/10.1002/bmc.4532.

186. Jacobs MR, Appelbaum PC. Nadifloxacin: A quinolone for topical treatment of skin infections and potential for systemic use of its active isomer, WCK 771. Exp Opin Pharmacother. 2006; 7:1957-66.

187. Bhagwat SS, McGhee P, Kosowska-Shick K, Patel MV, Appelbaum PC. In vitro activity of the quinolone WCK 771 against recent U.S. hospital and community-acquired Staphylococcus aureus pathogens with various resistance types. Antimicrob Agents Chemother. 2009;53:811-3.

188. de Souza NJ, Gupte SV, Deshpande PK, Desai VN, Bhawsar SB, Yeole RD, et al. A chiral benzoquinolizine-2-carboxylic acid arginine salt active against vancomycin-resistant Staphylococcus aureus. J Med Chem. 2005;48:5232-42.

189. Blais J, Lopez S, Li C, Ruzin A, Ranjitkar S, Dean CR, et al. In vitro activity of LYS228, a novel monobactam antibiotic, against multidrug-resistant Enterobacteriaceae. Antimicrob Agents Chemother. 2018;62:e0552-18. https://doi.org/10.1128/AAC. 00552-18.

190. Reck F, Bermingham A, Blais J, Capka V, Cariaga T, Casarez A, et al. Optimization of novel monobactams with activity against carbapenem-resistant Enterobacteriaceae-identification of LYS228. Bioorg Med Chem Lett. 2018;28:748-55.

191. Dean CR, Barkan DT, Bermingham A, Blais J, Casey F, Casarez A, et al. Mode of action of the monobactam LYS228 and mechanisms decreasing in vitro susceptibility in Escherichia coli and Klebsiella pneumoniae. Antimicrob Agents Chemother. 2018;62:e1200-18. https://doi.org/10.1128/AAC.01200-18.

192. Osborn M, Stachulski N, Sun H, Blais J, Venishetty V, Raccuglia M, et al. A first-in-Human study to assess the safety and pharmacokinetics of LYS228, a novel intravenous monobactam antibiotic in healthy volunteers. Antimicrob Agents Chemother. 2019;63:e2592-18. https://doi.org/10.1128/AAC.02592-18.

193. Novartis licenses three novel anti-infective programs to Boston Pharmaceuticals (Press Release 3 October 2018). https://www. novartis.com/news/media-releases/novartis-licenses-three-novel-a nti-infective-programs-boston-pharmaceuticals. Accessed 20 May 2019.

194. Sihuan Pharmaceutical Holdings Group Ltd. interim results presentation (2019). https://doc.irasia.com/listco/hk/sihuanpha rm/web/presentation/interimpre2019_e.pdf. Accessed 26 Sept 2019.

195. Zhao C-Y, Lv Y, Zhu Y, Wei M-J, Liu M-Y, Ji X-W, et al. A first-in-human safety, tolerability, and pharmacokinetics study of benapenem in healthy Chinese volunteers. Antimicrob Agents Chemother. 2019;63:e02188-18. https://doi.org/10.1128/aac. 02188-18. 
196. Rodvold KA, Gotfried MH, Chugh R, Gupta M, Friedland HD, Bhatia A. Comparison of plasma and intrapulmonary concentrations of nafithromycin (WCK 4873) in healthy adult subjects. Antimicrob Agents Chemother. 2017;61:e01096-17. https://doi. org/10.1128/aac.01096-17.

197. Hackel MA, Karlowsky JA, Dressel D, Sahm DF. Determination of disk diffusion and MIC quality control ranges for nafithromycin (WCK 4873), a new lactone-ketolide. J Clin Microbiol. 2017;55:3021-7.

198. Anthony NG, Breen D, Clarke J, Donoghue G, Drummond AJ, Ellis EM, et al. Antimicrobial lexitropsins containing amide, amidine, and alkene linking groups. J Med Chem. 2007;50:6116-25.

199. Maisch T, Bosl C, Szeimies RM, Lehn N, Abels C. Photodynamic effects of novel XF porphyrin derivatives on prokaryotic and eukaryotic cells. Antimicrob Agents Chemother. 2005; 49:1542-52.

200. Ooi N, Miller K, Hobbs J, Rhys-Williams W, Love W, Chopra I. XF-73, a novel antistaphylococcal membrane-active agent with rapid bactericidal activity. J Antimicrob Chemother. 2009;64:735-40.

201. Farrell DJ, Robbins M, Rhys-Williams W, Love WG. In vitro activity of XF-73, a novel antibacterial agent, against antibioticsensitive and -resistant Gram-positive and Gram-negative bacterial species. Int J Antimicrob Agents. 2010;35:531-6.

202. Ooi N, Miller K, Randall C, Rhys-Williams W, Love W, Chopra I. XF-70 and XF-73, novel antibacterial agents active against slowgrowing and non-dividing cultures of Staphylococcus aureus including biofilms. J Antimicrob Chemother. 2010;65:72-8.

203. Yendewa GA, Griffiss JM, Jacobs MR, Fulton SA, O'Riordan MA, Gray WA, et al. A two-part phase I study to establish and compare the safety and local tolerability of two nasal formulations of XF-73 for decolonization of Staphylococcus aureus: a previously investigated $0.5 \mathrm{mg} / \mathrm{g}$ viscosified gel formulation versus a modified formulation. J Glob Antimicrob Resist. 2019. https://doi.org/10.1016/j.jgar.2019.09.017.

204. TenNor receives QIDP designation for TNP-2092 (Press Release 27 February 2019). http://www.tennorx.com/companynews/246. html. Accessed 30 May 2019.

205. Ma Z, Lynch AS. Development of a dual-acting antibacterial agent (TNP-2092) for the treatment of persistent bacterial infections. J Med Chem. 2016;59:6645-57.

206. Robertson GT, Bonventre EJ, Doyle TB, Du Q, Duncan L, Morris TW, et al. In vitro evaluation of CBR-2092, a novel rifamycin-quinolone hybrid antibiotic: microbiology profiling studies with staphylococci and streptococci. Antimicrob Agents Chemother. 2008;52:2324-34.

207. Robertson GT, Bonventre EJ, Doyle TB, Du Q, Duncan L, Morris TW, et al. In vitro evaluation of CBR-2092, a novel rifamycin-quinolone hybrid antibiotic: studies of the mode of action in Staphylococcus aureus. Antimicrob Agents Chemother. 2008;52:2313-23.

208. Delavenne EFA, Simon DJJ, Sommer MOA, Toft-Kehler RV, inventors; Antibiotx A/S, assignee. Antibacterial use of halogenated salicylanilides. World patent WO 2016038035. 2016.

209. Sommer MOA, Toft-Kehler RV, inventors; Antibiotx A/S, assignee. Dosage regimen of halogenated salicylanilides World patent WO 2019038443. Accessed 24 Aug 2019.

210. Andrews P, Thyssen J, Lorke D. The biology and toxicology of molluscicides, bayluscide. Pharm Ther. 1982;19:245-95.

211. UNION Therapeutics announces completion of phase 2 studies with ATx201 (Press Release 19 December 2018). Accessed 3 Sept 2019.

212. Rajamuthiah R, Fuchs BB, Conery AL, Kim W, Jayamani E, Kwon B, et al. Repurposing salicylanilide anthelmintic drugs to combat drug resistant Staphylococcus aureus. PLoS ONE. 2015;10:e0124595. https://doi.org/10.1371/journal.pone.0124595.
213. Gooyit M, Janda KD. Reprofiled anthelmintics abate hypervirulent stationary-phase Clostridium difficile. Sci Rep. 2016;6: 33642. https://doi.org/10.1038/srep33642.

214. Mohammad H, AbdelKhalek A, Abutaleb NS, Seleem MN. Repurposing niclosamide for intestinal decolonization of vancomycin-resistant enterococci. Int $\mathrm{J}$ Antimicrob Agents. 2018;51:897-904.

215. Domalaon R, De Silva PM, Kumar A, Zhanel GG, Schweizer F. The anthelmintic drug niclosamide synergizes with colistin and reverses colistin resistance in Gram-negative bacilli. Antimicrob Agents Chemother. 2019;63:e02574-18. https://doi.org/10.1128/ AAC.02574-18.

216. Chen W, Mook RA, Premont RT, Wang J. Niclosamide: Beyond an antihelminthic drug. Cell Signal. 2018;41:89-96.

217. Kadri H, Lambourne OA, Mehellou Y. Niclosamide, a drug with many (re)purposes. ChemMedChem. 2018;13:1088-91.

218. de Carvalho LPS, Darby CM, Rhee KY, Nathan C. Nitazoxanide disrupts membrane potential and intrabacterial $\mathrm{pH}$ homeostasis of Mycobacterium tuberculosis. ACS Med Chem Lett. 2011;2:849-54.

219. Imperi F, Massai F, Ramachandran Pillai C, Longo F, Zennaro E, Rampioni G, et al. New life for an old drug: The anthelmintic drug niclosamide inhibits Pseudomonas aeruginosa quorum sensing. Antimicrob Agents Chemother. 2013;57:9961005.

220. Sutton BM, McGusty E, Walz DT, DiMartino MJ. Oral gold. Antiarthritic properties of alkylphosphinegold coordination complexes. J Med Chem. 1972;15:1095-8.

221. Furst DE. Mechanism of action, pharmacology, clinical efficacy and side effects of auranofin: An orally administered organic gold compound for the treatment of rheumatoid arthritis. Pharmacotherapy. 1983;3:284-96.

222. Roder C, Thomson MJ. Auranofin: Repurposing an old drug for a golden new age. Drugs RD. 2015;15:13-20.

223. Harbut MB, Vilchèze C, Luo X, Hensler ME, Guo H, Yang B, et al. Auranofin exerts broad-spectrum bactericidal activities by targeting thiol-redox homeostasis. Proc Natl Acad Sci USA. 2015;112:4453-8.

224. Lin K, O'Brien KM, Trujillo C, Wang R, Wallach JB, Schnappinger D, et al. Mycobacterium tuberculosis thioredoxin reductase is essential for thiol redox homeostasis but plays a minor role in antioxidant defense. PLoS Pathog. 2016;12:e1005675. https://doi.org/10.1371/journal.ppat.1005675.

225. Zhang X, Selvaraju K, Saei AA, D'Arcy P, Zubarev RA, Arnér ESJ, et al. Repurposing of auranofin: Thioredoxin reductase remains a primary target of the drug. Biochimie. 2019;162:46-54.

226. Thangamani S, Mohammad H, Abushahba MFN, Sobreira TJP, Hedrick VE, Paul LN, et al. Antibacterial activity and mechanism of action of auranofin against multi-drug resistant bacterial pathogens. Sci Rep. 2016;6:22571. https://doi.org/10.1038/srep22571.

227. Jackson-Rosario S, Cowart D, Myers A, Tarrien R, Levine RL, Scott RA, et al. Auranofin disrupts selenium metabolism in Clostridium difficile by forming a stable $\mathrm{Au}-\mathrm{Se}$ adduct. $\mathrm{J}$ Biol Inorg Chem. 2009;14:507-19.

228. AbdelKhalek A, Abutaleb NS, Elmagarmid KA, Seleem MN. Repurposing auranofin as an intestinal decolonizing agent for vancomycin-resistant enterococci. Sci Rep. 2018;8:8353. https:// doi.org/10.1038/s41598-018-26674-0.

229. Hutton ML, Pehlivanoglu H, Vidor CJ, James ML, Thomson MJ, Lyras D. Repurposing auranofin as a Clostridioides difficile therapeutic. J Antimicrob Chemother. 2019;75:409-17.

230. Owings JP, McNair NN, Mui YF, Gustafsson TN, Holmgren A, Contel $\mathrm{M}$, et al. Auranofin and N-heterocyclic carbene goldanalogs are potent inhibitors of the bacteria Helicobacter pylori. FEMS Microbiol Lett. 2016; 363. https://doi.org/10.1093/femsle/ fnw148. 
231. Aguinagalde L, Díez-Martínez R, Yuste J, Royo I, Gil C, Lasa Í, et al. Auranofin efficacy against MDR Streptococcus pneumoniae and Staphylococcus aureus infections. J Antimicrob Chemother. 2015;70:2608-17.

232. She P, Zhou L, Li S, Liu Y, Xu L, Chen L, et al. Synergistic microbicidal effect of auranofin and antibiotics against planktonic and biofilm-encased $S$. aureus and E. faecalis. Front Microbiol. 2019;10. https://doi.org/10.3389/fmicb.2019.02453.

233. Folsom JP, Baker B, Stewart PS. In vitro efficacy of bismuth thiols against biofilms formed by bacteria isolated from human chronic wounds. J Appl Microbiol. 2011;111:989-96.

234. Baker BHJ, inventor; Microbion Corporation, assignee. Bismuth-thiols as antiseptics for agricultural, industrial and other uses. Unites States patent US 9,408,393. 2016.

235. Microbion and Haisco announce equity investment and development \& commercialization agreement for MBN-101 in China and Related Territories (Press Release 29 February 2016). https://www.fiercepharma.com/pharma-asia/microbion-and-ha isco-announce-equity-investment-and-development-commercia lization. Accessed 17 May 2019.

236. Bierer DW. Bismuth subsalicylate: History, chemistry, and safety. Clin Infect Dis. 1990;12:S3-8.

237. Barillo DJ, Barillo AR, Korn S, Lam K, Attar PS. The antimicrobial spectrum of Xeroform . Burns. 2017;43:1189-94.

238. Alkim H, Koksal AR, Boga S, Sen I, Alkim C. Role of bismuth in the eradication of Helicobacter pylori. Am J Ther. 2017;24: e751-7. https://doi.org/10.1136/gutjnl-2015-311019.

239. Menetrey A, Janin A, Pullman J, Overcash JS, Haouala A, Leylavergne $\mathrm{F}$, et al. Bone and joint tissue penetration of the Staphylococcus-selective antibiotic afabicin in patients undergoing elective hip replacement surgery. Antimicrob Agents Chemother. 2019;63:e01669-18. https://doi.org/10.1128/aac.01669-18.

240. Parsons JB, Kukula M, Jackson P, Pulse M, Simecka JW, Valtierra D, et al. Perturbation of Staphylococcus aureus gene expression by the enoyl-acyl carrier protein reductase inhibitor AFN-1252. Antimicrob Agents Chemother. 2013;57:2182-90.

241. Kaplan N, Albert M, Awrey D, Bardouniotis E, Berman J, Clarke T, et al. Mode of action, in vitro activity, and in vivo efficacy of AFN-1252, a selective antistaphylococcal FabI inhibitor. Antimicrob Agents Chemother. 2012;56:5865-74.

242. Lu H, Tonge PJ. Inhibitors of FabI, an enzyme drug target in the bacterial fatty acid biosynthesis pathway. Acc Chem Res. 2008;41:11-20.

243. Gerusz V. Recent advances in the inhibition of bacterial fatty acid biosynthesis. In: John EM (ed). Annual Reports in Medicinal Chemistry, Vol. 45. New York: Academic Press; 2010. p 295-311.

244. Payne DJ, Miller WH, Berry V, Brosky J, Burgess WJ, Chen E, et al. Discovery of a novel and potent class of FabI-directed antibacterial agents. Antimicrob Agents Chemother. 2002;46:3118-24.

245. Payne DJ, Gwynn MN, Holmes DJ, Pompliano DL. Drugs for bad bugs: confronting the challenges of antibacterial discovery. Nat Rev Drug Discov. 2007;6:29-40.

246. Hafkin B, Kaplan N, Murphy B. Efficacy and safety of AFN1252, the first Staphylococcus-specific antibacterial agent, in the treatment of acute bacterial skin and skin structure infections, including those in patients with significant comorbidities. Antimicrob Agents Chemother. 2016;60:1695-701.

247. Otsuka Pharmaceutical Co., Ltd. pipeline. https://www.otsuka.co. jp/en/research-and-development/pipeline/. Accessed 19 Nov 2019.

248. Jeong J-W, Jung S-J, Lee H-H, Kim Y-Z, Park T-K, Cho Y-L, et al. In vitro and in vivo activities of LCB01-0371, a new oxazolidinone. Antimicrob Agents Chemother. 2010;54:5359-62.

249. Zong Z, Jing W, Shi J, Wen S, Zhang T, Huo F, et al. Comparison of in vitro activity and MIC distributions between the novel oxazolidinone delpazolid and linezolid against multidrugresistant and extensively drug-resistant Mycobacterium tuberculosis in China. Antimicrob Agents Chemother. 2018;62: e00165-18. https://doi.org/10.1128/AAC.00165-18.

250. Kim TS, Choe JH, Kim YJ, Yang C-S, Kwon H-J, Jeong J, et al. Activity of LCB01-0371, a novel oxazolidinone, against Mycobacterium abscessus. Antimicrob Agents Chemother. 2017;61: e02752-16. https://doi.org/10.1128/AAC.02752-16.

251. HaiHe Biopharma and CSPC formed a joint venture to codevelop innovative drugs (Press release 18 February 2019) [Internet]. [Accessed 20 May 2019]. Available from 2019: http:// en.haihepharma.com/haihe_en/vip_doc/12399249.html. Accessed 20 May 2019.

252. Barbachyn MR, Hutchinson DK, Brickner SJ, Cynamon MH, Kilburn JO, Klemens SP, et al. Identification of a novel oxazolidinone (U-100480) with potent antimycobacterial activity. J Med Chem. 1996;39:680-5.

253. Cynamon MH, Klemens SP, Sharpe CA, Chase S. Activities of several novel oxazolidinones against Mycobacterium tuberculosis in a murine model. Antimicrob Agents Chemother. 1999;43:1189-91.

254. Alffenaar JWC, van der Laan T, Simons S, van der Werf TS, van de Kasteele PJ, de Neeling H, et al. Susceptibility of cinical Mycobacterium tuberculosis isolates to a potentially less toxic derivate of linezolid, PNU-100480. Antimicrob Agents Chemother. 2011;55:1287-9.

255. Williams KN, Stover CK, Zhu T, Tasneen R, Tyagi S, Grosset $\mathrm{JH}$, et al. Promising antituberculosis activity of the oxazolidinone PNU-100480 relative to that of linezolid in a murine model. Antimicrob Agents Chemother. 2009;53:1314-9.

256. Wallis RS, Dawson R, Friedrich SO, Venter A, Paige D, Zhu T, et al. Mycobactericidal activity of sutezolid (PNU-100480) in sputum (EBA) and blood (WBA) of patients with pulmonary tuberculosis. PLoS ONE. 2014;9:e94462. https://doi.org/10. 1371/journal.pone.0094462.

257. DEINOVE is now ready to start Phase II clinical trial for its antibiotic compound DNV3837 (Press Release 16 May 2019). http://www.deinove.com/en/news/all-press-releases/deinovenow-ready-start-phase-ii-clinical-trial-its-antibiotic-compounddnv3837. Accessed 23 Jul 2019.

258. Rashid M-U, Dalhoff A, Weintraub A, Nord CE. In vitro activity of MCB3681 against Clostridium difficile strains. Anaerobe. 2014;28:216-9.

259. Rashid M-U, Dalhoff A, Bäckström T, Björkhem-Bergman L, Panagiotidis G, Weintraub A, et al. Ecological impact of MCB3837 on the normal human microbiota. Int $\mathbf{J}$ Antimicrob Agents. 2014;44:125-30.

260. Dalhoff A, Rashid MU, Kapsner T, Panagiotidis G, Weintraub A, Nord CE. Analysis of effects of MCB3681, the antibacterially active substance of prodrug MCB3837, on human resident microflora as proof of principle. Clin Microbiol Infec. 2015;21:767.e761-4. https://doi.org/10.1016/j.cmi.2015.05.025.

261. DNV3837: An antibiotic in the clinical phase to fight severe Clostridioides difficile infections and DNV3681 evaluated by the U.S. Department of Defense as a potential treatment against two pathogenic agents classified as most dangerous possible bioterrorist threat. http://www.deinove.com/en/antibiotics/portfolio/ dnv3837/dnv3681. Accessed 23 July 2019.

262. Pethe K, Bifani P, Jang J, Kang S, Park S, Ahn S, et al. Discovery of Q203, a potent clinical candidate for the treatment of tuberculosis. Nat Med. 2013;19:1157-60.

263. Kang S, Kim RY, Seo MJ, Lee S, Kim YM, Seo M, et al. Lead optimization of a novel series of imidazo[1,2-a]pyridine amides leading to a clinical candidate (Q203) as a multi- and extensively-drug-resistant anti-tuberculosis agent. J Med Chem. 2014; 57:5293-305.

264. Moraski GC, Seeger N, Miller PA, Oliver AG, Boshoff HI, Cho S, et al. Arrival of imidazo[2,1- $b$ ]thiazole-5-carboxamides: Potent 
anti-tuberculosis agents that target QcrB. ACS Infect Dis. 2016; 2:393-8.

265. Lee BS, Kalia NP, Jin XEF, Hasenoehrl EJ, Berney M, Pethe K. Inhibitors of energy metabolism interfere with antibiotic-induced death in mycobacteria. J Biol Chem. 2019;294:1936-43.

266. Infectex successfully completes phase 1 clinical study of Q203 for treatment of tuberculosis (Press release 22 June 2017). http:// infectex.ru/en/\%D0\%B1\%D0\%B5\%D0\%B7-\%D1\%80\%D1\% $83 \% \mathrm{D} 0 \% \mathrm{~B} 1 \% \mathrm{D} 1 \% 80 \% \mathrm{D} 0 \% \mathrm{~B} 8 \% \mathrm{D} 0 \% \mathrm{BA} \% \mathrm{D} 0 \% \mathrm{~B} 8-\mathrm{en} /$ infectex-successfully-completes-phase-1-clinical-study-of-q203for-treatment-of-tuberculosis/. Accessed 20 May 2019.

267. Makarov V, Lechartier B, Zhang M, Neres J, van der Sar AM, Raadsen SA, et al. Towards a new combination therapy for tuberculosis with next generation benzothiazinones. EMBO Mol Med. 2014;6:372-83.

268. Zhang G, Howe M, Aldrich CC. Spirocyclic and bicyclic 8nitrobenzothiazinones for tuberculosis with improved physicochemical and pharmacokinetic properties. ACS Med Chem Lett. 2019;10:348-51.

269. Makarov V, Manina G, Mikusova K, Möllmann U, Ryabova O, Saint-Joanis B, et al. Benzothiazinones kill Mycobacterium tuberculosis by blocking arabinan synthesis. Science. 2009; 324:801-4.

270. Trefzer C, Škovierová H, Buroni S, Bobovská A, Nenci S, Molteni E, et al. Benzothiazinones are suicide inhibitors of mycobacterial decaprenylphosphoryl- $\beta$-D-ribofuranose $2^{\prime}$-oxidase DprE1. J Am Chem Soc. 2012;134:912-5.

271. Neres J, Pojer F, Molteni E, Chiarelli LR, Dhar N, Boy-Röttger $\mathrm{S}$, et al. Structural basis for benzothiazinone-mediated killing of Mycobacterium tuberculosis. Sci Transl Med. 2012;4:150ra121. https://doi.org/10.1126/scitranslmed.3004395.

272. Shi J, Lu J, Wen Sa, Zong Z, Huo F, Luo J, et al. In vitro activity of PBTZ169 against multiple Mycobacterium species. Antimicrob Agents Chemother. 2018;62:e01314-8. https://doi.org/ 10.1128/aac.01314-18.

273. Kloss F, Krchnak V, Krchnakova A, Schieferdecker S, Dreisbach $\mathrm{J}$, Krone V, et al. In vivo dearomatization of the potent antituberculosis agent BTZ043 via Meisenheimer complex formation. Angew Chem, Int Ed. 2017;56:2187-91.

274. OPC-167832 (Working Group on New TB Drugs). https://www. newtbdrugs.org/pipeline/compound/opc-167832. Accessed 23 July 2019.

275. Shimizu H, Kawano Y, Ishikawa S, Uematsu Y, Shinohara T, Itotani M. et al. inventors; Otsuka Pharmaceutical, assignee. Heterobicyclic compounds and their use for the treatment of tuberculosis. United States patent US 10,053,446. 2018.

276. Batt SM, Jabeen T, Bhowruth V, Quill L, Lund PA, Eggeling L, et al. Structural basis of inhibition of Mycobacterium tuberculosis DprE1 by benzothiazinone inhibitors. Proc Natl Acad Sci USA. 2012;109:11354-9.

277. Li X, Hernandez V, Rock FL, Choi W, Mak YSL, Mohan M, et al. Discovery of a potent and specific M. tuberculosis leucyltRNA synthetase inhibitor: ( $S$ )-3-(aminomethyl)-4-chloro-7-(2hydroxyethoxy)benzo[c][1,2]oxaborol-1(3H)-ol (GSK656). J Med Chem. 2017;60:8011-26.

278. Tenero D, Derimanov G, Carlton A, Tonkyn J, Davies M, Cozens S, et al. First-time-in-Human study and prediction of early bactericidal activity for GSK3036656, a potent leucyltRNA synthetase inhibitor for tuberculosis treatment. Antimicrob Agents Chemother. 2019;63:e0240-19. https://doi. org/10.1128/aac.00240-19.

279. Palencia A, Li X, Bu W, Choi W, Ding CZ, Easom EE, et al. Discovery of novel oral protein synthesis inhibitors of Mycobacterium tuberculosis that target leucyl-tRNA synthetase. Antimicrob Agents Chemother. 2016;60:6271-80.
280. O’Dwyer K, Spivak AT, Ingraham K, Min S, Holmes DJ, Jakielaszek C, et al. Bacterial resistance to leucyl-tRNA synthetase inhibitor GSK2251052 develops during treatment of complicated urinary tract infections. Antimicrob Agents Chemother. 2015;59:289-98.

281. Gupta A, Monteferrante C, Rasina D, Leitis G, Randall CP, Tomlinson $\mathrm{JH}$, et al. A polymorphism in leuS confers reduced susceptibility to GSK2251052 in a clinical isolate of Staphylococcus aureus. Antimicrob Agents Chemother. 2016; 60:3219-21.

282. Falagas ME, Skalidis T, Vardakas KZ, Voulgaris GL, Papanikolaou G, Legakis N. Activity of TP-6076 against carbapenem-resistant Acinetobacter baumannii isolates collected from inpatients in Greek hospitals. Int J Antimicrob Agents. 2018;52:269-71.

283. Tetraphase Pharmaceuticals' TP-6076 selected by Carb-X to receive $\$ 4$ million in research funding (Press Release 30 March 2017). https://ir.tphase.com/news-releases/news-release-details/ tetraphase-pharmaceuticals-tp-6076-selected-carb-x-receive-4. Accessed 20 May 2019.

284. Grossman TH, Fyfe C, O'Brien W, Hackel M, Minyard MB, Waites KB, et al. Fluorocycline TP-271 is potent against complicated community-acquired bacterial pneumonia pathogens. mSphere. 2017;2:e00004-17. https://msphere.asm.org/content/ $\mathrm{msph} / 2 / 1 / \mathrm{e} 00004-17$. full.pdf.

285. Grossman TH, Anderson MS, Christ D, Gooldy M, Henning LN, Heine HS, et al. The fluorocycline TP-271 is efficacious in models of aerosolized Francisella tularensis SCHU S4 infection in BALB/c mice and cynomolgus macaques. Antimicrob Agents Chemother. 2017;61:e00448-17. https://doi.org/10.1128/aac. 00448-17.

286. Grossman TH, Anderson MS, Drabek L, Gooldy M, Heine HS, Henning LN, et al. The fluorocycline TP-271 is efficacious in models of aerosolized Bacillus anthracis infection in BALB/c mice and cynomolgus macaques. Antimicrob Agents Chemother. 2017;61:e01103-17. https://doi.org/10.1128/aac.01103-17.

287. Trimble MJ, Mlynárčik P, Koláŕ M, Hancock REW. Polymyxin: Alternative mechanisms of action and resistance. Cold Spring Harb Perspect Med. 2016;6:a025288. https://doi.org/10.1101/ cshperspect.a025288.

288. Vaara M. Polymyxin derivatives that sensitize Gram-negative bacteria to other antibiotics. Molecules. 2019;24:E249. https:// doi.org/10.3390/molecules24020249.

289. Vaara M, Vaara T. Structure-activity studies on novel polymyxin derivatives that carry only three positive charges. Peptides. 2010;31:2318-21.

290. Vaara M, Siikanen O, Apajalahti J, Fox J, Frimodt-Møller N, He $\mathrm{H}$, et al. A novel polymyxin derivative that lacks the fatty acid tail and carries only three positive charges has strong synergism with agents excluded by the intact outer membrane. Antimicrob Agents Chemother. 2010;54:3341-6.

291. Corbett D, Wise A, Langley T, Skinner K, Trimby E, Birchall S, et al. Potentiation of antibiotic activity by a novel cationic peptide: Potency and spectrum of activity of SPR741. Antimicrob Agents Chemother. 2017;61:e0200-17. https://doi.org/10. 1128/aac.00200-17.

292. Zurawski DV, Reinhart AA, Alamneh YA, Pucci MJ, Si Y, Abu-Taleb R, et al. SPR741, an antibiotic adjuvant, potentiates the in vitro and in vivo activity of rifampin against clinically relevant extensively drug-resistant Acinetobacter baumannii. Antimicrob Agents Chemother. 2017;61:e01239-17. https:// doi.org/10.1128/aac.01239-17.

293. Stainton SM, Abdelraouf K, Utley L, Pucci MJ, Lister T, Nicolau DP. Assessment of the in vivo activity of SPR741 in combination with azithromycin against multidrug-resistant Enterobacteriaceae isolates in the neutropenic murine thigh infection model. 
Antimicrob Agents Chemother. 2018;62:e00239-18. https://doi. org/10.1128/aac.00239-18.

294. In vitro activity evaluation of a next-generation polymyxin, SPR206, against non-fermentative Gram-negative bacilli responsible for human infections (ASM-ESCMID Conference, 4-7 September 2018, Poster \#80). https://www.jmilabs.com/ publications/in-vitro-activity-evaluation-of-a-next-generationpolymyxin-spr206-against-non-fermentative-gram-negative-ba cilli-responsible-for-human-infections/. Accessed 17 Nov 2019.

295. Spero Therapeutics signs license agreement with Everest Medicines to develop, manufacture and commercialize SPR206 in Asia, with option for SPR741 rights, and initiates SPR206 Phase 1 Clinical Trial (Press Release 7 January 2019). https://investors. sperotherapeutics.com/news-releases/news-release-details/sperotherapeutics-signs-license-agreement-everest-medicines. Accessed 4 June 2019.

296. Thompson RQ, Presti EA Nebramycin, a new broad-spectrum antibiotic complex. III. Isolation and chemical-physical properties. Antimicrob Agents Chemother. 1968:332-40.

297. O'Connor S, Lam LKT, Jones ND, Chaney MO. Apramycin, a unique aminocyclitol antibiotic. J Org Chem. 1976;41:2087-92.

298. Tian E, Muhammad I, Hu W, Wu Z, Li R, Lu X, et al. Tentative epidemiologic cut-off value and resistant characteristic detection of apramycin against Escherichia coli from chickens. FEMS Microbiol Lett. 2019;366. https://doi.org/10.1093/femsle/fnz196.

299. Kang AD, Smith KP, Eliopoulos GM, Berg AH, McCoy C, Kirby JE. In vitro apramycin activity against multidrug-resistant Acinetobacter baumannii and Pseudomonas aeruginosa. Diagn Microbiol Infect Dis. 2017;88:188-91.

300. Juhas M, Widlake E, Teo J, Huseby DL, Tyrrell JM, Polikanov YS, et al. In vitro activity of apramycin against multidrug-, carbapenem- and aminoglycoside-resistant Enterobacteriaceae and Acinetobacter baumannii. J Antimicrob Chemother. 2019; 74:944-52.

301. Kang AD, Smith KP, Berg AH, Truelson KA, Eliopoulos GM, McCoy C, et al. Efficacy of apramycin against multidrug-resistant Acinetobacter baumannii in the murine neutropenic thigh model. Antimicrob Agents Chemother. 2018;62:e2585-17. https://doi.org/10.1128/AAC.02585-17.

302. Wright GE, Brown NC, Xu W-C, Long Z-y, Zhi C, Gambino JJ, et al. Active site directed inhibitors of replicationspecific bacterial DNA polymerases. Bioorg Med Chem Lett. 2005;15:729-32.

303. Xu W-C, Wright GE, Brown NC, Long Z-Y, Zhi C-X, Dvoskin $\mathrm{S}$, et al. 7-Alkyl-N2-substituted-3-deazaguanines. Synthesis, DNA polymerase III inhibition and antibacterial activity. Bioorg Med Chem Lett. 2011;21:4197-202.

304. Acurx announces first-in-man clinical trial data of ACX-362E for CDI (Press Release 25 February 2019). https://www.acurxpha rma.com/news-media/press-releases/detail/8/acurx-announcesfirst-in-man-clinical-trial-data-of. Accessed 12 Aug 2019.

305. Xu W-C, Silverman MH, Yu XY, Wright G, Brown N. Discovery and development of DNA polymerase IIIC inhibitors to treat Gram-positive infections. Bioorg Med Chem. 2019;27: 3209-17.

306. Dvoskin S, Xu W-C, Brown NC, Yanachkov IB, Yanachkova M, Wright GE. A novel agent effective against Clostridium difficile infection. Antimicrob Agents Chemother. 2012;56:1624-6.

307. Nesterenko LN, Zigangirova NA, Zayakin ES, Luyksaar SI, Kobets NV, Balunets DV, et al. A small-molecule compound belonging to a class of 2,4-disubstituted 1,3,4-thiadiazine-5ones suppresses Salmonella infection in vivo. J Antibiot. 2016;69:422-7.

308. Zigangirova NA, Zayakin ES, Kapotina LN, Kost EA, Didenko LV, Davydova DY, et al. Development of chlamydial type III secretion system inhibitors for suppression of acute and chronic forms of chlamydial infection. Acta Nat. 2012;4:87-97.

309. Sheremet AB, Zigangirova NA, Zayakin ES, Luyksaar SI, Kapotina LN, Nesterenko LN, et al. Small molecule inhibitor of type three secretion system belonging to a class 2,4-disubstituted-4H-[1,3,4]-thiadiazine-5-ones improves survival and decreases bacterial loads in an airway Pseudomonas aeruginosa infection in mice. Biomed Res Int. 2018;13:5810767. https://doi. org/10.1155/2018/5810767.

310. Dey S, Chakravarty A, Guha Biswas P, De Guzman RN. The type III secretion system needle, tip, and translocon. Protein Sci. 2019;28:1582-93.

311. O'Dowd H, Shannon DE, Chandupatla KR, Dixit V, Engtrakul JJ, Ye Z, et al. Discovery and characterization of a water-soluble prodrug of a dual inhibitor of bacterial DNA Gyrase and Topoisomerase IV. ACS Med Chem Lett. 2015;6:822-6.

312. Locher CP, Jones SM, Hanzelka BL, Perola E, Shoen CM, Cynamon $\mathrm{MH}$, et al. A novel inhibitor of gyrase B is a potent drug candidate for treatment of tuberculosis and nontuberculosis mycobacterial infections. Antimicrob Agents Chemother. 2015; 59:1455-65.

313. Bisacchi GS, Manchester JI. A new-class antibacterial-almost. Lessons in drug discovery and development: A critical analysis of more than 50 years of effort toward ATPase inhibitors of DNA Gyrase and Topoisomerase IV. ACS Infect Dis. 2015;1:4-41.

314. Brown-Elliott BA, Rubio A, Wallace RJ Jr. In vitro susceptibility testing of a novel benzimidazole, SPR719, against nontuberculous mycobacteria. Antimicrob Agents Chemother. 2018;62:e0150318. https://doi.org/10.1128/aac.01503-18.

315. Durcik M, Tomašič T, Zidar N, Zega A, Kikelj D, Mašič LP, et al. ATP-competitive DNA gyrase and topoisomerase IV inhibitors as antibacterial agents. Exp Opin Ther Pat. 2019;29:171-80.

316. Spero Therapeutics announces second quarter 2019 operating results and provides pipeline update (Press Release 8 August 2019). https://investors.sperotherapeutics.com/news-releases/newsrelease-details/spero-therapeutics-announces-second-quarter-2019operating. Accessed 29 Aug 2019.

317. Carro L. Recent progress in the development of small-molecule FtsZ inhibitors as chemical tools for the development of novel antibiotics. Antibiotics (Basel). 2019;8:E217. https://doi.org/10. 3390/antibiotics8040217.

318. Elsen NL, Lu J, Parthasarathy G, Reid JC, Sharma S, Soisson $\mathrm{SM}$, et al. Mechanism of action of the cell-division inhibitor PC190723: Modulation of FtsZ assembly cooperativity. J Am Chem Soc. 2012;134:12342-5.

319. TAXIS secures NIH Funding (Press Release 17 June 2019). https://www.taxispharma.com/news/taxis-secures-nih-funding/. Accessed 19 Nov 2019.

320. Haydon DJ, Stokes NR, Ure R, Galbraith G, Bennett JM, Brown DR, et al. An inhibitor of FtsZ with potent and selective antistaphylococcal activity. Science. 2008;321:1673-5.

321. Haydon DJ, Bennett JM, Brown D, Collins I, Galbraith G, Lancett $\mathrm{P}$, et al. Creating an antibacterial with in vivo efficacy: synthesis and characterization of potent inhibitors of the bacterial cell division protein FtsZ with improved pharmaceutical properties. J Med Chem. 2010;53:3927-36.

322. Stokes NR, Baker N, Bennett JM, Berry J, Collins I, Czaplewski LG, et al. An improved small-molecule inhibitor of FtsZ with superior in vitro potency, drug-like properties, and in vivo efficacy. Antimicrob Agents Chemother. 2013;57:317-25.

323. TAXIS acquires novel antimicrobial drug candidates from Biota (Press Release 11 August 2014). https://www.taxispharma.com/ news/taxis-acquires-novel-antimicrobial-drug-candidates-biota/. Accessed 19 Nov 2019.

324. Kaul M, Mark L, Zhang Y, Parhi AK, LaVoie EJ, Pilch DS Pharmacokinetics and in vivo antistaphylococcal efficacy of 
TXY541, a 1-methylpiperidine-4-carboxamide prodrug of PC190723. Biochem Pharm. 2013;86:1699-707.

325. Kaul M, Mark L, Zhang Y, Parhi AK, Lyu YL, Pawlak J, et al. TXA709, an FtsZ-targeting benzamide prodrug with improved pharmacokinetics and enhanced in vivo efficacy against methicillin-resistant Staphylococcus aureus. Antimicrob Agents Chemother. 2015;59:4845-55.

326. Lepak AJ, Parhi A, Madison M, Marchillo K, VanHecker J, Andes DR. In vivo pharmacodynamic evaluation of an FtsZ inhibitor, TXA-709, and its active metabolite, TXA-707, in a murine neutropenic thigh infection mode. Antimicrob Agents Chemother. 2015;59:6568-74.

327. Krutikov M, Bruchfeld J, Migliori GB, Borisov S, Tiberi S. New and repurposed drugs. In: Migliori GB, Bothamley G, Duarte R, Rendon A (eds). Tuberculosis. European Respiratory Society; Wakefield, UK: Charlesworth Press; 2018. p 179-204.

328. Everett D TB Alliance Clinical programs update (CPTR Annual Meeting, April, 2017). http://www.cptrinitiative.org/wp-content/ uploads/2017/05/21_04_Everitt.pdf. Accessed 26 Sept 2019.

329. Zhang D, Lu Y, Liu K, Liu B, Wang J, Zhang G, et al. Identification of less lipophilic riminophenazine derivatives for the treatment of drug-resistant tuberculosis. J Med Chem. 2012;55:8409-17.

330. Dey T, Brigden G, Cox H, Shubber Z, Cooke G, Ford N. Outcomes of clofazimine for the treatment of drug-resistant tuberculosis: a systematic review and meta-analysis. J Antimicrob Chemother. 2012;68:284-93.

331. Mirnejad R, Asadi A, Khoshnood S, Mirzaei H, Heidary M, Fattorini L, et al. Clofazimine: a useful antibiotic for drugresistant tuberculosis. Biomed Pharmacother. 2018;105:1353-9.

332. Xu J, Wang B, Fu L, Zhu H, Guo S, Huang H, et al. In vitro and in vivo activities of the riminophenazine TBI-166 against Mycobacterium tuberculosis. Antimicrob Agents Chemother. 2019;63:e02155-18. https://doi.org/10.1128/aac.02155-18.

333. Zhang Y, Zhu H, Fu L, Wang B, Guo S, Chen X, et al. Identifying regimens containing TBI-166, a new drug candidate against Mycobacterium tuberculosis in vitro and in vivo. Antimicrob Agents Chemother. 2019;63:e02496-18. https://doi.org/ 10.1128/aac.02496-18.

334. Shirude PS, Shandil R, Sadler C, Naik M, Hosagrahara V, Hameed S, et al. Azaindoles: noncovalent DprE1 inhibitors from scaffold morphing efforts, kill Mycobacterium tuberculosis and are efficacious in vivo. J Med Chem. 2013;56:9701-8.

335. Shirude PS, Shandil RK, Manjunatha MR, Sadler C, Panda M, Panduga V, et al. Lead optimization of 1,4-azaindoles as antimycobacterial agents. J Med Chem. 2014;57:5728-37.

336. Chatterji M, Shandil R, Manjunatha MR, Solapure S, Ramachandran V, Kumar N, et al. 1,4-Azaindole, a potential drug candidate for treatment of tuberculosis. Antimicrob Agents Chemother. 2014;58:5325-31.

337. TNP-2198, TenNor's new drug for anaerobic bacterial infections, has been approved for clinical research (Press Release 3 December 2018). http://www.tennorx.com/companynews/185. html. Accessed 17 Nov 2019.

338. Biocidium Biopharmaceuticals pipeline (2019). https://biocidium. com/product-pipeline/. Accessed 3 Sept 2019.

339. Linghu X, Segraves NL, Abramovich I, Wong N, Müller B, Neubauer N, et al. Highly efficient synthesis of a Staphylococcus aureus targeting payload to enable the first antibody-antibiotic conjugate. Chem Eur J. 2018;24:2837-40.

340. Lehar SM, Pillow T, Xu M, Staben L, Kajihara KK, Vandlen R, et al. Novel antibody-antibiotic conjugate eliminates intracellular S. aureus. Nature. 2015;527:323-8.

341. Peck M, Rothenberg ME, Deng R, Lewin-Koh N, She G, Kamath AV, et al. A phase 1, randomized, single-ascendingdose study to investigate the safety, tolerability, and pharmacokinetics of DSTA4637S, an anti-Staphylococcus aureus thiomab antibody-antibiotic conjugate, in healthy volunteers. Antimicrob Agents Chemother. 2019;63:e0258818. https://doi.org/10.1128/aac.02588-18.

342. Deng R, Zhou C, Li D, Cai H, Sukumaran S, Carrasco-Triguero $\mathrm{M}$, et al. Preclinical and translational pharmacokinetics of a novel THIOMAB ${ }^{\mathrm{TM}}$ antibody-antibiotic conjugate against Staphylococcus aureus. mAbs. 2019;11:1162-74.

343. Shen B-Q, Xu K, Liu L, Raab H, Bhakta S, Kenrick M, et al. Conjugation site modulates the in vivo stability and therapeutic activity of antibody-drug conjugates. Nat Biotechnol. 2012; 30:184-9.

344. Brown AG, Butterworth D, Cole M, Hanscomb G, Hood JD, Reading $\mathrm{C}$, et al. Naturally-occurring $\beta$-lactamase inhibitors with antibacterial activity. J Antibiot. 1976;29:668-9.

345. Howarth TT, Brown AG, King TJ. Clavulanic acid, a novel $\beta$ lactam isolated from Streptomyces clavuligerus; X-ray crystal structure analysis. J Chem Soc, Chem Commun. 1976: 266-7.

346. Reading C, Cole M. Clavulanic acid: a beta-lactamase-inhibiting beta-lactam from Streptomyces clavuligerus. Antimicrob Agents Chemother. 1977;11:852-7.

347. Mameli M, Vezzelli A, Verze' S, Biondi S, Motta P, Greco A, et al. Liquid chromatography-tandem mass spectrometry for the simultaneous quantitation of enmetazobactam and cefepime in human plasma. J Pharm Biomed Anal. 2019;174:655-62.

348. Crandon JL, Nicolau DP. In vivo activities of simulated human doses of cefepime and cefepime-AAI101 against multidrugresistant Gram-negative Enterobacteriaceae. Antimicrob Agents Chemother. 2015;59:2688-94.

349. Crandon JL, Nicolau DP. In vitro activity of cefepime/AAI101 and comparators against cefepime non-susceptible Enterobacteriaceae. Pathogens. 2015;4:620-5.

350. Durand-Réville TF, Guler S, Comita-Prevoir J, Chen B, Bifulco $\mathrm{N}$, Huynh $\mathrm{H}$, et al. ETX2514 is a broad-spectrum $\beta$-lactamase inhibitor for the treatment of drug-resistant Gram-negative bacteria including Acinetobacter baumannii. Nat Microbiol. 2017;2:17104. https://doi.org/10.1038/nmicrobiol.2017.104.

351. Shapiro AB, Gao N, Jahić H, Carter NM, Chen A, Miller AA. Reversibility of covalent, broad-spectrum serine $\beta$-lactamase inhibition by the diazabicyclooctenone ETX2514. ACS Infect Dis. 2017;3:833-44.

352. O'Donnell J, Preston RA, Mamikonyan G, Stone E, Isaacs R. Pharmacokinetics, safety, and tolerability of intravenous durlobactam and sulbactam in subjects with renal impairment and healthy matched control subjects. Antimicrob Agents Chemother. 2019;63:e0794-19. https://doi.org/10.1128/AAC. 00794-19.

353. Barnes MD, Kumar V, Bethel CR, Moussa SH, O’Donnell J, Rutter JD, et al. Targeting multidrug-resistant Acinetobacter spp.: sulbactam and the diazabicyclooctenone $\beta$-lactamase inhibitor ETX2514 as a novel therapeutic agent. mBio. 2019;10:e00159-19. https://doi.org/10.1128/mBio.00159-19.

354. McLeod SM, Shapiro AB, Moussa SH, Johnstone M, McLaughlin RE, de Jonge BLM, et al. Frequency and mechanism of spontaneous resistance to sulbactam combined with the novel $\beta$-lactamase inhibitor ETX2514 in clinical isolates of Acinetobacter baumannii. Antimicrob Agents Chemother. 2018;62:e01576-17. https://doi. org/10.1128/aac.01576-17.

355. Liu B, Trout REL, Chu G-H, McGarry D, Jackson RW, Hamrick $\mathrm{J}$, et al. Discovery of taniborbactam (VNRX-5133): A broadspectrum serine- and metallo- $\beta$-lactamase inhibitor for carbapenem-resistant bacterial infections. J Med Chem. 2019. https://doi. org/10.1021/acs.jmedchem.9b01518.

356. Krajnc A, Brem J, Hinchliffe P, Calvopina K, Panduwawala T, Lang PA, et al. Bicyclic boronate VNRX-5133 inhibits metalloand serine- $\beta$-lactamases. J Med Chem. 2019;62:8544-56. 
357. Morinaka A, Tsutsumi Y, Yamada M, Suzuki K, Watanabe T, Abe T, et al. OP0595, a new diazabicyclooctane: mode of action as a serine $\beta$-lactamase inhibitor, antibiotic and $\beta$-lactam 'enhancer'. J Antimicrob Chemother. 2015;70:2779-86.

358. Asempa TE, Motos A, Abdelraouf K, Bissantz C, Zampaloni C, Nicolau DP. Efficacy of Human-simulated epithelial lining fluid exposure of meropenem-nacubactam combination against class a serine $\beta$-lactamase-producing Enterobacteriaceae in the neutropenic murine lung infection model. Antimicrob Agents Chemother. 2019;63:e02382-18. https://doi.org/10.1128/aac.02382-18.

359. Livermore DM, Warner M, Mushtaq S, Woodford N. Interactions of OP0595, a novel triple-action diazabicyclooctane, with $\beta$-lactams against OP0595-resistant Enterobacteriaceae mutants. Antimicrob Agents Chemother. 2016;60:554-60.

360. Fedora Pharmaceuticals and Meiji Seika Pharma sign basic agreement to establish NacuGen Therapeutics Inc., a joint venture to develop and commercialize nacubactam for bacterial infections (Press Release 7 January 2019). https://www.nacugen. com/new-joint-venture. Accessed 26 Sept 2019.

361. Garde D Roche inks a $\$ 750 \mathrm{M}$ antibiotics deal as it re-embraces the field (Fierce Biotech 13 Jan 2015). http://www.fiercebiotech. com/story/roche-inks-750m-antibiotics-deal-it-re-embraces-field/ 2015-01-13. Accessed 17 Nov 2019.

362. Roche, $\mathrm{M}$ and Fedora join forces to tackle increasing bacterial resistance to antibiotics: Roche licenses investigational beta-lactamase inhibitor OP0595, OP0595 targets beta-lactamase enzymes in combination with new or existing beta-lactam antibiotics to enhance their effectiveness in difficult-to-treat bacterial infections (Press Release 13 Jan 2015). http://www.roche.com/media/store/ releases/med-cor-2015-01-13.htm. Accessed 17 Nov 2019.

363. Preston RA, Mamikonyan G, DeGraff S, Chiou J, Kemper CJ, $\mathrm{Xu} \mathrm{A}$, et al. Single-center evaluation of the pharmacokinetics of WCK 5222 (cefepime-zidebactam combination) in subjects with renal impairment. Antimicrob Agents Chemother. 2019;63: e01484-18. https://doi.org/10.1128/aac.01484-18.

364. Papp-Wallace KM, Nguyen NQ, Jacobs MR, Bethel CR, Barnes MD, Kumar V, et al. Strategic approaches to overcome resistance against Gram-negative pathogens using $\beta$-lactamase inhibitors and $\beta$-lactam enhancers: Activity of three novel diazabicyclooctanes WCK 5153, zidebactam (WCK 5107), and WCK 4234. J Med Chem. 2018;61:4067-86.

365. Sader HS, Rhomberg PR, Flamm RK, Jones RN, Castanheira M. WCK 5222 (cefepime/zidebactam) antimicrobial activity tested against Gram-negative organisms producing clinically relevant $\beta$-lactamases. J Antimicrob Chemother. 2017;72:1696-703.

366. Moya B, Barcelo IM, Bhagwat S, Patel M, Bou G, Papp-Wallace KM, et al. Potent $\beta$-lactam enhancer activity of zidebactam and WCK 5153 against Acinetobacter baumannii, including carbapenemase-producing clinical isolates. Antimicrob Agents Chemother. 2017;61:e01238-17. https://doi. org/10.1128/aac.01238-17.

367. Avery LM, Abdelraouf K, Nicolau DP. Assessment of the in vivo efficacy of WCK 5222 (cefepime-zidebactam) against carbapenem-resistant Acinetobacter baumannii in the neutropenic murine lung infection model. Antimicrob Agents Chemother. 2018;62:e00948-18. https://doi.org/10.1128/aac.00948-18.
368. Monogue ML, Tabor-Rennie J, Abdelraouf K, Nicolau DP. In vivo efficacy of WCK 5222 (cefepime-zidebactam) against multidrug-resistant Pseudomonas aeruginosa in the neutropenic murine thigh infection model. Antimicrob Agents Chemother. 2019;63:e00233-19. https://doi.org/10.1128/aac.00233-19.

369. Entasis Therapeutics announces initial ETX0282 phase 1 results (Press Release 13 June 2019). https://investors.entasistx.com/newsreleases/news-release-details/entasis-therapeutics-announces-initia 1-etx0282-phase-1-results. Accessed 17 Sept 2019.

370. Weiss W, Carter K, Pulse M, Nguyen P, Valtierra D, Peterson K, et al. Efficacy of cefpodoxime proxetil and ETX0282 in a murine UTI model with E. coli and K. pneumoniae (Poster P1991, 29th ECCMID Conference, Amsterdam, Netherlands, 13-16 April 2019). https://www.entasistx.com/application/files/2115/5795/ 6547/Entasis_ECCMID_2019_BWfinal.pdf. Accessed 17 Sept 2019.

371. Basarab GS, Comita-Prevoir J, Durand-Reville TF, Gauthier L, Moss B, O'Donnell J, et al. inventors; Entasis Therapeutics, assignee. Beta-lactamase inhibitor compounds. United States patent US 20190202832. 2019.

372. Burns CJ, Daigle D, Liu B, Jackson RW, Hamrick J, McGarry D, et al, inventors; VenatoRx Pharmaceuticals, assignee. Beta-lactamase inhibitors. United States patent US 9,637,504. 2017.

373. Myers CL, Daigle DM, Burns CJ, Pevear DC Ceftibuten/VNRX7145 , an orally bioavailable $\beta$-lactam/ $\beta$-lactamase inhibitor combination active against serine- $\beta$-lactamase-producing Enterobacteriaceae (Poster P1182, 29th ECCMID Conference, Amstedam, Netherlands, 13-16 April 2019). https://www.vena torx.com/wp-content/uploads/2019/07/ECCMID2019-P1182FINAL.pdf. Accessed 17 Sept 2019.

374. VenatoRx Pharmaceuticals names Joseph C. Larsen, Ph.D. Vice President, Strategic Portfolio Development (Press Release 4 September 2019). https://www.venatorx.com/press-releases/vena torx-pharmaceuticals-names-joseph-c-larsen-ph-d-vice-presidentstrategic-portfolio-development/. Accessed 17 Sept 2019.

375. Gordon EM, Duncton MAJ, Gallop MA. Orally absorbed derivatives of the $\beta$-lactamase inhibitor avibactam. Design of novel prodrugs of sulfate containing drugs. J Med Chem. 2018;61:10340-4.

376. Gordon E, Duncton M, Lal R, Trias J. Oral prodrugs of avibactam, medicinal chemistry, and synthesis of ARX-1796 (Poster P1159, 29th ECCMID Conference, Amsterdam, Netherlands, 13-16 April 2019). https://www.escmid.org/escmid_ publications/escmid_elibrary/material/?mid $=68540$. Accessed 17 Nov 2019.

377. Kohanski MA, Dwyer DJ, Collins JJ. How antibiotics kill bacteria: From targets to networks. Nat Rev Microbiol. 2010;8:423-35.

378. Hards K, Adolph C, Harold LK, McNeil MB, Cheung C-Y, Jinich A, et al. Two for the price of one: Attacking the energeticmetabolic hub of mycobacteria to produce new chemotherapeutic agents. Prog Biophys Mol Biol. 2019. https://doi.org/10.1016/j. pbiomolbio.2019.11.003.

379. Stokes JM, Lopatkin AJ, Lobritz MA, Collins JJ. Bacterial metabolism and antibiotic efficacy. Cell Metab. 2019;30:251-9.

380. O'Shea R, Moser HE. Physicochemical properties of antibacterial compounds: implications for drug discovery. J Med Chem. 2008;51:2871-8. 